\author{
UNIVERSIDADE DE SÃO PAULO \\ FACULDADE DE CIÊNCIAS FARMACÊUTICAS DE RIBEIRÃO PRETO
}

Expressão de DIDO em células Bcr-Abl+: associação com resistência à apoptose e fisiopatologia da leucemia mielóide crônica

Maria Gabriela Berzoti Coelho

Ribeirão Preto

2015 


\author{
UNIVERSIDADE DE SÃO PAULO \\ FACULDADE DE CIÊNCIAS FARMACÊUTICAS DE RIBEIRÃO PRETO
}

\title{
Expressão de DIDO em células Bcr-Abl+: associação com resistência à apoptose e fisiopatologia da leucemia mielóide crônica
}
Dissertação de Mestrado apresentada ao Programa de Pós-Graduação em Biociências Aplicadas à Farmácia em 06 de agosto de 2015 para obtenção do Título de Mestre em Ciências

Área de Concentração: Biociências Aplicadas à Farmácia

Orientada: Maria Gabriela Berzoti Coelho Orientadora: Profa. Dra. Fabíola Attié de Castro

Versão corrigida da Dissertação de Mestrado apresentada ao programa de PósGraduação em Biociências Aplicadas à Farmácia em 06/08/2015. A versão orignal encontra-se disponível na Faculdade de Ciências Farmacêuticas de Ribeirão Preto/USP. 
Autorizo a reprodução e divulgação total ou parcial deste trabalho, por qualquer meio convencional ou eletrônico, para fins de estudo e pesquisa, desde que citada a fonte.

Coelho, Maria Gabriela Berzoti

Expressão de DIDO em células Bcr-Abl+: associação com resistência a apoptose e fisiopatologia da Leucemia Mielóide Crônica. Ribeirão Preto, 2015.

117 p.; il. $30 \mathrm{~cm}$.

Dissertação de Mestrado, apresentada à Faculdade de Ciências Farmacêuticas de Ribeirão Preto/USP - Área de concentração: Biociências Aplicadas à Farmácia.

Orientadora: Fabíola Attié de Castro

1.Leucemia Mielóide Crônica 2.BCR-ABL1 3 3. Inibidores de tirosinaquinase 4.Apoptose 5.DIDO 
COELHO, M. G. B

Expressão de DIDO em células Bcr-Abl+: associação com resistência a apoptose e fisiopatologia da leucemia mielóide crônica

Dissertação de Mestrado apresentada ao Programa de Pós-Graduação em Biociências Aplicadas à Farmácia para obtenção do Título de Mestre em Ciências

Área de Concentração: Biociências Aplicadas à Farmácia.

Orientadora: Profa. Dra. Fabíola Attié de Castro

Aprovado em:

Banca Examinadora

Prof. Dr.

Instituição: Assinatura:

Prof. Dr.

Instituição: Assinatura:

Prof. Dr. Instituição: Assinatura: 


\section{Dedicatória}

Dedico este trabalho à minha família.

Ao meu pai José Roberto, por me ensinar a batalhar por meus objetivos e a ser perseverante mesmo frente a adversidades.

À minha mãe Olga, pelo carinho e zelo incessáveis e que com seu coração nobre me ensinou a humildade e integridade.

Aos meus irmãos Ana Cláudia e Tiago, pelo apoio e admiração que me motivam.

Ao meu pequeno amor João Luis, que sempre me alegra.

Aos meus avós Naida e Maurício (in memorian) que onde quer que estejam, devem estar orgulhosos com mais essa vitória.

Vocês me ensinaram e ajudaram a me tornar quem hoje sou. Agradeço pelo apoio e amor incondicional de cada um de vocês, por sonharem junto comigo e, sobretudo, por nunca desacreditarem de meus esforços. Eu amo vocês! Muito obrigada! 


\section{Agradecimentos}

Agradeço à Deus por me guiar em cada passo e abençoar em cada escolha.

Aos familiares e amigos que de alguma forma colaboraram para que eu chegasse até aqui, em especial ao Mateus, pelo amor, carinho e paciência, e à Larissa, pelo cuidado e por sempre acreditar em mim, mesmo nos momentos em que fraquejei.

À minha orientadora Fabíola, pela paciência, pelos valiosos ensinamentos e principalmente por sua amizade, sua grande compreensão e apoio em momentos de dificuldade.

À todos os colegas de laboratório, pela convivência, pelo auxílio e pelos ensinamentos compartilhados. Agradeço em especial a Ana, pelo auxílio em experimentos e ajuda na coleta de amostras.

À Maira, Ju e Sandrinha por todo apoio e força que me deram e, principalmente, pela amizade sincera que construímos.

Ao Dr. Maurício Cristiano Rocha Júnior, por sua ajuda, paciência e ensinamentos sobre PCR em tempo real.

À Fundação Hemocentro de Ribeirão Preto e ao Dr. Dimas Tadeu Covas pela oportunidade de utilizar o aparelho de PCR em tempo real.

Aos professores doutores Marcelo Dias Baruffi, Luciana Simon Pereira Crott, Sérgio Akira Uyemura e Maria Regina Torqueti por disponibilizarem equipamentos de seus laboratórios e pelo fornecimento de materiais para realização de experimentos.

À Dra. Belinda Pinto Simões pela abertura do ambulatório de Hematologia do Hospital das Clínicas de Ribeirão Preto para obtenção de amostras de pacientes e ao Dr. Leonardo, pelo seu auxílio durante as coletas. 
À todos os pacientes e controles que gentilmente cederam amostras de sangue, sem as quais seria impossível a realização desse estudo.

À Coordenação de Aperfeiçoamento de Pessoal de Nível Superior, CAPES, pelo apoio financeiro através do fornecimento da bolsa de estudos.

E à todos que conviveram comigo durante esses dois anos e que, direta ou indiretamente, contribuíram para a realização desse trabalho. 


\section{Epígrafe}

Se as coisas são inatingíveis... ora! Não é motivo para não querê-las... Que tristes os caminhos, se não fora A presença distante das estrelas! 


\section{RESUMO}

COELHO, M. G. B. Expressão de DIDO em células Bcr-Abl+: associação com resistência à apoptose e fisiopatologia da leucemia mielóide crônica. 2015. 121f. Dissertação (Mestrado) - Faculdade de Ciências Farmacêuticas de Ribeirão Preto, Universidade de São Paulo, Ribeirão Preto, 2015.

Na leucemia mielóide crônica (LMC) a proteína Bcr-Abl possui atividade tirosinaquinase constitutivamente ativada, induzindo a mieloproliferação e a resistência das células à apoptose. A maioria dos pacientes na fase crônica da LMC tratados com inibidores de tirosina-quinase (TKIs), como o mesilato de imatinibe, apresenta remissão citogenética completa da doença, mas uma parcela desses pacientes tem se mostrado resistente à terapia. A fisiopatologia da LMC e os mecanismos celulares e moleculares envolvidos na resistência à terapia com TKls são diversos e precisam ser melhor estudados. Nesse contexto, o objetivo do presente estudo foi quantificar os níveis de expressão do gene DIDO, incluindo suas diferentes isoformas (DIDO 1, 2 e 3) e promotores (DIDO PP e $P D$ ) em controles e em pacientes com LMC nas diferentes fases da doença, tratados ou não com TKIs, bem como em linhagens celulares $B C R-A B L 1^{+}$sensíveis (S) e resistentes (R) ao mesilato de imatinibe (MI). A literatura relata que DIDO 1 participa do processo de apoptose e que alterações na expressão de DIDO 2 e DIDO 3 podem estar associadas com o desenvolvimento de neoplasias mielóides. Dessa forma, foram estudados 60 pacientes com LMC e 57 controles, assim como as linhagens celulares HL-60, HL-60.Bcr-Abl ${ }^{+}$, LAMA $84 \mathrm{~S}$, LAMA $84 \mathrm{R}, \mathrm{KCL} 22 \mathrm{~S}$ e KCL $22 \mathrm{R}$. Foram separadas as células mononucleares de sangue periférico dos pacientes e controles, com posterior extração de RNA e síntese de cDNA, que foi então empregado nas reações de PCR em tempo real (qPCR) para quantificação das expressões gênicas de DIDO 1, 2, 3, PP, PD e ORF. As linhagens celulares foram tratadas por $4 \mathrm{~h}$ com TKls e então a expressão das diferentes isoformas de DIDO foi também quantificada por qPCR. A avaliação da expressão proteica de Bcr-Abl, c-Abl e proteínas fosforiladas nas linhagens foi realizada por Western-blotting. A expressão de DIDO 1 e 2 foi maior nos pacientes nas fases avançadas da LMC e nos pacientes na fase crônica da doença tratados com TKIs (mesilato de imatinibe ou dasatinibe) do que nos controles. Os pacientes na fase crônica da LMC tratados com Ml expressaram mais DIDO 1 e 3 do que os pacientes na fase crônica sem tratamento. Houve uma correlação positiva entre expressão de $B C R-A B L 1$ e de DIDO 2 e entre índice de Sokal dos pacientes e

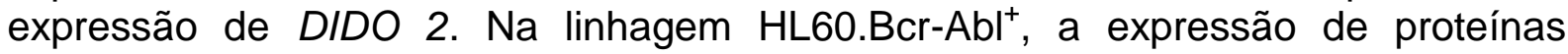
fosforiladas reduziu após tratamento de $4 \mathrm{~h}$ com TKIs, mas não houve alteração na expressão gênica de DIDO. Nas linhagens celulares $\mathrm{S}$ e $\mathrm{R}$, houve aumento da expressão de DIDO 1 após o tratamento de $4 \mathrm{~h}$ com Ml. Conclui-se, portanto, que as diferentes isoformas de DIDO parecem exercer funções distintas na leucemia mielóide crônica; que o tratamento de pacientes e linhagens $B C R-A B L 1$ positivas com inibidores de tirosina-quinase aumenta expressão de $D I D O 1$; e que a expressão de DIDO 2 correlaciona-se positivamente à expressão de $B C R-A B L 1 \mathrm{e}$ ao índice de Sokal dos pacientes.

Palavras-chave: Leucemia mielóide crônica. $B C R-A B L 1$. Inibidores de tirosinaquinase. Apoptose. DIDO. 


\begin{abstract}
COELHO, M. G. B. DIDO gene expression in Bcr-Abl+ cells: association to apoptosis resistance and pathophysiology of chronic myeloid leukemia. 2015. 121p. Dissertation (Master's degree) - Faculdade de Ciências Farmacêuticas de Ribeirão Preto, Universidade de São Paulo, Ribeirão Preto, 2015.

In chronic myeloid leukemia (CML) the Bcr-Abl protein has constitutively activated tyrosine kinase activity, that induces to myeloproliferation and apoptosis resistance of the cells. Most patients in chronic phase of CML treated with the tyrosine kinase inhibitor (TKI) imatinib mesylate have a complete cytogenetic remission, but a portion of these patients have been shown to be resistant to therapy. The pathophysiology of $\mathrm{CML}$ and the cellular and molecular mechanisms involved in resistance to TKIs therapy are diverse and require further study. In this sense, the aim of this study was to quantify the expression levels of the DIDO gene, including its isoforms (DIDO 1, 2 and 3) and promoters (DIDO PP and $P D$ ) in controls and in patients with CML in different phases of the disease treated or not treated with TKls, as well as in cell lines BCR-ABL1 ${ }^{+}$sensitive (S) and resistant (R) to imatinib mesylate (IM). The literature reports that DIDO 1 is involved in apoptosis process and that alterations of DIDO 2 and DIDO 3 expression may be associated with the development of myeloid neoplasms. Thus, $60 \mathrm{CML}$ patients, 57 control individuals and the cell lines HL-60, $\mathrm{HL}-60 . \mathrm{Bcr}_{-} \mathrm{Abl}^{+}$, LAMA $84 \mathrm{~S}$, LAMA $84 \mathrm{R}, \mathrm{KCL} 22 \mathrm{~S}$ and $\mathrm{KCL} 22 \mathrm{R}$ were studied. Peripheral blood mononuclear cells of patients and controls were isolated and RNA extraction and cDNA synthesis were performed. The cDNA samples were used in Real-Time PCR reactions (qPCR) to quantify the DIDO 1,2, 3, PP, PD and ORF gene expression. The cell lines were treated during $4 \mathrm{~h}$ with TKIs and then the expression of DIDO different isoforms was also quantified by qPCR. The assessment of protein expression of Bcr-Abl, c-Abl and phosphorylated proteins in this cell lines was performed by Western blotting. The DIDO 1 and 2 expression was higher in advanced phases patients and in chronic phase patients CML treated with TKls (imatinib mesylate and dasatinib) than in controls. Chronic phase CML Patients treated with IM expressed more DIDO 1 and 3 than chronic phase untreated patients. There was a positive correlation between BCR-ABL1 expression and DIDO 2 expression and between Sokal score prognostic and DIDO 2 expression. In HL60.Bcr-Abl ${ }^{+}$cells the expression of phosphorylated proteins was lower after treatment during $4 \mathrm{~h}$ with TKIs, but there was no change in DIDO gene expression. There were an increase of DIDO 1 expression in all $\mathrm{S}$ and $\mathrm{R}$ cell lines after treatment during $4 \mathrm{~h}$ with $I \mathrm{M}$. Therefore we conclude that the DIDO different isoforms may have different functions in chronic myeloid leukemia; the treatment of patients and $B C R$ $A B L 1^{+}$cell lines with TKIs increases DIDO 1 expression; and that the DIDO 2 expression is positively correlated to the BCR-ABL1 expression and Sokal score prognostic of CML patients.
\end{abstract}

Keywords: Chronic myeloid leukemia. BCR-ABL1. Tyrosine kinase inhibitors. Apoptosis. DIDO. 


\section{RESUMEN}

COELHO, M. G. B. DIDO expresión en las células Bcr-Abl+: asociación con resistencia a la apoptosis y fisiopatología de la leucemia mieloide crónica. 2015. 121p. Disertación (Maestría) - Faculdade de Ciências Farmacêuticas de Ribeirão Preto, Universidade de São Paulo, Ribeirão Preto, 2015.

En la leucemia mieloide crónica (LMC) la proteína Bcr-Abl ha actividad tirosina quinasa activada constitutivamente, induciendo mieloproliferação y resistencia a la apoptosis de las células. La mayoría de los pacientes en fase crónica de LMC tratados con el inhibidor de la tirosina quinasa (TKI) mesilato de imatinib tiene una remisión citogenética completa, pero una porción de estos pacientes han demostrado ser resistentes a la terapia. La fisiopatología de la LMC y los mecanismos celulares y moleculares implicados en la resistencia a la terapia de TKI son diversas y requieren un mayor estudio. En este sentido, el objetivo de este estudio fue cuantificar los niveles de expresión del gen DIDO, incluyendo sus isoformas (DIDO 1, 2 y 3 ) y promotores (DIDO $P P$ y $P D)$ en los controles y pacientes con LMC en diferente fases de la enfermedad tratada o no con TKIs, así como en líneas celulares de $B C R-A B L 1^{+}$sensible (S) y resistentes $(\mathrm{R})$ para el mesilato de imatinib (MI). DIDO 1 está implicado en el proceso de apoptosis y las alteraciones en la expresión de DIDO 2 y DIDO 3 pueden estar asociados con el desarrollo de neoplasias mieloides. De este modo, se estudiaron 60 pacientes con LMC y 57 controles, así como líneas de células HL-60, HL-60.Bcr-Abl ${ }^{+}$, LAMA 84 S, LAMA 84 $\mathrm{R}, \mathrm{KCL} 22 \mathrm{~S}$ y KCL $22 \mathrm{R}$. Se aislaron células mononucleares de sangre de pacientes y controles y la extracción de ARN y síntesis de ADNc se realizaron. Las muestras de ADNc se usaron en reacciones de PCR en tiempo real (qPCR) para cuantificar la expresión de los genes DIDO 1, 2, 3, PP, PD y ORF. Las líneas celulares fueron tratados con TKI durante $4 \mathrm{~h}$ y luego la expresión de las diferentes isoformas de DIDO también se cuantificó por qPCR. La evaluación de la expresión de la proteína Bcr-Abl, c-Abl y las proteínas fosforiladas en estas líneas de células se realizo mediante inmunoblot. La expresión de DIDO 1 y 2 fue mayor en los pacientes en las etapas avanzadas de la LMC y en pacientes en fase crónica tratados con TKI (mesilato de imatinib y dasatinib) que en los controles. Los pacientes en fase crónica de LMC tratados con MI expresaron más DIDO 1 y 3 que los pacientes no tratados. Hubo una correlación positiva entre la expresión de BCR-ABL1 y DIDO 2 y entre el índice de Sokal de los pacientes y la expresión DIDO 2. En las células HL60.Bcr$\mathrm{ABL}^{+}$la expresión de proteínas fosforiladas fue menor después del tratamiento de $4 \mathrm{~h}$ con TKI, pero no hubo ningún cambio en la expresión génica de DIDO. Hubo un aumento de expresión de DIDO 1 en todas las células $\mathrm{S}$ y $\mathrm{R}$ después del tratamiento de $4 \mathrm{~h}$ con MI. Llegamos a la conclusión, por lo tanto, que las diferentes isoformas de DIDO parecen tener funciones distintas en la leucemia mieloide crónica; el tratamiento de los pacientes y líneas de células BCR-ABL $1^{+}$con TKIs aumenta la expresión de DIDO 1; y que la expresión de DIDO 2 se correlaciona positivamente con la expresión de $B C R-A B L 1$ y índice Sokal de los pacientes.

Palabras claves: Leucemia mieloide crônica. $B C R-A B L 1$. Inhibidores de la tirosina quinasa. Apoptosis. DIDO. 


\section{LISTA DE FIGURAS}

Figura 1. Gene $B C R-A B L 1$

Figura 2. Representação esquemática dos transcritos de DIDO

Figura 3. Mecanismo de ação do Mesilato de Imatinibe (MI) em células Bcr-Abl positivas

Figura 4. Eletroforese para avaliação da qualidade das amostras de RNA

Figura 5. Expressão de DIDO 1 em controles, pacientes com LMC na fase crônica sem tratamento e pacientes com LMC nas fases avançadas da doença (fase acelerada e crise blástica)

Figura 6. Expressão de DIDO 2 em controles, pacientes com LMC na fase crônica sem tratamento e pacientes com LMC nas fases avançadas da doença (fase acelerada e crise blástica)

Figura 7. Expressão de DIDO 1 em pacientes com LMC na fase crônica tratados com mesilato de imatinibe e controles.

Figura 8. Expressão de DIDO $P P$ em pacientes com LMC na fase crônica tratados com mesilato de imatinibe e controles.

Figura 9. Expressão de DIDO 1 em pacientes com LMC na fase crônica sem tratamento e pacientes com LMC na fase crônica tratados com mesilato de imatinibe.

Figura 10. Expressão de DIDO 3 em pacientes com LMC na fase crônica sem tratamento e pacientes com LMC na fase crônica tratados com mesilato de imatinibe.

Figura 11. Expressão de DIDO PP em pacientes com $L M C$ na fase crônica sem tratamento e pacientes com LMC na fase crônica tratados com mesilato de imatinibe......

Figura 12. Expressão de DIDO $P D$ em pacientes com LMC na fase crônica sem tratamento e pacientes com LMC na fase crônica tratados com mesilato de imatinibe.

Figura 13. Expressão de DIDO PD em pacientes com LMC antes do tratamento e após 12 meses de tratamento com MI.

Figura 14. Correlação entre a expressão de $B C R-A B L 1$ com a junção b2a2 e a expressão de DIDO 2 dos pacientes na fase crônica da LMC sem tratamento.

Figura 15. Correlação entre o índice de Sokal e a expressão de DIDO 2 dos pacientes com LMC.

Figura 16. Expressão de DIDO 1, DIDO2, DIDO 3, DIDO PP e DIDO PD na linhagem $\mathrm{HL}-60$ após $4 \mathrm{~h}$ de tratamento com inibidores de tirosina-quinase. 
Figura 17. Expressão de DIDO 1, DIDO2, DIDO 3, DIDO PP e DIDO PD na linhagem $\mathrm{HL}-60 . \mathrm{Bcr}^{-\mathrm{Abl}^{+}}$após $4 \mathrm{~h}$ de tratamento com inibidores de tirosina-quinase...

Figura 18. Expressão de DIDO 1, DIDO2, DIDO 3, DIDO PP e DIDO PD nas linhagens KCL22 S, KCL 22 R, LAMA 84 S e LAMA 84 R

Figura 19. Expressão gênica de DIDO 1, DIDO2 e DIDO 3 em KCL 22 S e KCL 22 R após $4 \mathrm{~h}$ de tratamento com o inibidor de tirosina-quinase mesilato de imatinibe......

Figura 20. Expressão gênica de DIDO 1, DIDO2 e DIDO 3 em LAMA 84 S e LAMA 84 $R$ após $4 \mathrm{~h}$ de tratamento com o inibidor de tirosina-quinase mesilato de imatinibe.

Figura 21. Expressão de tubulina, fosfotirosina, c-Abl e Bcr-Abl em HL60.Bcr-Abl ${ }^{+}$ após $4 \mathrm{~h}$ de tratamento com TKIs

Figura 22. Expressão de tubulina, fosfotirosina, c-Abl e Bcr-Abl nas linhagens KCL 22 $\mathrm{S}$ e KCL $22 \mathrm{R}$

Figura 23. Expressão de tubulina, fosfotirosina, c-Abl e Bcr-Abl nas linhagens celulares LAMA 84 S e LAMA 84 R. 


\section{LISTA DE TABELAS}

Tabela 1. Caracterização demográfica, fase da doença, fármaco utilizado, resposta ao tratamento e Índice de Sokal dos pacientes com LMC estudados.

Tabela 2. Caracterização demográfica dos controles.

Tabela 3. Sequência dos Oligonucleotideos utilizados nas reações de qPCR, temperaturas de anelamento e tamanho dos fragmentos gerados (amplicons).....

Tabela 4. Anticorpos e diluições utilizados para Western-blotting.

Tabela 5. Medianas e valores de $p$ da expressão gênica das isoformas de DIDO entre o grupo de pacientes na fase crônica da LMC sem tratamento e controles e entre o grupo de pacientes nas fases avançadas da LMC (fase acelerada e crise blástica) e controles.

Tabela 6. Medianas e valores de $p$ da expressão gênica das isoformas de DIDO entre o grupo de pacientes na fase crônica da LMC sem tratamento e o grupo de pacientes nas fases avançadas da LMC (fase acelerada e crise blástica).

Tabela 7. Medianas e valores de $p$ da expressão das diferentes isoformas de DIDO que foram diferentes entre o grupo de pacientes na fase crônica da LMC tratados com dasatinibe e o grupo controle.

Tabela 8. Medianas e valores de $p$ da expressão das isoformas de DIDO entre o grupo de pacientes na fase crônica da LMC tratados com mesilato de imatinibe e controles e entre pacientes na fase crônica tratados com dasatinibe e controles.

Tabela 9. Medianas e valores de $p$ da expressão das isoformas de DIDO entre o grupo de pacientes na fase crônica da LMC sem tratamento e o grupo de pacientes na fase crônica da LMC tratados com mesilato de imatinibe.

Tabela 10. Medianas e valores de $p$ da expressão das isoformas de DIDO entre o grupo de pacientes antes do tratamento e o grupo de pacientes 12 meses após o tratamento com mesilato de imatinibe....

Tabela 11. Medianas e valores de $p$ da expressão de DIDO entre os grupos de pacientes que atingiram a RCC ou foram resistentes à terapia com MI

Tabela 12. Relação entre a expressão gênica de $B C R-A B L 1$ com junções b2a2 e b3a2, fases da doença e respostas ao tratamento com os TKIs dos pacientes.

Tabela 13. Correlações entre as expressões de $B C R-A B L 1$ (junções b2a2 e b3a2) e a expressão de DIDO nos pacientes na fase crônica da LMC sem tratamento.. 
Tabela 14. Correlações entre as expressões de $B C R-A B L 1$ (junções b2a2 e b3a2) e de DIDO dos pacientes na fase crônica da LMC tratados com mesilato de imatinibe

Tabela 15. Correlações entre as expressões de $B C R-A B L 1$ (junções b2a2 e b3a2) e de $D I D O$ dos pacientes nas fases avançadas da LMC

Tabela 16. Correlação entre o índice de Sokal e as expressões da diferentes isoformas de DIDO dos pacientes com LMC.

Tabela 17. Médias entre os valores de fold change da expressão gênica de DIDO na linhagem celular HL-60 após 4 h de tratamento com inibidores de tirosinaquinase.

Tabela 18. Médias entre os valores de fold change da expressão gênica de DIDO na linhagem celular HL-60.Bcr-Abl ${ }^{+}$após $4 \mathrm{~h}$ de tratamento com inibidores de tirosina-quinase.

Tabela 19. Médias entre os valores de fold change da expressão gênica de DIDO nas linhagens celulares KCL $22 \mathrm{~S}, \mathrm{KCL} 22$ R, LAMA 84 S e LAMA 84 $\mathrm{R}$

Tabela 20. Média dos valores de fold change da expressão gênica de DIDO 1, DIDO 2 e DIDO 3 nas linhagens celulares KCL 22 S, KCL 22 R, LAMA 84 S e LAMA $84 \mathrm{R}$ após $4 \mathrm{~h}$ de tratamento com mesilato de imatinibe.

Tabela 21. Resultados das análises comparativas da expressão gênica das diferentes isoformas de DIDO em controles, pacientes nas diferentes fases da LMC e pacientes tratados com inibidores de tirosina-quinase.

Tabela 22. Resultados das correlações entre expressão de $B C R-A B L 1$ e expressão de $D I D O$ e entre Índice de Sokal e expressão de DIDO nos pacientes com LMC 


\section{LISTA DE ABREVIATURAS E SIGLAS}

$A B L$ - abelson murine leukemia viral oncogene homolog 1

$A C$ - fase acelerada

Ac - anticorpo

AKT - v-akt murine thymoma viral oncogene homolog 1

AlloSCT - allogeneic stem cell transplatation

AT -antes do tratamento

ATCC - American Type Culture Collection

ATP - adenosine triphosphate

B2M - beta-2-microglobulina

$B A D$ - BCL2-assciated agonist of cell death

BAK - BCL2-antagonist/killer

BAX - BCL2-associated $X$ protein

$B C A$ - bicinchoninic acid

BCL-2 - B-cell CLL/lymphoma 2

BCL-XL - B-cell lymphoma-extra large

$\mathrm{BCR}$ - breakpoint cluster region protein

BCR-ABL1 - oncogene de fusão

$\mathrm{BID}$ - $\mathrm{BH} 3$ interacting domain death agonist

BIK - BCL2-interacting killer (apoptosis-inducing)

$\mathrm{BL}$ - crise blástica

BSA - bovine serum albumine

C-FLIP - cellular FLICE-like inhibitory protein

CEP - comitê de ética em pesquisa

cDNA - complementary desoxirribunucleic acid

CR - fase crônica

$\mathrm{Ct}$ - cycle threshold

CT - controles

Das - dasatinibe

DATF - death-associated transcription factor

dDelta $\mathrm{Ct}$ - delta delta cycle treshold

DIDO - death inducer-obliterator 1

DISC - death-inducing signaling complex 
DR - death receptor

EDTA - ethylenediamine tetraacetic acid

et al. - et alii

$\mathrm{F}$ - feminino

FA - fase avançada

Fas - Fas cell surface death receptor

FasL - Fas ligand (TNF superfamily, member 6)

FADD - Fas (TNFRSF6)-associated via death domain

FDA - Food and Drug Administration

FC - fase crônica

FCFRP - Faculdade de Ciências Farmacêuticas de Ribeirão Preto

FISH - fluorescence in situ hybridization

g - gravity (centrifugação)

h - horas

HCFMRP - Hospital das clínicas da faculdade de medicina de Ribeirão Preto

HCK - Hemopoietic Cell Kinase

HLA - human leukocyte antigen

IAP - inhibitory apoptosis proteins

IFN- $\alpha$ - interferon alfa

Ig - imunoglobulina

IM - imatinib mesylate

JUN - Jun proto-oncogene

kDa - kilodaltons

LYN - v-yes-1 Yamaguchi sarcoma viral related oncogene homolog

LMC - leucemia mielóide crônica

Log10 - logarítimo 10

M - masculino

MCL-1 - myeloid cell leukemia 1

Md - mediana

MI - mesilato de imatinibe

$\mathrm{mL}$ - mililitros

$\mathrm{mM}$ - mili molar

mRNA - messenger ribonucleic acid

MYC - v-myc avian myelocytomatosis viral oncogene homolog 
n - número de indivíduos

$\mathrm{NaCl}$ - cloreto de Sódio

Nil - nilotinibe

NLS - nuclear localization signal

nm - nanômetro

nM - nano Molar

p - probabilidade

$\mathrm{pb}$ - pares de bases

PBS - phosphate buffered saline

PCR - polymerase chain reaction

PD - promotor distal

$\mathrm{Ph}$ - Philadelphia

$\mathrm{Ph}+$ - Philadelphia positivo

PI3K - Phosphoinositide-3-kinase

PP - promotor proximal

Primer-F - primer foward

Primer-R - primer reverse

PT - após 12 meses de tratamento com mesilato de imatinibe qPCR - quantitative polymerase chain reaction

$\mathrm{R}$ - resistentes

RCC - remissão citogenética completa

RCP - remissão citogenética parcial

RHC - remissão hematológica completa

RNA - ribonucleic acid

rRNA - ribosomal ribonucleic acid

$r_{s}$ - valor da correlação.

$S$ - sensíveis

SBF - serum bovine fetal

SDS - dodecil sulfato de sódio

siRNA - small intereference ribonucleic acid

SP - São Paulo

SRC - v-src avian sarcoma (Schmidt-Ruppin A-2) viral oncogene homolog STAT - Signal Transducer and Activator of Transcription

$\mathrm{S} / \mathrm{T}$ - paciente ao diagnóstico 
t- translocação

TA - temperatura de anelamento

TBS-T - Tris-Buffered Saline and Tween 20

TCLE - termo de consentimento livre e esclarecido

TNF-a - tumor necrosis factor alpha

TK - tyrosine kinase

TKI - tyrosine kinase inhibitor

Tris - trisaminometano

Tris-HCL - (hydroxymethyl)aminomethane-hydrochloride

URE - Unidade Relativa de Expressão

USP - Universidade de São Paulo

e13a2 - éxon 13 de BCR e éxon 2 de $A B L 1$

$14 a 2$ - éxon 14 de BCR e éxon 2 de ABL1

$18 s$ - 18 Svedberg units

28s - 28 Svedberg units

$\mu \mathrm{M}$ - micro molar

$\mu \mathrm{L}$ - microlitro

$\mu \mathrm{g}$ - micrograma 


\section{LISTA DE SÍMBOLOS}

+ positivo

\pm mais ou menos

$\mu-\mathrm{mi}$

$\gamma$-gama

TM - trademark

${ }^{\circledR}$ - registrado

${ }^{\circ} \mathrm{C}$ - graus Celsius

$<-$ valor menor que

$>$ - valor maior que

$=$ igual

$\bar{x}$-média 


\section{SUMÁRIO}

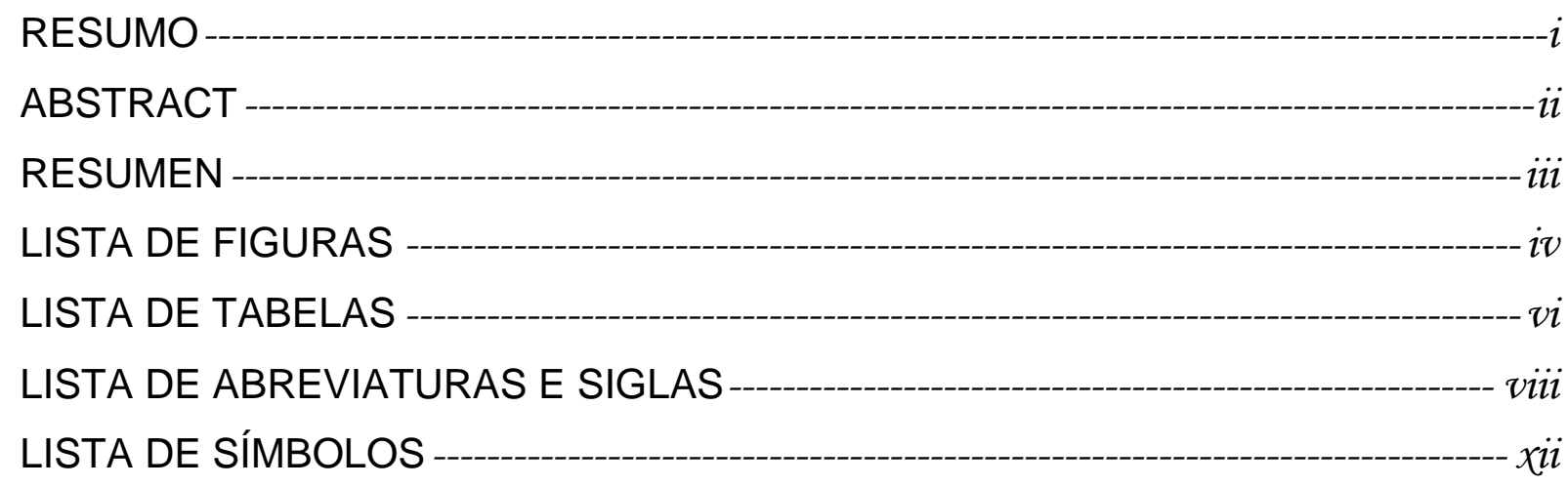

I. Introdução-- 16

I.1 Leucemia Mielóide Crônica: Definição, Características Gerais e Diagnóstico ------2

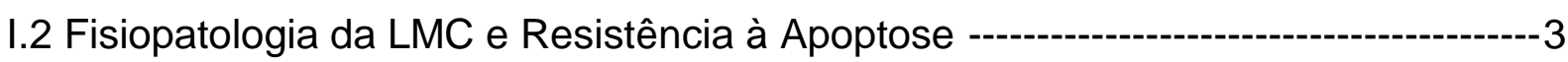

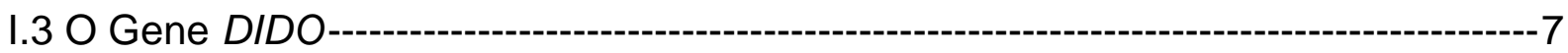

I.4 Tratamento da Leucemia Mielóide Crônica---

II. Objetivos-- 15

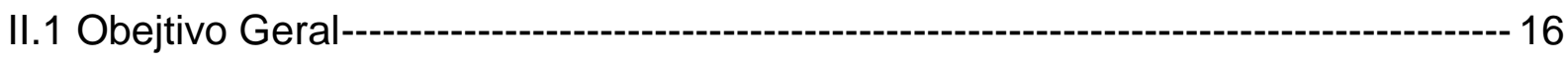

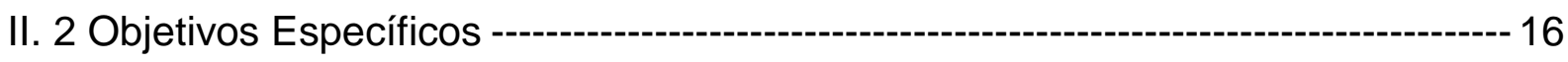

III. Casuística, Material e Métodos--------17

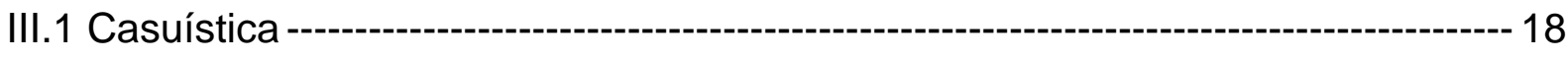

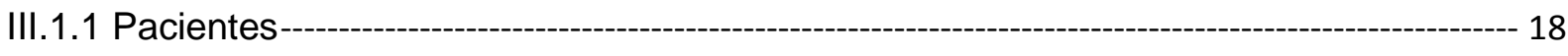

III.1.2 Controles --- 18

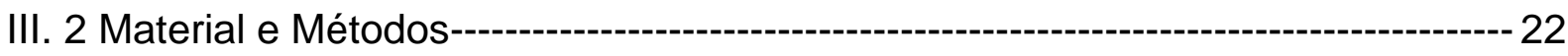

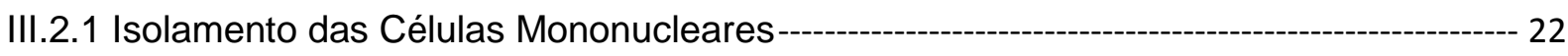

III.2.2 Extração de RNA--- 23

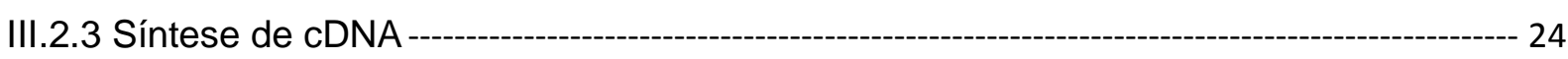

III.2.4 Linhagens Celulares, Cultivo e Tratamento com Inibidores de Tirosina-Quinase (TKIs)

III.2.5 Quantificação da expressão do gene DIDO por PCR em Tempo Real (qPCR) -------- 27

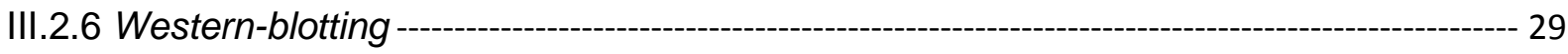

III.2.7 Cálculo do Índice de Sokal --- 30

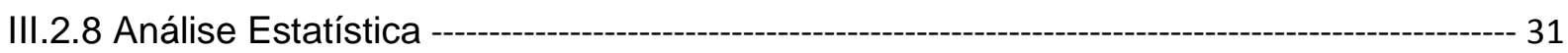


IV.1 Expressão gênica de DIDO 1, DIDO 2, DIDO 3, DIDO PP e DIDO PD em pacientes e controles

IV.1.1 Expressão gênica de DIDO 1, DIDO 2, DIDO 3, DIDO PP e DIDO PD em controles, pacientes na fase crônica e nas fases avançadas (fase acelerada e crise blástica) da LMC 33 IV.1.2 Expressão gênica de DIDO 1, DIDO 2, DIDO 3, DIDO PP e DIDO PD em controles e em pacientes com $L M C$ na fase crônica tratados com mesilato de imatinibe ou dasatinibe - 35 IV.1.3 Expressão dos genes DIDO 1, DIDO 2, DIDO 3, DIDO PP e DIDO PD em pacientes com LMC na fase crônica sem tratamento e pacientes na fase crônica tratados com mesilato de imatinibe-

IV.1.4 Expressão dos genes DIDO 1, DIDO 2, DIDO 3, DIDO PP e DIDO PD em pacientes com $L M C$ antes do tratamento e tratados com mesilato de imatinibe

IV.1.5 Expressão dos genes DIDO 1, DIDO 2, DIDO 3, DIDO PP e DIDO PD em pacientes com LMC tratados com mesilato de imatinibe que atingiram a resposta citogenética completa $(\mathrm{RCC})$ e em pacientes resistentes à terapia

IV.1.6 Expressão dos transcritos do gene $B C R-A B L 1$ com junções b2a2 e b3a2

IV.1.7 Correlações entre a expressão gênica de $B C R-A B L 1$ e dos genes DIDO 1, DIDO 2, DIDO 3, DIDO PP e DIDO PD dos pacientes com LMC

IV.1.8 Correlações entre os índices de Sokal e a expressão dos genes DIDO 1, DIDO 2,

DIDO 3, DIDO PP e DIDO PD dos pacientes com LMC

IV.2 Expressão gênica de DIDO 1, DIDO 2, DIDO 3, DIDO PP e DIDO PD em linhagens celulares

IV.2.1 Expressão dos genes DIDO 1, DIDO 2, DIDO 3, DIDO PP e DIDO PD em HL-60 após tratamento com Inibidores de Tirosina-quinase-

IV.2.2 Expressão dos genes DIDO 1, DIDO 2, DIDO 3, DIDO PP e DIDO PD em HL-60.Bcr$\mathrm{Abl}^{+}$após tratamento com Inibidores de Tirosina-quinase

IV.2.3 Expressão dos genes DIDO 1, DIDO 2, DIDO 3, DIDO PP e DIDO PD em KCL $22 \mathrm{~S}$, KCL 22 R, LAMA 84 S e LAMA $84 \mathrm{R}$

IV.2.4 Expressão dos genes DIDO 1, DIDO 2 e DIDO 3 em KCL 22 S, KCL 22 R, LAMA $84 \mathrm{~S}$ e LAMA $84 \mathrm{R}$ após tratamento com mesilato de Imatinibe -- 53

IV.3 Expressão proteica de Bcr-Abl e fosfotirosina ---

IV.4 Resultados compilados ---_- 58

V. Discussão

V.1 Discussão dos resultados da expressão das diferentes isoformas de DIDO em pacientes e controles nas diferentes fases da doença

V.2 Discussão dos resultados da expressão das diferentes isoformas de DIDO em pacientes resistentes e sensíveis ao mesilato de imatinibe 
V.3 Discussão dos resultados da expressão das diferentes isoformas de $D I D O$ em linhagens celulares

VI. Conclusões 71

VII. Referências 73

VIII. Anexos 84 
I. Introdução 


\section{I.1 Leucemia Mielóide Crônica: Definição, Características Gerais e Diagnóstico}

A leucemia mielóide crônica (LMC) é uma neoplasia mieloproliferativa com incidência de um a dois casos para cada 100.000 pessoas e representa aproximadamente $15 \%$ dos casos de leucemia diagnosticados em adultos (JEMAL et al., 2010). Homens apresentam maior incidência de LMC, com uma taxa de acometimento que varia de 1,3 a 1,5 casos para cada caso diagnosticado em mulheres. A média de idade de desenvolvimento da doença varia conforme a região estudada, sendo que na Austrália, Europa e Estados Unidos, a idade média ao diagnóstico é de 55 anos, enquanto que na África e América Latina os pacientes são diagnosticados com pelo menos 15 anos a menos (QUINTÁS-CARDAMA; CORTES, 2006; MENDIZABAL; GARCIA-GONZALEZ; LEVINE, 2013). O único fator de risco comprovado para o desenvolvimento da doença é a exposição à radiação ionizante de alta dosagem (CORSO et al., 1995).

A LMC é uma doença de evolução trifásica: fase crônica (CR), fase acelerada $(\mathrm{AC})$ e crise blástica (BL). O diagnóstico é comumente feito durante a fase crônica por meio da realização de exame físico de rotina e hemograma do paciente (JABBOUR; KANTARJIAN, 2014; QUINTÁS-CARDAMA; CORTES, 2006). A presença de leucocitose, com desvio a esquerda não escalonado, associado ou não a trombocitose, caracteriza essa fase da LMC. Os sinais e sintomas, quando presentes, resultam da leucocitose, anemia e hepatoesplenomegalia e incluem fadiga, perda de peso, mal estar e plenitude no quadrante superior esquerdo ou dor (JABBOUR; KANTARJIAN, 2014; von BUBNOFF; DUYSTER, 2010).

Quando não tratados ou resistentes ao tratamento, os pacientes com LMC evoluem para fase acelerada. Tal fase pode ser insidiosa ou se apresentar nos pacientes com anemia mais grave do que a verificada na fase crônica, basofilia, esplenomegalia, infiltração de órgãos e número de blastos que varia entre 10 e 20\% na medula óssea. Cerca de $20 \%$ dos pacientes evolui para crise blástica sem sinais de alerta de fase acelerada. A crise blástica se apresenta como leucemia aguda com pancitopenia, blastos no sangue periférico e medula óssea maior que $20 \%$ e piora constitucional dos sintomas do paciente, com sangramentos, febre e infecções (von BUBNOFF; DUYSTER, 2010; JABBOUR; KANTARJIAN, 2014). O fenótipo da crise 
blástica pode ser mielóide ou linfoide e, em casos raros, ambos. O fenótipo mielóide é mais comum que o linfoide, em uma proporção de 2:1 (KANTARJIAN; KEATING; TALPAZ, 1987).

A confirmação do diagnóstico de LMC consiste em documentar, quando em casos de leucocitose persistente e inexplicada, a presença do cromossomo Philadelphia $(\mathrm{Ph})$, resultante da translocação entre os cromossomos 9 e 22 $(\mathrm{t}(9 ; 22)(q 34 ; q 11))$ por citogenética de rotina ou hibridação in situ por fluorescência (FISH) e o gene de fusão BCR-ABL1 por meio de técnicas moleculares (JABBOUR; CORTES; KANTARJIAN, 2008; SCHOCH et al., 2002). Os testes de PCR (reação em cadeia da polimerase) podem ser qualitativos, provendo informações acerca da presença de transcritos de $B C R-A B L 1$, ou quantitativos, com realização de PCR em tempo real que determina a quantidade desses transcritos ao diagnóstico para posterior monitoração terapêutica (JABBOUR; KANTARJIAN, 2014).

\section{I.2 Fisiopatologia da LMC e Resistência à Apoptose}

A LMC foi a primeira neoplasia associada a uma anormalidade cromossômica recorrente, a translocação $t(9 ; 22)(q 34 ; q 11)$, que gera o Cromossomo Philadelphia (Ph) (NOWELL; HUNGERFORD, 1960). Essa translocação ocorre entre os braços longos dos cromossomos 9 e 22, causando a justaposição dos genes da Região do Ponto de Quebra (Breakpoint Cluster Region - BCR) e Abelson1 (ABL1), que levam a formação do gene de fusão $B C R-A B L 1$. O oncogene $B C R-A B L 1$ consiste da extremidade 5' de $B C R$ e da extremidade 3' de ABL1 (SCORE; CALASANZ; OTTMAN, 2010). A fusão entre os genes $B C R$ e $A B L 1$ origina os transcritos com junções e13a2 (éxon 13 de $B C R$ e éxon 2 de $A B L 1$ ) ou e14a2 (éxon 14 de $B C R$ e éxon 2 de $A B L 1$ ), originalmente referidos como b2a2 e b3a2, respectivamente. Ambos os transcritos resultam na expressão de uma proteína de $210 \mathrm{KDa}$, a Bcr-Abl (DEININGER; GOLDMAN; MELO, 2000; MELO, 1996), que origina o quadro clínicolaboratorial clássico da LMC (Figura 1). 


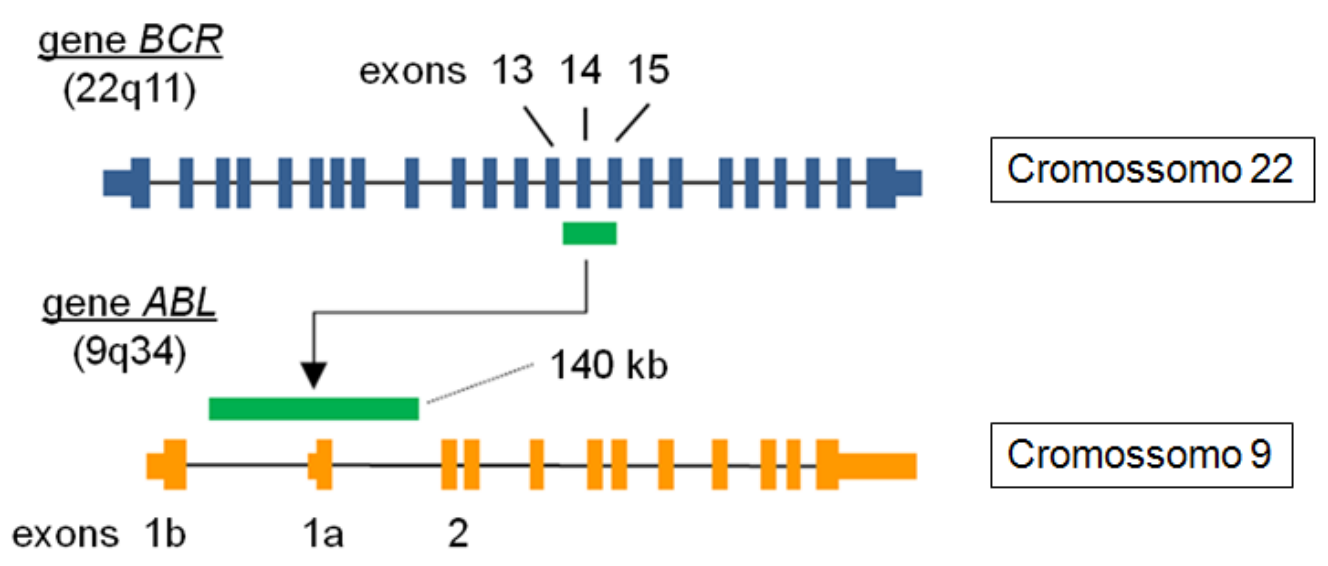

$B C R-A B L \mathrm{t}(9 ; 22)(\mathrm{q} 34 ; \mathrm{q} 11)$

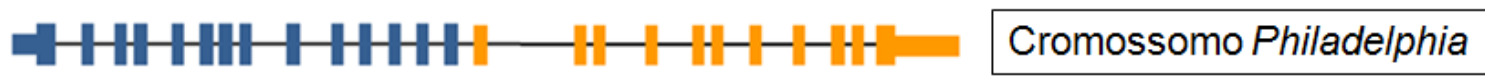

Figura 1. Gene $B C R-A B L 1$. A localização da translocação geralmente envolve a fusão dos exons 13 ou 14 de $B C R$ com uma região de $140 \mathrm{~kb}$ de $A B L 1$, compreendida entre os exons $1 \mathrm{~b}$ e 2 . Adaptado de CHEREDA; MELO. Natural course and biology of CML. Annals of Hematology, v. 94, n. 2, p. 107$121,2015$.

A Bcr-Abl, proteína codificada pelo gene $B C R-A B L 1$, possui atividade de tirosina-quinase constitutivamente ativa, proporcionando estímulo contínuo de vias de sinalização celular como a RAS/MEK, PI3K/Akt, JUN quinase, MYC e STAT (JABBOUR; KANTARJIAN, 2014; CHEREDA; MELO, 2015). Essa ativação exacerbada das vias de sinalização está associada à transformação da célula hematopoética normal em leucêmica. A célula leucêmica apresenta independência aos fatores de crescimento, resistência ao processo de apoptose, intensa proliferação e adesão alterada ao estroma medular. Tais alterações resultam em mieloproliferação e no mieloacúmulo observados na doença (DALEY; VAN ETTEN; BALTIMORE, 1990).

Um estudo realizado por Baum e Ren (2008) demonstrou que a interrupção da sinalização de RAS impediu o desenvolvimento de doença semelhante à LMC induzida por $B C R-A B L 1$ em camundongos. A Ras/Raf/MEK/ERK é uma via central de transdução de sinais de múltiplos receptores da superfície celular para fatores de transcrição no núcleo e interage com outras vias de sinalização relevantes para as funções celulares como a PI3K/Akt e JAK/STAT (STEELMAN et al., 2004). A ativação da via Ras/MEK promove crescimento celular por meio da transcrição de genes que codificam fatores de crescimento e está frequentemente desregulada em cânceres. No entanto, o conhecimento sobre como a via de RAS contribui para o 
desenvolvimento da LMC e quais moléculas efetoras são importantes para esse processo ainda é limitado (CHEREDA; MELO, 2015; REUTHER et al., 1998).

Na LMC, PI3K é requerida para a transformação, mediada por $B C R-A B L 1$, de células hematopoéticas normais em células leucêmicas e para a manutenção da doença. As proteínas PI3K transduzem sinais extracelulares capazes de modular a ativação de fatores de transcrição que favorecem o crescimento e sobrevivência celular. Akt é um efetor de PI3K e exerce papel importante na sua sinalização (ZHAO et al., 2006), portanto, a inibição dessa via pode bloquear a oncogênese de $B C R-A B L 1$ e induzir a morte das células leucêmicas primárias (SKORSKI et al., 1997; KLEJMAN et al., 2002).

Estudos realizados por Raitano et al. (1995), demonstraram que a proteína tirosina-quinase Bcr-Abl aumenta a função da via JUN quinase e que a interrupção dessa via, por sua vez, prejudica a atividade de transformação maligna de Bcr-Abl. Os receptores de tirosina-quinases usam moléculas transdutoras de sinais do exterior para o núcleo celular e os primeiros estágios dessa transmissão envolvem a ativação da proteína Ras. JUN quinase é uma das vias cuja ativação é Ras dependente e ela está envolvida na transformação maligna causada por Bcr-Abl na LMC (RAITANO et al., 1995).

A atividade quinase da proteína Bcr-Abl aumenta diretamente a ativação de JAK2/STAT na LMC, promovendo crescimento e sobrevivência das células. As proteínas STAT são fatores de transcrição ativados pelo receptor celular JAK. (CHAl; NICHOLS; ROTHMAN, 1997; CHEREDA; MELO, 2015). Hoelbl et al. (2010) demonstraram que STAT3 e STAT5 são necessárias para o desenvolvimento de LMC em linhagens celulares leucêmicas sensíveis e resistentes ao tratamento com mesilato de imatinibe. Esses autores também observaram que em camundongos nocaute para STAT5, a LMC induzida por BCR-ABL1 não se desenvolve.

Reavie et al. (2013) demonstraram, em modelos animais, que a expressão aumentada do proto-oncogene c-MYC é requerida para a manutenção e o desenvolvimento da LMC. Handa et al. (1997) também demonstraram que a expressão de c-MYC foi relativamente maior em pacientes na fase acelerada e na crise blástica do que em pacientes na fase crônica da LMC. Um estudo realizado por Stuppia et al. (1997) demonstrou que a progressão da doença para crise blástica em pacientes com LMC está relacionada à perda e mutações no gene supressor de 
tumor p53 e que essas mutações são raras ao diagnóstico ou na fase crônica da LMC, geralmente aparecendo mais tardiamente, durante a evolução da doença.

Como citado anteriormente, outra alteração importante das células leucêmicas que expressam $B C R-A B L 1$ é o seu fenótipo de resistência à morte celular por apoptose. A apoptose é uma modalidade de morte celular empregada por organismos multicelulares para eliminar células indesejáveis ou senescentes (TAYLOR; CULLEN; MARTIN, 2008). Possui importante papel no desenvolvimento normal e manutenção da homeostase dos tecidos, defesa contra invasão viral e modulação da resposta imune (GARCÍA-DOMINGO et al., 2003).

A apoptose caracteriza-se fisio-morfologicamente pelo encolhimento da célula, condensação da cromatina, clivagem de DNA internucleossomal, pregueamento da membrana e formação de corpos apoptóticos que são eliminados por fagocitose. Essas mudanças morfológicas das células são promovidas pela atividade de proteases conhecidas como caspases. (TAYLOR; CULLEN; MARTIN, 2008).

Há duas principais vias de ativação de caspases efetoras da apoptose: a via intrínseca e a via extrínseca. Na via intrínseca, diversos estímulos que provocam estresse ou dano celular ativam uma ou mais proteínas pró-apoptóticas. Essa ativação é capaz de superar o efeito das proteínas anti-apoptóticas e promover a montagem de oligômeros de Bak-Bax na membrana mitocondrial externa. Esses oligômeros permitem o efluxo de proteínas do espaço intermembrana mitocondrial para o citosol, dentre as quais se destaca o citocromo c, que por sua vez desencadeia a formação do apoptossomo, complexo proteico que promove a ativação de caspase 9 . Uma vez ativada, a caspase 9 propaga a cascata proteolítica de ativação de outras caspases (TAYLOR; CULLEN; MARTIN, 2008) culminando com a morte celular.

A via extrínseca de ativação de caspases envolve a interação de ligantes extracelulares, como FasL e TNFa, aos receptores de morte da superfície das células (FAS, DR4, DR5, etc.) promovendo o recrutamento de proteínas adaptadoras, como FADD (proteína associada ao domínio de morte de Fas), que por sua vez promove formação do complexo DISC e, consequentemente, o recrutamento e ativação de várias moléculas de caspase 8 . A caspase 8 ativada processa e ativa as caspases efetoras 3 e 7, resultando na proteólise de substratos e morte celular. Em algumas situações, a via extrínseca interage ou conecta-se com 
a via intrínseca por meio da proteólise de Bid via caspase 8. A proteína Bid truncada pode promover a liberação do citocromo c e a montagem do apoptossomo, culminando com o estímulo da cascata proteolítica de ativação de outras caspases e morte celular (TAYLOR; CULLEN; MARTIN, 2008).

A atividade quinase de Bcr-Abl parece ser parcialmente responsável pelo fenótipo de resistência à apoptose na LMC. A expressão da proteína Bcr-Abl bloqueia a permeabilidade mitocondrial e a liberação do citocromo c, inibindo, portanto, a cascata apoptótica (BUENO-da-SILVA et al., 2003; DEININGER et al., 2000; AMARANTE-MENDES et al., 1998). A expressão e a atividade quinase dessa proteína também inibem a apoptose por meio do aumento da expressão de proteínas anti-apoptóticas, como Bcl-2 e Bcl-X (SALOMONI et al., 2000). Nesse contexto, as sinalizações de STAT5 e PI3K são importantes mediadoras da função anti-apoptótica da proteína Bcr-Abl, pois a ativação de STAT5 aumenta a expressão de $\mathrm{Bcl}-\mathrm{X}_{\mathrm{L}}$, enquanto que a fosforilação da proteína pró-apoptótica Bad, promovida por PI3K/Akt, facilita a interação entre Bad e a proteína chaperona 14-3-3, dificultando a passagem de Bad para o citoplasma e prevenindo a ação próapoptótica (de GROOT et al., 2000; HORITA et al., 2000; NESHAT et al., 2000; CHEREDA; MELO, 2015).

Ferreira et al. (2015) demonstraram que os genes anti-apoptóticos c-FLIP e MCL-1 estavam com a expressão aumentada em amostras de pacientes com LMC, enquanto que o gene pró-apoptótico BIK apresentou expressão reduzida. Esses pesquisadores encontraram, também, que em pacientes resistentes ao tratamento com o inibidor de tirosina-quinase mesilato de imatinibe há maior expressão dos genes anti-apoptóticos $c-F L I P, I A P-1$ e $M C L-1$ e baixa expressão dos genes próapoptóticos $B A K, B A X, B I K$ e FASL.

\section{I.3 O Gene DIDO}

O gene DIDO, ou DIO (Death Inducer Obliterator) ou DATF (Death-Associated Transcription Factor) possui 16 éxons, os quais, por splicing alternativo, geram 3 diferentes transcritos denominados Dido 1, Dido 2 e Dido 3. Todos os transcritos de DIDO apresentam extremidade 5' idênticas, mas o mesmo não ocorre para a extremidade 3'. O menor deles é o Dido 1, enquanto que Dido 3 é a isoforma maior e mais amplamente expressa (FÜTTERER et al. 2005, 2012). A sequência de 
aminoácidos de Dido 1 revela domínios de ativação transcricional, um sinal de localização nuclear (NLS), dois motivos Zn finger e uma região carboxi-terminal rica em lisina (Figura 2) (GARCÍA-DOMINGO et al., 1999, 2003).

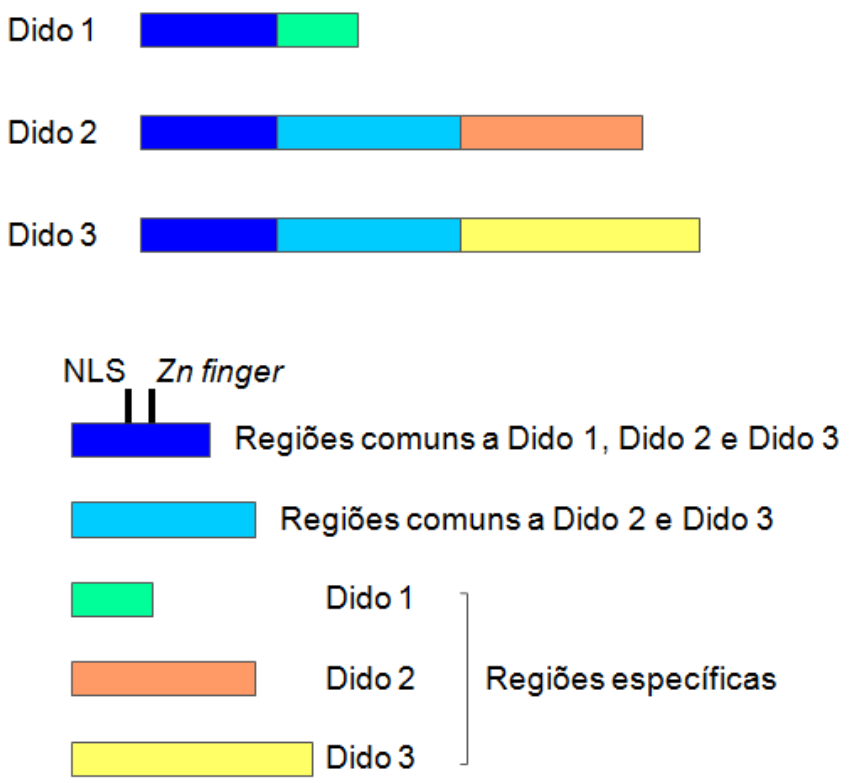

Figura 2. Representação esquemática dos transcritos de DIDO. As cores iguais indicam regiões comuns das sequências de nucleotídeos. Os três transcritos apresentam região $5^{\prime}$ idêntica, e regiões 3' diferentes. NLS: sinal de localização nuclear. Adaptado de FÜTTERER et al. Dido gene expression alterations are implicated in the induction of hematological myeloid neoplasms. The Journal of Clinical Investigation, v. 115, n. 9, p. 2351-2362, 2005.

Dido 1 está presente em baixos níveis no citoplasma de diversos tecidos, como coração, cérebro, baço, pulmões, fígado, etc. (GARCíA-DOMINGO et al., 1999). Experimentos in vitro, com linhagens celulares de origem hematopoética, realizados por García-domingo et al. (1999, 2003), demonstraram que frente a estímulos apoptóticos, Dido 1 se desloca do citoplasma para o núcleo e ativa o processo apoptótico por meio de ativação da transcrição das pró-caspases 3 e 9 .

Em seus estudos, García-domingo et al. $(1999,2003)$ também observaram que o deslocamento de Dido 1 do citoplasma para o núcleo é dependente de seu sinal de localização nuclear (NLS), uma vez que a deleção dessa região resultou na incapacidade de Dido 1 se deslocar e promover a transcrição das pró-caspases 3 e 9. Dessa forma, esses pesquisadores concluíram que Dido 1 atua no núcleo desempenhando a função de fator de transcrição de genes pró-apoptóticos.

Fütterer et al. (2005) descreveram que o locus do gene DIDO localiza-se no braço longo do cromossomo 20. A deleção do braço longo do cromossomo 20 é a segunda anormalidade estrutural mais comum em pacientes com neoplasias 
mielóides. A associação de deleções no cromossomo $20 q$ com essas malignidades sugere a presença de um ou mais genes supressores de tumor nessa região. A perda e a inativação desses genes, dentre os quais está o gene DIDO, estão relacionadas à alteração da regulação da apoptose, diferenciação e proliferação dos progenitores hematopoéticos multipotentes por mecanismos ainda desconhecidos (DEWALD et al., 1993; FÜTTERER et al. 2005).

Fütterer et al. (2005) descreveram que a expressão de Dido 2 e 3 em pacientes com doenças mieloproliferativas e mielodisplásicas está reduzida, enquanto que os níveis de Dido 1 estão normais, sugerindo, então, que alterações na expressão de DIDO podem estar associadas com neoplasias mielóides.

Pelo exposto sobre a relação do gene DIDO com a regulação da apoptose e sobre o fenótipo de resistência das células Bcr-Abl positivas a esse processo de morte celular, o objetivo do presente estudo foi de descrever a potencial relação entre os níveis de expressão de DIDO e a resistência à apoptose em células Bcr-Abl positivas.

\section{I.4 Tratamento da Leucemia Mielóide Crônica}

Com o desenvolvimento da quimioterapia na década de 1950, o bussulfano e a hidroxiuréia se tornaram a principal opção terapêutica para o tratamento da leucemia mielóide crônica. Embora essas drogas possam controlar a proliferação de leucócitos, elas não erradicam os clones leucêmicos e não impedem a progressão da doença (GALTON, 1953; ALLAN, 1989). A ascensão do uso de Interferon-a na década de 1980 representou um grande avanço para o tratamento da LMC, uma vez que representou a possibilidade de eliminar os clones leucêmicos pela potencialização da resposta imune anti-leucêmica e inibição da proliferação da célula tronco hematopoética (KANTARJIAN; O'BRIEN; CORTES, 2003; de CASTRO et al., 2003). O IFN- $\alpha$ pode conduzir a remissões moleculares e citogenéticas e melhorar a sobrevida, mas é pouco tolerado pelos pacientes, pois causa múltiplas toxicidades (CHRONIC MYELOID LEUKEMIA TRIALISTS' COLLABORATIVE GROUP, 1997; JABBOUR; KANTARJIAN, 2014).

$O$ transplante alogênico de células tronco (AlloSCT) é a única intervenção terapêutica curativa para a doença, mas ainda apresenta alto risco de morbidade e mortalidade. Além disso, o AlloSCT é opção somente para pacientes que 
apresentam excelente performance ao procedimento. Pacientes com baixo risco relacionado ao procedimento são aqueles que possuem doador HLA compatível, idade menor que 40 anos, estão na fase crônica da doença e têm diagnóstico confirmado há menos de um ano (JABBOUR; KANTARJIAN, 2014; HEHLMANN; HOCHHAUS; BACCARANI, 2007).

Com o desenvolvimento de pequenas moléculas conhecidas como inibidores de tirosina-quinase (TKIs), o cenário de tratamento da LMC melhorou drasticamente. O Mesilato de Imatinibe (MI) foi o primeiro TKI a receber aprovação pelo FDA (Food and Drug Administration) para tratamento de pacientes com LMC em fase crônica (JABBOUR; KANTARJIAN, 2014; DRUKER; LYDON, 2000).

$O$ estudo internacional randomizado de Interferon e mesilato de imatinibe (IRIS) investigou 1.106 pacientes que receberam MI (400 mg/dia) ou IFN- $\alpha$ com baixa dose de citarabina via subcutânea. Após acompanhamento de pacientes com LMC por cerca de 19 meses, os resultados do tratamento de pacientes com MI foram significativamente melhores do que aqueles observados nos pacientes tratados com Interferon-alfa (IFN- $\alpha$ ) em associação com citarabina, uma vez que a taxa de remissão citogenética completa (RCC) foi de $74 \%$ versus $9 \%$, respectivamente. A resposta ao mesilato de imatinibe também foi mais duradoura em comparação a observada nos pacientes que usaram o IFN- $\alpha$ (DEININGER et al., 2009).

Os inibidores de TK, como o $\mathrm{Ml}$, atuam por competição inibitória pelo sítio de ligação do ATP na proteína Bcr-Abl, o que resulta na inibição da fosforilação das proteínas envolvidas na transdução de sinais (Figura 3). Dessa forma, o Ml e os demais inibidores de TK bloqueiam a proliferação celular dos clones malignos e conduzem à célula leucêmica Bcr-abl positiva à morte (DRUKER; LYDON, 2000). 

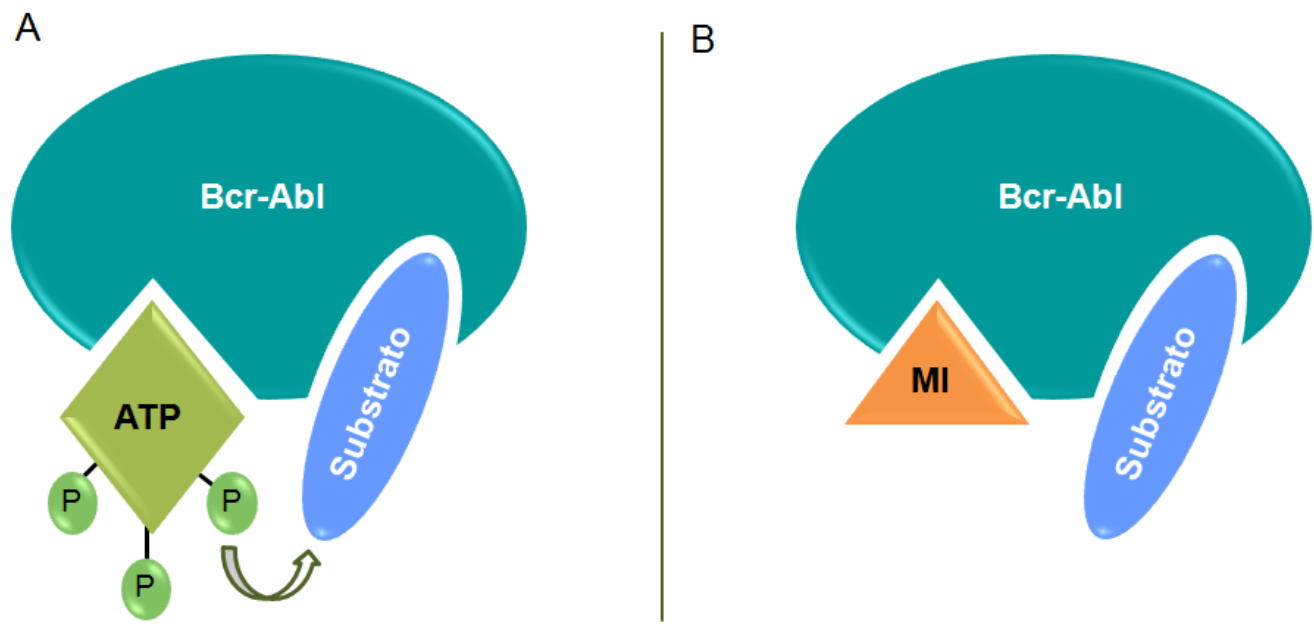

Figura 3. Mecanismo de ação do Mesilato de Imatinibe (MI) em células Bcr-Abl positivas. A. Células leucêmicas não tratadas com o MI. O ATP consegue interagir com seu sítio de ligação na oncoproteína Bcr-Abl, promovendo a fosforilação dos substratos de diferentes vias de sinalização; B. O MI ocupa o sítio de ligação do ATP, impedindo a ligação do ATP e a fosforilação do substrato. O substrato não fosforilado é incapaz de se ligar à proteína efetora e, portanto, a via transdutora de sinal é interrompida. MI: mesilato de imatinibe; P: fosfato. Adaptado de NOVARTIS BIOCIÊNCIAS S.A. Imatinib (Glivec ${ }^{\circledR}$ ): Revolutionising the treatment of chronic myeloid leukaemia (CML) through signal transduction inhibition. São Paulo, 2004. 1 CD.

Devido à morbidade e mortalidade associadas ao AlloSCT, o consenso atual é de que o TKI mesilato de imatinibe seja o tratamento de primeira escolha para pacientes na fase crônica da LMC. O AlloSCT é indicado em casos de resistência ao tratamento com $\mathrm{Ml}$ ou aos outros inibidores de tirosina-quinase, ou progressão da doença para fase acelerada ou crise blástica (BACCARANI; SAGLIO; GOLDMAN, 2006; von BUBNOFF; DUYSTER, 2010).

Evidências clínicas indicam que pacientes com LMC tratados com MI devem ser monitorados para avaliação da resposta à terapia e para detecção precoce de possíveis recaídas. As respostas dos pacientes à terapia denominam-se remissão hematológica, citogenética e molecular. A remissão hematológica completa $(\mathrm{RHC})$ ao mesilato de imatinibe é definida como a normalização da contagem de células sanguíneas e do tamanho do baço e deve ser pesquisada nos pacientes a cada três meses (AN; TIWARI; SUN, 2010).

O monitoramento da remissão citogenética é realizado pela contagem de células $\mathrm{Ph}+$ em aspirados de medula e sangue periférico. A remissão citogenética parcial $(\mathrm{RCP})$ é alcançada quando células $\mathrm{Ph}$ positivas correspondem de $0 \%$ a $35 \%$ do total de células e a ausência de células $\mathrm{Ph}$ positivas define a remissão citogenética completa (RCC). A remissão citogenética deve ser avaliada a cada três ou seis meses até que o paciente atinja RCC, quando então passa a ser avaliada 
anualmente. A remissão molecular é determinada pela diminuição da quantidade de transcritos de $B C R-A B L 1$ e o seu monitoramento deve ser realizado a cada três meses. A remissão molecular completa é definida pela ausência de transcritos de $B C R-A B L 1$ em aspirados de medula e sangue periférico (BACCARANI et al., 2009; AN; TIWARI; SUN, 2010).

Embora muitos pacientes na fase crônica da LMC tratados com imatinibe tenham a doença bem controlada, uma parcela deles têm se mostrado resistente à terapia, apresentando recaídas ou progressão da LMC para fase acelerada ou crise blástica. Além disso, muitos pacientes em fases avançadas da doença inicialmente respondem ao $\mathrm{Ml}$ e apresentam recaídas subsequentemente (DRUKER et al., 2006; CILLONI; SAGLIO, 2009).

Há vários mecanismos celulares e moleculares associados com a resistência ao $\mathrm{Ml}$, convencionalmente divididos em Bcr-Abl dependentes e independentes (APPERLEY, 2007). Os mecanismos Bcr-Abl independentes são aqueles que ou impedem o $\mathrm{Ml}$ de atingir a proteína Bcr-Abl, como efluxo de drogas e níveis plasmáticos do mesilato de imatinibe insuficientes ou a baixa adesão do paciente ao tratamento. Os mecanismos dependentes do $\mathrm{Bcr}-\mathrm{Abl}$ são àqueles que tornam a proteína Bcr-Abl insensível ao $\mathrm{Ml}$, devido a mutações ou amplificações do gene BCR-ABL1 (GORRE, et al, 2001; CILLONI; SAGLIO, 2009).

Sabe-se que pelo menos $50 \%$ dos pacientes que apresentam recaídas após terapia com o mesilato de imatinibe possuem mutações pontuais no gene $B C R$ $A B L 1$, no domínio Abl quinase, como a mutação T315l. O segundo grupo de mutações também se localiza no domínio Abl quinase da Bcr-Abl, afetando sua conformação de tal modo que o Ml fica incapaz de se ligar a essa proteína (CORBIN et al., 2002; SHAH et al., 2002).

Estudos recentes sobre LMC têm demonstrado que a ativação compensatória de vias de sinalização intracelulares é um mecanismo comum de resistência aos inibidores de tirosina-quinase. Dessa maneira, as células continuam a proliferar mesmo com a inibição da atividade quinase de Bcr-Abl. Um exemplo são as proteínas, membros da família SRC quinase, como HCK e LYN, que estão frequentemente expressas em células leucêmicas resistentes ao mesilato de imatinibe que não possuem mutações em BCR-ABL1 (BALBANOV; BRAIG; BRÜMMENDORF, 2014). 
Wu et al. (2008) demonstraram que a ativação de LYN não depende da proteína Bcr-Abl; esses pesquisadores observaram que embora o tratamento com mesilato de imatinibe bloqueie a sinalização da proteína Bcr-Abl, ele não suprime a fosforilação de LYN em células de pacientes resistentes ao Ml que não apresentam mutações em Bcr-Abl. Assim sendo, os mecanismos de resistência à terapia com inibidores de tirosina-quinase, principalmente àqueles Bcr-Abl independentes, são diversos e pouco entendidos e, portanto, ainda necessitam ser melhor investigados.

Assim como o entendimento da patogênese molecular da LMC levou ao desenvolvimento do mesilato de imatinibe, a compreensão dos mecanismos de resistência a essa droga envolvidos no fenótipo das células Bcr-Abl positivas conduziram ao rápido desenvolvimento de drogas mais eficientes (CILLONI; SAGLIO, 2009).

O dasatinibe (Das) é um inibidor de tirosina-quinase de uso oral utilizado para o tratamento dos pacientes com LMC cuja estrutura não se assemelha a do mesilato de imatinibe. O Das apresenta-se como sendo 325 vezes mais potente que 0 imatinibe contra a Bcr-Abl e já foi aprovado pelo FDA para escolha como primeira linha de tratamento para os pacientes com LMC e para aqueles resistentes ou intolerantes ao Ml. O Das, no entanto, também não tem atividade contra a mutação T315I (SANTOS et al., 2011; O'HARE et al., 2005).

A modificação do grupo metilpiperazinilo do imatinibe com objetivo de melhorar suas características de ligação, promoveu o desenvolvimento de nilotinibe, um inibidor de tirosina-quinase de uso oral que tem potencial da ordem de 10 a 30 vezes maior que o de $\mathrm{Ml}$ contra a proteína Bcr-Abl. O nilotinibe tem atividade contra muitas mutações resistentes ao $\mathrm{Ml}$, mas, assim como dasatinibe, também não possui atividade contra a mutação T315I (WEISBERG et al., 2005; SANTOS et al., 2011).

O dasatinibe e o nilotinibe estão aprovados pelo FDA para pacientes com resistência ou intolerância ao MI, por mostrarem atividade significante e duradoura na indução de resposta de pacientes com recaídas na fase crônica (SHAH et al., 2004). No entanto, frente à incapacidade desses inibidores de tirosina-quinase em agir contra as células que carregam a mutação T315I, novos inibidores de tirosinaquinase foram desenvolvidos, como ponatinibe e bosutinibe (YANG; FU, 2015).

A persistência de células Bcr-Abl positivas em pacientes com LMC após o tratamento com mesilato de imatinibe indica que a inibição da atividade tirosina- 
quinase não é suficiente para eliminar todas as células leucêmicas (BEWRY et al., 2008). Portanto, apesar de todos os conhecimentos acima descritos acerca da fisiopatologia da LMC, ainda há mecanismos celulares e moleculares envolvidos na resistência da célula leucêmica à terapia e à apoptose que necessitam ser melhor elucidados.

Nesse contexto, o presente trabalho contribui para o estudo dos mecanismos de resistência das células Bcr-Abl positivas ao tratamento com o Ml por meio da investigação da possível relação entre a expressão de DIDO e a resposta dos pacientes ao tratamento. 
II. Objetivos 


\section{II.1 Obejtivo Geral}

Quantificar os níveis de expressão do gene DIDO em pacientes com Leucemia Mielóide Crônica.

\section{2 Objetivos Específicos}

- Quantificar a expressão dos 3 transcritos do gene DIDO (Dido 1, Dido 2 e Dido 3) em células de pacientes com leucemia mielóide crônica nas diferentes fases da doença, controles e linhagens celulares Bcr-Abl+ sensíveis e resistentes ao Ml;

- Determinar se a expressão de DIDO 1, DIDO 2 e DIDO 3 correlaciona-se à expressão de $B C R-A B L 1$;

- Avaliar se a expressão das moléculas Dido 1, Dido 2 e Dido 3 é modulada pela atividade quinase de Bcr-Abl;

- Correlacionar os níveis de expressão de DIDO 1, DIDO 2 e DIDO 3 com o índice prognóstico de Sokal dos pacientes com leucemia mielóide crônica. 
III. Casuística, Material e Métodos 


\section{III.1 Casuística}

O presente estudo foi aprovado pelos Comitês de Ética em Pesquisa em Humanos da Faculdade de Ciências Farmacêuticas de Ribeirão Preto - FCFRPUSP (CEP/FCFRP n. ${ }^{\circ} 256$ ) e do Hospital das Clínicas da Faculdade de Medicina de Ribeirão Preto - HCFMRP-USP (anexos I e II). Foram coletadas amostras de sangue periférico de 60 pacientes com LMC e 57 indivíduos saudáveis (controles), após assinatura do Termo de Consentimento Livre e Esclarecido (TCLE; anexos III, IV e V).

\section{III.1.1 Pacientes}

Foram estudados 60 pacientes com Leucemia Mielóide Crônica, sendo 26 amostras do Biorrepositório do Laboratório de Hematologia da FCFRP-USP de pacientes provenientes do Hospital de Transplantes Euryclides Zerbini- SP e 34 do Hospital das Clínicas - HCFMRP-USP, de Ribeirão Preto - SP. A seleção dos pacientes foi realizada pelo diagnóstico de LMC com detecção da presença do cromossomo Filadélfia e do gene BCR-ABL1. Foram excluídos quaisquer pacientes com doenças adicionais à LMC.

Dentre as 60 amostras, 35 foram obtidas de indivíduos do sexo masculino e 25 do sexo feminino, com idade média de 45 anos. No momento da coleta, 41 pacientes estavam em Fase Crônica, 10 pacientes em Fase Acelerada e 9 pacientes em Crise Blástica. A tabela 1 relata as informações sobre os pacientes estudados.

\section{III.1.2 Controles}

Cinquenta e sete indivíduos saudáveis, voluntários, da Comunidade da FCFRP-USP constituíram o grupo controle. Destes, 35 indivíduos eram do sexo masculino e 22 do sexo feminino, com idade média de 45 anos. A seleção foi feita na tentativa de obter o pareamento em gênero, idade e cor da pele (tabela 2) com os pacientes, sendo aceitável uma variação de \pm 3 anos na idade. Foram excluídos indivíduos que apresentaram quaisquer doenças e que faziam uso de imunossupressores, hormônios, anti-inflamatórios e medicamentos que pudessem influenciar a expressão dos genes estudados. 
Tabela 1. Caracterização demográfica, fase da doença, fármaco utilizado, resposta ao tratamento e Índice de Sokal dos pacientes com LMC estudados.

\begin{tabular}{|c|c|c|c|c|c|c|c|}
\hline $\begin{array}{l}\text { IDENTIFICAÇÃO } \\
\text { DA AMOSTRA }\end{array}$ & GÊNERO & IDADE & $\begin{array}{l}\text { COR DA } \\
\text { PELE }\end{array}$ & $\begin{array}{l}\text { FASE DA } \\
\text { DOENÇA }\end{array}$ & FÁRMACO & $\begin{array}{l}\text { RESPOSTA AO } \\
\text { TRATAMENTO }\end{array}$ & SOKAL \\
\hline $1 \mathrm{P}$ & $M$ & 45 & Branca & $\mathrm{CR}$ & Ml & $\mathrm{RCC}$ ao $\mathrm{Ml}$ & 1,29 \\
\hline $2 \mathrm{P}$ & M & 44 & Branca & $A C$ & $\mathrm{Ml}$ & Resistente ao MI & 1,03 \\
\hline $3 P$ & M & 68 & Branca & $A C$ & $\mathrm{Ml}$ & Resistente ao Ml & 1,28 \\
\hline $4 \mathrm{P}$ & M & 51 & Branca & $\mathrm{CR}$ & $\mathrm{S} / \mathrm{T}$ & - & 0,77 \\
\hline $5 P$ & $\mathrm{~F}$ & 30 & Branca & $\mathrm{CR}$ & $\mathrm{S} / \mathrm{T}$ & - & 0,54 \\
\hline $6 \mathrm{P}$ & $\mathrm{F}$ & 31 & Branca & $\mathrm{CR}$ & $\mathrm{S} / \mathrm{T}$ & - & 1,01 \\
\hline $7 \mathrm{P}$ & $\mathrm{F}$ & 36 & Branca & $\mathrm{CR}$ & $\mathrm{S} / \mathrm{T}$ & - & 0,85 \\
\hline $8 P$ & $\mathrm{~F}$ & 66 & Branca & $\mathrm{CR}$ & $\mathrm{S} / \mathrm{T}$ & - & 1,04 \\
\hline $9 P$ & M & 44 & Branca & $\mathrm{CR}$ & $\mathrm{S} / \mathrm{T}$ & - & 1,03 \\
\hline $10 \mathrm{P}$ & $\mathrm{F}$ & 77 & Branca & $A C$ & Ml & Resistente ao Ml & 1,13 \\
\hline $11 P$ & $\mathrm{~F}$ & 59 & Branca & $B L$ & Ml & Resistente ao Ml & 2,13 \\
\hline $12 \mathrm{P}$ & $\mathrm{F}$ & 42 & Branca & $\mathrm{CR}$ & Ml & $\mathrm{RCC}$ ao $\mathrm{Ml}$ & 0,58 \\
\hline $13 P$ & M & 45 & Amarela & $\mathrm{CR}$ & Ml & $\mathrm{RCC}$ ao $\mathrm{Ml}$ & 0,61 \\
\hline $14 \mathrm{P}$ & M & 51 & Branca & $\mathrm{CR}$ & Ml & $\mathrm{RCC}$ ao $\mathrm{Ml}$ & 0,77 \\
\hline $15 P$ & M & 52 & Branca & $\mathrm{CR}$ & DAS & RCC ao DAS & 0,76 \\
\hline $16 \mathrm{P}$ & M & 30 & Branca & BL & Ml & Resistente ao Ml & 13,93 \\
\hline $17 P$ & M & 35 & Branca & $\mathrm{CR}$ & Ml & $\mathrm{RCC}$ ao $\mathrm{Ml}$ & 0,70 \\
\hline $18 \mathrm{P}$ & M & 64 & Branca & $\mathrm{CR}$ & DAS & RCC ao DAS & 5,30 \\
\hline $19 P$ & $\mathrm{~F}$ & 56 & Branca & $\mathrm{CR}$ & $\mathrm{S} / \mathrm{T}$ & - & 0,60 \\
\hline $20 \mathrm{P}$ & M & 19 & Branca & $\mathrm{CR}$ & $\mathrm{S} / \mathrm{T}$ & - & 0,71 \\
\hline $21 \mathrm{P}$ & $\mathrm{F}$ & 51 & Branca & $\mathrm{CR}$ & Ml & $\mathrm{RCC}$ ao $\mathrm{Ml}$ & 0,82 \\
\hline $22 \mathrm{P}$ & M & 48 & Branca & $\mathrm{CR}$ & $\mathrm{S} / \mathrm{T}$ & - & 0,73 \\
\hline $23 P$ & M & 19 & Branca & $B L$ & DAS & Resistente ao Ml & 6,50 \\
\hline $24 \mathrm{P}$ & M & 53 & Branca & $A C$ & DAS & Resistente ao Ml & 5,30 \\
\hline $25 \mathrm{P}$ & M & 55 & Branca & $B L$ & DAS & Resistente ao Ml & 0,91 \\
\hline $26 \mathrm{P}$ & $\mathrm{F}$ & 39 & Branca & $B L$ & DAS & Resistente ao Ml & 7,51 \\
\hline $27 \mathrm{P}$ & M & 61 & Branca & $\mathrm{BL}$ & Ml & Resistente ao Ml & 6,30 \\
\hline $28 \mathrm{P}$ & M & 62 & Branca & $\mathrm{CR}$ & $\mathrm{S} / \mathrm{T}$ & - & 1,10 \\
\hline $29 \mathrm{P}$ & $\mathrm{F}$ & 51 & Negra & $B L$ & DAS & Resistente ao Ml & 4,40 \\
\hline $30 \mathrm{P}$ & $\mathrm{F}$ & 40 & Negra & AC & DAS & Resistente ao Ml & 1,70 \\
\hline $31 \mathrm{P}$ & $\mathrm{F}$ & 41 & Branca & $\mathrm{CR}$ & $\mathrm{S} / \mathrm{T}$ & - & 1,10 \\
\hline $32 P$ & $\mathrm{~F}$ & 21 & Branca & $\mathrm{CR}$ & $\mathrm{S} / \mathrm{T}$ & - & 1,70 \\
\hline $33 P$ & M & 28 & Branca & $\mathrm{CR}$ & $S / T$ & - & 3,10 \\
\hline $34 \mathrm{P}$ & $\mathrm{F}$ & 63 & Branca & $A C$ & Ml & Resistente ao Ml & 2,30 \\
\hline $35 \mathrm{P}$ & M & 28 & Branca & $\mathrm{CR}$ & $\mathrm{S} / \mathrm{T}$ & - & 0,93 \\
\hline $36 \mathrm{P}$ & $\mathrm{F}$ & 53 & Branca & $\mathrm{CR}$ & $\mathrm{S} / \mathrm{T}$ & - & 0,27 \\
\hline $37 P$ & $\mathrm{~F}$ & 39 & Branca & $A C$ & MI & Resistente ao Ml & 7,32 \\
\hline
\end{tabular}




\begin{tabular}{|c|c|c|c|c|c|c|c|}
\hline $\begin{array}{l}\text { IDENTIFICAÇÃO } \\
\text { DA AMOSTRA }\end{array}$ & GÊNERO & IDADE & $\begin{array}{l}\text { COR DA } \\
\text { PELE }\end{array}$ & $\begin{array}{l}\text { FASE DA } \\
\text { DOENÇA }\end{array}$ & FÁRMACO & $\begin{array}{l}\text { RESPOSTA AO } \\
\text { TRATAMENTO }\end{array}$ & SOKAL \\
\hline $38 \mathrm{P}$ & $M$ & 52 & Branca & $\mathrm{CR}$ & DAS & Resistente ao Ml & 0,78 \\
\hline $39 P$ & $M$ & 52 & Branca & $\mathrm{BL}$ & DAS & RCC ao DAS & 1,39 \\
\hline $40 \mathrm{P}$ & $\mathrm{F}$ & 41 & Branca & $A C$ & DAS & Resistente ao Ml & 7,32 \\
\hline $41 \mathrm{P}$ & M & 32 & Branca & $A C$ & DAS & Resistente ao Ml & 2,53 \\
\hline $42 \mathrm{P}$ & $\mathrm{F}$ & 69 & Mulata & $A C$ & DAS & Resistente ao Ml & 1,87 \\
\hline $43 P$ & M & 22 & Branca & $\mathrm{CR}$ & MI & $\mathrm{RCC}$ ao $\mathrm{Ml}$ & 0.99 \\
\hline $44 \mathrm{P}$ & M & 50 & Branca & $\mathrm{CR}$ & DAS & Resistente ao Ml & 0,94 \\
\hline $45 \mathrm{P}$ & M & 37 & Branca & $\mathrm{CR}$ & MI & $\mathrm{RCC}$ ao $\mathrm{Ml}$ & 1,01 \\
\hline $46 \mathrm{P}$ & $\mathrm{F}$ & 63 & Parda & $\mathrm{CR}$ & $\mathrm{S} / \mathrm{T}$ & - & 1,59 \\
\hline $47 \mathrm{P}$ & M & 55 & Branca & $\mathrm{CR}$ & MI & $\mathrm{RCC}$ ao $\mathrm{Ml}$ & 0,96 \\
\hline $48 \mathrm{P}$ & $\mathrm{F}$ & 32 & Branca & $\mathrm{CR}$ & MI & $\mathrm{RCC}$ ao $\mathrm{Ml}$ & 1,47 \\
\hline $49 P$ & M & 51 & Branca & $\mathrm{CR}$ & MI & $\mathrm{RCC}$ ao $\mathrm{Ml}$ & 1,08 \\
\hline $50 \mathrm{P}$ & $\mathrm{F}$ & 57 & Branca & $\mathrm{CR}$ & MI & $\mathrm{RCC}$ ao $\mathrm{Ml}$ & 0,80 \\
\hline $51 \mathrm{P}$ & M & 58 & Branca & $\mathrm{CR}$ & MI & $\mathrm{RCC}$ ao $\mathrm{Ml}$ & 0,69 \\
\hline $52 \mathrm{P}$ & M & 23 & Branca & $\mathrm{CR}$ & MI & $\mathrm{RCP}$ ao $\mathrm{Ml}$ & 0,71 \\
\hline $53 \mathrm{P}$ & $\mathrm{F}$ & 40 & Branca & $\mathrm{CR}$ & MI & $\mathrm{RCC}$ ao $\mathrm{Ml}$ & 0,77 \\
\hline $54 \mathrm{P}$ & M & 44 & Branca & $\mathrm{CR}$ & MI & $\mathrm{RCC}$ ao $\mathrm{Ml}$ & 0,70 \\
\hline $55 \mathrm{P}$ & M & 34 & Branca & $\mathrm{BL}$ & DAS & Resistente ao Ml & 1,18 \\
\hline $56 \mathrm{P}$ & M & 56 & Branca & $\mathrm{CR}$ & Ml & $\mathrm{RCC}$ ao $\mathrm{Ml}$ & 1,30 \\
\hline $57 \mathrm{P}$ & $\mathrm{F}$ & 38 & Branca & $\mathrm{CR}$ & Ml & $\mathrm{RCC}$ ao $\mathrm{Ml}$ & 1,17 \\
\hline $58 \mathrm{P}$ & $\mathrm{F}$ & 60 & Branca & $\mathrm{CR}$ & DAS & Resistente ao Ml & 0,81 \\
\hline $59 P$ & M & 33 & Branca & $\mathrm{CR}$ & Ml & $\mathrm{RCC}$ ao $\mathrm{Ml}$ & 0,55 \\
\hline $60 P$ & $M$ & 27 & Branca & $\mathrm{CR}$ & NIL & Resistente ao Ml & 0,53 \\
\hline
\end{tabular}

M: sexo masculino; F: sexo feminino; AC: fase acelerada; CR: fase crônica; BL: crise blástica; MI: mesilato de imatinibe; DAS: dasatinibe; NIL: nilotinibe; S/T: paciente ao diagnóstico, sem tratamento; RCC: remissão citogenética completa; RCP: remissão citogenética parcial. 
Tabela 2. Caracterização demográfica dos controles.

\begin{tabular}{|c|c|c|c|}
\hline $\begin{array}{c}\text { IDENTIFICAÇÃO } \\
\text { DA AMOSTRA }\end{array}$ & GÊNERO & IDADE & COR DA PELE \\
\hline $1 \mathrm{C}$ & M & 45 & Branca \\
\hline $2 \mathrm{C}$ & $M$ & 46 & Branca \\
\hline $3 C$ & $M$ & 65 & Branca \\
\hline $4 C$ & $M$ & 52 & Branca \\
\hline $5 C$ & $\mathrm{~F}$ & 32 & Branca \\
\hline $6 C$ & $\mathrm{~F}$ & 31 & Branca \\
\hline $7 C$ & $\mathrm{~F}$ & 35 & Branca \\
\hline $8 C$ & $\mathrm{~F}$ & 68 & Branca \\
\hline $9 \mathrm{C}$ & $M$ & 42 & Branca \\
\hline $10 \mathrm{C}$ & $\mathrm{F}$ & 80 & Branca \\
\hline $11 \mathrm{C}$ & $\mathrm{F}$ & 59 & Branca \\
\hline $12 \mathrm{C}$ & $F$ & 43 & Branca \\
\hline $13 C$ & M & 50 & Amarela \\
\hline $14 \mathrm{C}$ & $M$ & 52 & Branca \\
\hline $15 \mathrm{C}$ & $M$ & 52 & Branca \\
\hline $16 \mathrm{C}$ & $M$ & 31 & Branca \\
\hline $17 \mathrm{C}$ & $M$ & 35 & Branca \\
\hline $18 \mathrm{C}$ & $M$ & 67 & Branca \\
\hline $19 \mathrm{C}$ & $\mathrm{F}$ & 56 & Branca \\
\hline $20 \mathrm{C}$ & $M$ & 20 & Branca \\
\hline $21 C$ & $\mathrm{~F}$ & 48 & Branca \\
\hline $22 \mathrm{C}$ & $M$ & 50 & Branca \\
\hline $23 C$ & $M$ & 22 & Branca \\
\hline $24 C$ & $M$ & 55 & Branca \\
\hline $25 \mathrm{C}$ & $M$ & 58 & Branca \\
\hline $26 C$ & $\mathrm{~F}$ & 41 & Branca \\
\hline $27 \mathrm{C}$ & $M$ & 60 & Branca \\
\hline $28 \mathrm{C}$ & $\mathrm{M}$ & 65 & Branca \\
\hline $29 C$ & $\mathrm{~F}$ & 50 & Negra \\
\hline $30 \mathrm{C}$ & $\mathrm{F}$ & 39 & Branca \\
\hline $31 \mathrm{C}$ & $\mathrm{F}$ & 24 & Branca \\
\hline $32 \mathrm{C}$ & $M$ & 29 & Branca \\
\hline $33 C$ & $\mathrm{~F}$ & 66 & Branca \\
\hline $34 \mathrm{C}$ & $M$ & 31 & Branca \\
\hline $35 \mathrm{C}$ & $\mathrm{F}$ & 52 & Branca \\
\hline $36 \mathrm{C}$ & $\mathrm{F}$ & 38 & Branca \\
\hline $37 C$ & $M$ & 50 & Branca \\
\hline $38 \mathrm{C}$ & $M$ & 51 & Branca \\
\hline
\end{tabular}




\begin{tabular}{cccc}
\hline $\begin{array}{c}\text { IDENTIFICAÇÃO } \\
\text { DA AMOSTRA }\end{array}$ & GÊNERO & IDADE & PELE \\
\hline 39C & $\mathrm{F}$ & 44 & Branca \\
$40 \mathrm{C}$ & $\mathrm{M}$ & 30 & Branca \\
$41 \mathrm{C}$ & $\mathrm{M}$ & 23 & Branca \\
$42 \mathrm{C}$ & $\mathrm{M}$ & 52 & Branca \\
$43 \mathrm{C}$ & $\mathrm{M}$ & 36 & Branca \\
$44 \mathrm{C}$ & $\mathrm{M}$ & 58 & Branca \\
$45 \mathrm{C}$ & $\mathrm{F}$ & 35 & Branca \\
$46 \mathrm{C}$ & $\mathrm{M}$ & 51 & Branca \\
$47 \mathrm{C}$ & $\mathrm{F}$ & 55 & Branca \\
$48 \mathrm{C}$ & $\mathrm{M}$ & 59 & Branca \\
$49 \mathrm{C}$ & $\mathrm{M}$ & 23 & Branca \\
$50 \mathrm{C}$ & $\mathrm{F}$ & 39 & Branca \\
$51 \mathrm{C}$ & $\mathrm{M}$ & 43 & Branca \\
$52 \mathrm{C}$ & $\mathrm{M}$ & 36 & Branca \\
$53 \mathrm{C}$ & $\mathrm{M}$ & 57 & Branca \\
$54 \mathrm{C}$ & $\mathrm{F}$ & 35 & Branca \\
$55 \mathrm{C}$ & $\mathrm{F}$ & 60 & Branca \\
$56 \mathrm{C}$ & $\mathrm{M}$ & 32 & Branca \\
$57 \mathrm{C}$ & $\mathrm{M}$ & 28 & Branca \\
\hline
\end{tabular}

M: sexo masculino; F: sexo feminino.

\section{2 Material e Métodos}

\section{III.2.1 Isolamento das Células Mononucleares}

Foram coletados $30 \mathrm{~mL}$ de sangue periférico dos pacientes e controles. $\mathrm{O}$ plasma foi separado após centrifugação (Centrifuge 5810, Eppendrof) a $240 \times \mathrm{g}$ durante 10 minutos e então os constituintes celulares foram ressuspendidos em tampão salina-fosfato (PBS; $\mathrm{pH}=7,4$ ) na proporção 1:2. Essa ressuspensão foi aplicada delicadamente em parede de tubo falcon, com capacidade de $50 \mathrm{~mL}$, contendo $13 \mathrm{~mL}$ de Ficoll-Paque ${ }^{\mathrm{TM}}$ Plus (GE Healthcare, Suécia). Após centrifugação de 30 minutos a $240 \times \mathrm{g}$, as células mononucleares foram recolhidas da interface plasma-ficoll e lavadas com PBS (tampão salina-fosfato). Nova centrifugação foi realizada a $240 \mathrm{x}$ g durante 10 minutos e o pellet de células mononucleares formado foi ressuspendido em $1 \mathrm{~mL}$ de PBS. A suspensão celular foi, então, diluída com líquido de Turk na proporção 1:20, respectivamente, para determinar a concentração 
celular em câmara de Neubauer. Concentrações celulares de $5 \times 10^{6}$ a $1 \times 10^{7}$ células foram congeladas em $1 \mathrm{~mL}$ de Trizol $^{\circledR}$ Reagent (Ambion, EUA) a $-80^{\circ} \mathrm{C}$ para posterior extração de RNA.

\section{III.2.2 Extração de RNA}

Às células nas concentrações de $5 \times 10^{6}$ a $1 \times 10^{7}$ em Trizol foi adicionado clorofórmio para recuperação do conteúdo de RNA total em fase aquosa. Após centrifugação a $12000 \times \mathrm{g}, 4^{\circ} \mathrm{C}$ durante 15 minutos, a fase aquosa foi coletada e tratada com isopropanol e mantida a $4^{\circ} \mathrm{C}$ overnight para precipitação do RNA. No dia seguinte, as amostras foram centrifugadas a $12000 \times \mathrm{g}$, a $4^{\circ} \mathrm{C}$ por 15 minutos e 0 pellet de RNA formado foi lavado com etanol. Após nova centrifugação, todo o conteúdo de etanol foi descartado e o pellet ressuspendido em $13 \mu \mathrm{L}$ de água livre de DNAses e RNAses (Water Molecular Biology Reagent, Sigma Aldrich, São Paulo Brasil). O conteúdo de RNA total foi quantificado em espectrofotômetro NanoVue Plus (GE Healthcare) a $260 \mathrm{~nm}$ e as amostras foram armazenadas em $-80^{\circ} \mathrm{C}$.

Para avaliação da integridade das amostras de RNA foram realizadas eletroforeses em gel de agarose a $1 \%$, aplicando-se $1 \mu \mathrm{g}$ de amostra de RNA. As amostras íntegras apresentaram bandas bem definidas referentes às subunidades de RNA ribossômico (rRNA) $18 \mathrm{~S}$ e 28S. A visualização das bandas foi feita aplicando-se corante gelRed (GelRed ${ }^{T M}$ Nucleic Acid Gel Stain, Biotium) às amostras, cuja fluorescência gerada foi observada e captada em aparelho fotodocumentador (Image Quant 100, GE Healthcare). As amostras degradadas foram excluídas do estudo. 


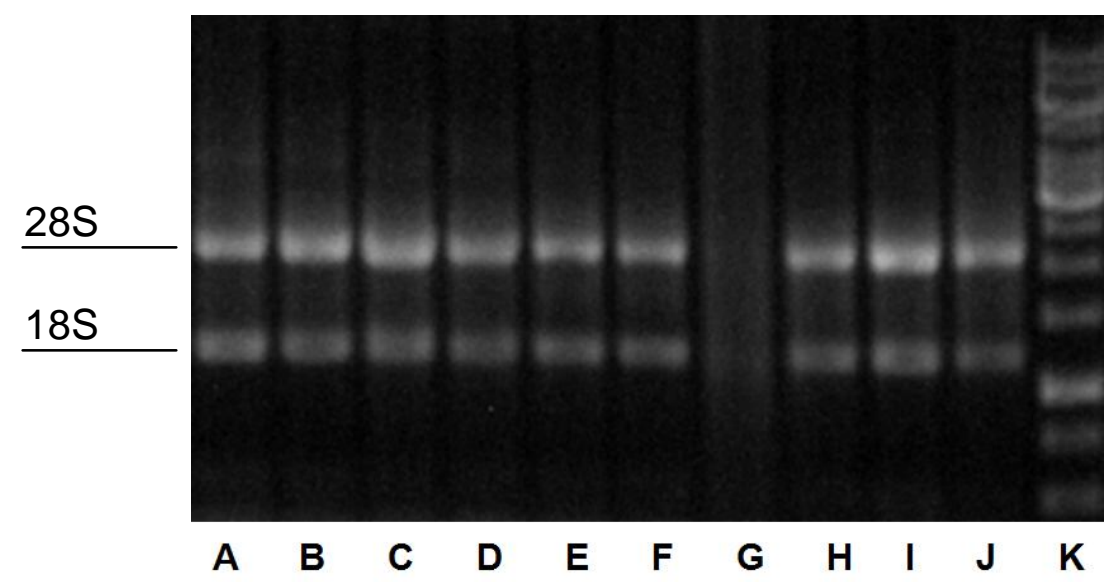

Figura 4. Eletroforese para avaliação da qualidade das amostras de RNA. De A a $F$ : bandas das subunidades $28 \mathrm{~S}$ e $18 \mathrm{~S}$ de rRNA, evidenciando amostras íntegras; G: amostra degradada; de H a J: amostras íntegras; K: marcador de peso molecular.

\section{III.2.3 Síntese de cDNA}

As amostras de RNA foram empregadas na síntese de cDNA com o kit High Capacity cDNA reverse transcription (Applied Biosystems ${ }^{\mathrm{TM}}$, EUA), que possui todos os reagentes necessários para reação de transcrição reversa. Aos reagentes do kit foi misturado $1 \mu \mathrm{g}$ de amostra de RNA e a polimerização das novas fitas de DNA complementar (cDNA) foi realizada em aparelho termociclador (Mastercycler, Eppendorf) a $25^{\circ} \mathrm{C}$ durante 10 minutos para promover o anelamento dos primers, aos quais seguiram-se 2 horas a $37^{\circ} \mathrm{C}$ para extensão das novas fitas.

As amostras de cDNA obtidas foram empregadas nas reações de PCR em Tempo Real para quantificação da expressão gênica das 3 isoformas do gene DIDO (DIDO 1, DIDO 2 e DIDO 3) e dos promotores proximal $(P P)$ e distal $(P D)$.

\section{III.2.4 Linhagens Celulares, Cultivo e Tratamento com Inibidores de Tirosina- Quinase (TKIs)}

Foram cultivadas e estudadas a expressão de DIDO em seis diferentes linhagens celulares: $\mathrm{HL}-60$ e HL-60.Bcr-Abl ${ }^{+}$, gentilmente cedidas pelo Prof. Dr. João P. Gustavo Amarante-Mendes do Instituto de Ciências Biomédicas da Universidade de São Paulo - USP; e as linhagens sensíveis (S) e resistentes $(R)$ ao mesilato de imatinibe: KCL $22 \mathrm{~S}, \mathrm{KCL} 22 \mathrm{R}$, LAMA $84 \mathrm{~S}$ e LAMA $84 \mathrm{R}$, gentilmente cedidas pela 
Profa. Dra. Junia Vaz de Melo, da School of Pharmacy and Medical Sciences, University of South Australia, Adelaide - Austrália.

A HL-60 é uma linhagem originada do sangue periférico de paciente caucasiana do sexo feminino, com 36 anos de idade, portadora de Leucemia Promielocítica Aguda $\left(\right.$ ATCC $\left.^{\circledR}, 2014\right)$. A cultura de leucócitos em meio condicionado resultou no desenvolvimento de uma linhagem celular imortalizada independente de fatores de crescimento e com características mielóides (GALLAGHER et al., 1979), uma vez que são células positivas para marcadores histoquímicos característicos como mieloperoxidase e fosfatase ácida (TSIFTSOGLOU; STEPHEN, 1985). A morfologia das células é de mieloblastos e promielócitos: grandes núcleos arredondados e citoplasma basofílico com grânulos azurofílicos. Cerca de 90\% a 95\% das células em cultura apresentam essa morfologia, enquanto o restante se assemelha a células mielóides mais maduras, principalmente mielócitos e alguns neutrófilos e monócitos (GRAHAM; TINDLE; BIRNIE, 1985).

As células HL-60.Bcr-Abl+ provém da infecção de células HL-60 selvagens com retrovírus recombinante. Foram produzidas por meio da transfecção por eletroporação de combinação de células empacotadoras das linhagens PA317 e $\Psi 2$ com o plasmídeo pSRaMSVp185bcr-abl tkneo, contendo o gene $B C R-A B L 1$. Importante ressaltar que as células HL-60.Bcr-Abl+ são resistentes à morte celular induzida por diferentes indutores da apoptose em comparação as células HL-60, conforme descrito por BRUMATTI et al. (2003) e BUENO-DA-SILVA et al. (2003).

A LAMA 84 foi estabelecida a partir do sangue periférico de paciente do sexo feminino, com 29 anos de idade e portadora de LMC em crise blástica. As células expressam marcadores megacariocíticos e eritróides e carregam a t(9;22) que leva ao gene de fusão BCR-ABL1 e14a2 (b3a2) (DSMZ, 2015a). Le Coutre et al. (2000) mostraram que a incubação de LAMA 84 e LAMA $84 \mathrm{R}$ com aumento de concentração de mesilato de imatinibe durante 60 horas causou inibição dramática da taxa proliferativa de LAMA 84, mas em menor grau de LAMA $84 \mathrm{R}$. Esses pesquisadores observaram que a $\mathrm{IC}_{50}$ do efeito inibitório de $\mathrm{MI}$ na proliferação de LAMA $84 R$ foi 10 vezes superior ao valor calculado para a linhagem celular parental.

A linhagem KCL 22 foi estabelecida em 1981 de efusão pleural de paciente do sexo feminino, com 32 anos de idade, que se encontrava em crise blástica. As células são $\mathrm{Ph}+$, contendo a t(9;22) que leva ao gene de fusão $B C R-A B L 1$ e13a2 
(b2a2) e também possuem a mutação p53 (DSMZ, 2015b). Segundo Rosenhahn et al. (2007), a proliferação celular de KCL 22-S foi significativamente reduzida quando tratada com $1 \mu \mathrm{M}$ de mesilato de imatinibe. Por outro lado, a linhagem resistente, KCL 22 R, exibiu elevada taxa de crescimento na presença de MI. A apoptose em KCL22 S aumentou significativamente após o tratamento com esse inibidor de tirosina-quinase, entretanto, esse tratamento não causou efeito significante na taxa de apoptose de KCL22 R.

Todas as linhagens celulares em estudo foram cultivadas com meio de cultura RPMI 1640 (Gibco ${ }^{\circledR}$, EUA) suplementado com 10\% de soro fetal bovino (SFB Gibco $^{\circledR}$, Itapevi - Brasil), 1\% de penicilina $10.000 \mathrm{U} / \mathrm{mL}$ e estreptomicina $10.000 \mu \mathrm{g} /$ $\mathrm{mL}\left(\right.$ Gibco $^{\circledR}$, EUA) e $1 \%$ de glutamina $200 \mathrm{mM}$ (Gibco ${ }^{\circledR}$, EUA) e incubadas em estufa a $37^{\circ} \mathrm{C}$ com $5 \%$ de $\mathrm{CO}_{2}$.

Tratamentos com inibidores de tirosina-quinase foram realizados em triplicata com o objetivo de checar se a expressão do gene DIDO é dependente da atividade quinase da proteína Bcr-Abl. Para isso, as linhagens foram cultivadas até atingirem alta viabilidade celular, acima de $80 \%$ de células vivas. A viabilidade celular foi avaliada por meio da utilização do corante Azul de Tripan 0,4\% (Sigma-Aldrich, São Paulo - Brasil) em câmara de Neubauer. Foram utilizados os inibidores Mesilato de Imatinibe (Glivec ${ }^{\circledR}$, Novartis), Dasatinibe (Sprycel ${ }^{T M}$, Bristol-Myers Squibb Company) e Nilotinibe (Tasigna ${ }^{\circledR}$, Novartis). Os tratamentos foram realizados em placa de 12 poços e as drogas foram utilizadas nas concentrações de $10 \mu \mathrm{M} /$ poço, $5 \mathrm{nM} /$ poço e $12,5 \mathrm{nM} /$ poço, respectivamente. As células ficaram incubadas na presença desses inibidores por 4 horas.

Para as linhagens HL-60 e HL-60.Bcr-Abl ${ }^{+}$, foram utilizadas $5 \times 10^{6}$ células em $3 \mathrm{~mL}$ de meio de cultura por poço. Para cada tempo de incubação foram ocupados 4 poços da placa, sendo um poço para cada um dos três inibidores e um poço controle, no qual as células não receberam nenhum tratamento. Após 4 horas de incubação, o conteúdo de cada um dos poços foi recolhido e centrifugado a 240 x g, $4^{\circ} \mathrm{C}$ por 10 minutos e o sobrenadante foi descartado. O pellet de células formado foi então lavado em PBS. Parte do conteúdo celular $\left(2 \times 10^{6}\right.$ células) foi ressuspendida em tampão de lise para proteínas ( $\mathrm{pH}=7,5 ; 20 \mathrm{mM}$ Tris-HCL, $150 \mathrm{mM} \mathrm{NaCl}, 1 \mathrm{mM}$ EDTA, 1\% Igepal, 10\% Inibidor de fosfatase, 1\% Inibidor de protease) e armazenada em $-80^{\circ} \mathrm{C}$ para posterior realização de Western-blotting. A outra parte $\left(3 \times 10^{6}\right.$ células $)$ 
foi ressuspendida em Trizol para posterior extração de RNA e síntese de cDNA. Tais amostras de cDNA foram então empregadas nas reações de PCR em Tempo Real.

O tratamento para as linhagens Sensíveis e Resistentes procedeu-se da mesma forma que o tratamento das demais linhagens. No entanto, essas células foram tratadas apenas com o inibidor Mesilato de Imatinibe para confirmação da resistência e sensibilidade ao fármaco.

\section{III.2.5 Quantificação da expressão do gene DIDO por PCR em Tempo Real (qPCR)}

Foram realizadas reações de $\mathrm{PCR}$ em tempo real para quantificação da expressão das diferentes isoformas do gene DIDO em pacientes, controles e linhagens. Para isso utilizou-se o método SYBR Green (GoTaq ${ }^{\circledR}$ qPCR Master Mix, Promega, EUA) e o aparelho utilizado foi o Applied Byosistems ${ }^{\circledR} 7500$ Real Time PCR System. Foram utilizados oligonucleotídeos específicos para a amplificação e quantificação dos genes DIDO 1, DIDO 2, DIDO 3, DIDO PP, DIDO PD, BCR-ABL1 (junção b2a2), e $B C R-A B L 1$ (junção b3a2), além dos genes de referência $B E T A$ ACTINA e BETA-2-MICROGLOBULINA (B2M) (Invitrogen ${ }^{\text {TM }}$ ). A tabela 3 descreve as informações de cada oligonucleotídeo utilizado no presente estudo. As reações de amplificação foram realizadas com 55 ciclos para amplificação dos genes, seguidos pela curva de melting $\left(95^{\circ} \mathrm{C}\right.$ por 15 segundos; $60^{\circ} \mathrm{C}$ por 1 minuto; $95^{\circ} \mathrm{C}$ por 30 segundos e $60^{\circ} \mathrm{C}$ por 15 segundos) para garantir a qualidade da amplificação. 
Tabela 3. Sequência dos Oligonucleotideos utilizados nas reações de qPCR, temperaturas de anelamento e tamanho dos fragmentos gerados (amplicons).

\begin{tabular}{|c|c|c|c|}
\hline PRIMER & SEQUÊNCIA (5'-3') & $\operatorname{TA}\left({ }^{\circ} \mathrm{C}\right)$ & AMPLICON (pb) \\
\hline $\begin{array}{l}\text { DIDO } 1-\mathrm{F} \\
\text { DIDO } 1-\mathrm{R}\end{array}$ & $\begin{array}{l}\text { AGG CGT TGG AGC GCG GAA AT } \\
\text { AGA GGC TGT TCC CGT GGA GT }\end{array}$ & 62 & 365 \\
\hline $\begin{array}{l}\text { DIDO } 2-\mathrm{F} \\
\text { DIDO } 2-\mathrm{R}\end{array}$ & $\begin{array}{l}\text { TCG GGG AAA TGG CTG CGA GA } \\
\text { AGA GGC TGT TCC CGT GGA GT }\end{array}$ & 62 & 331 \\
\hline $\begin{array}{l}\text { DIDO } 3-F \\
\text { DIDO } 3-\mathrm{R}\end{array}$ & $\begin{array}{c}\text { GTC TTC CGA AAT GCG GTG CTC A } \\
\text { ATG GTG CAG CCG GTG TCT GT }\end{array}$ & 60 & 133 \\
\hline $\begin{array}{l}\text { DIDO PP }-F \\
\text { DIDO PP }- \text { R }\end{array}$ & $\begin{array}{l}\text { ATC GCA CCG AAG ACA GTT TG } \\
\text { ACT CAG CAG GGC ATG TCA G }\end{array}$ & 60 & 61 \\
\hline $\begin{array}{l}\text { DIDO PD - F } \\
\text { DIDO PD - R }\end{array}$ & $\begin{array}{l}\text { ACT CTT GCC CTT TGA GGG ACC A } \\
\text { TCG GGT CCG CTT TTC GTC CA }\end{array}$ & 60 & 89 \\
\hline $\begin{array}{l}\text { BETA ACTINA - F } \\
\text { BETA ACTINA - R }\end{array}$ & $\begin{array}{c}\text { GCC CTG AGG CAC TCT TCC A } \\
\text { CCA GGG CAG TGA TCT CCT TCT }\end{array}$ & 58 & 192 \\
\hline $\begin{array}{l}B 2 M-F \\
B 2 M-R\end{array}$ & $\begin{array}{l}\text { CCA GCG TAC TCC AAA GAT TCA } \\
\text { TGG ATG AAA CCC AGA CAC ATA G }\end{array}$ & 60 & 94 \\
\hline $\begin{array}{l}\mathrm{B} 2 \mathrm{~A} 2-\mathrm{F} \\
\mathrm{B} 2 \mathrm{~A} 2-\mathrm{R}\end{array}$ & $\begin{array}{l}\text { GCA TTC CGC TGA CCA TCA AT } \\
\text { TGG GTC CAG CGA GAA GGT T }\end{array}$ & 60 & 200 \\
\hline $\begin{array}{l}\mathrm{B} 3 \mathrm{~A} 2-\mathrm{F} \\
\mathrm{B} 3 \mathrm{~A} 2-\mathrm{R}\end{array}$ & $\begin{array}{l}\text { TCC ACT CAG CCA CTG GAT TTA A } \\
\text { TGG GTC CAG CGA GAA GGT T }\end{array}$ & 60 & 129 \\
\hline
\end{tabular}

Os primers Dido 1, Dido 2, Dido 3, Dido PP, Dido PD, b2a2 e b3a2 foram utilizados na concentração de 10 picomolares, enquanto que os primers beta actina e B2M foram utilizados na concentração de 2,5 picomolares. Os resultados da expressão gênica obtidos para cada paciente e controle foram expressos em Unidade Relativa de Expressão (URE). Os resultados de expressão gênica das linhagens celulares estudadas foram expressos por fold change. Os cálculos de URE e fold change foram realizados da seguinte forma:

Delta $\mathbf{C t}=\mathrm{Ct}$ do gene alvo - média geométrica dos $\mathrm{Ct}$ dos genes referência

$$
\text { URE }=10000 / 2^{\text {deltaCt }}
$$

dDelta $\mathbf{C t}=$ deltaCt amostra - deltaCt controle

Fold change $=2^{-\mathrm{dDeltaCt}}$ 
No caso das linhagens celulares $S$ e $R$ não tratadas, foram considerados como calibradores os $\mathrm{Ct}$ das linhagens sensíveis. Para todas as linhagens celulares tratadas, foram consideradas controles as células que não receberam tratamento com TKIs.

\section{III.2.6 Western-blotting}

Este método foi utilizado para verificar a atividade fosforilativa da proteína Bcr-Abl nas linhagens celulares após tratamento com os TKIs e para confirmar a expressão de Bcr-Abl. Para isso foram determinadas a expressão de proteínas fosforiladas e a de proteínas Bcr-Abl e Abl. A proteína tubulina foi escolhida como controle endógeno.

Os lisados proteicos das linhagens celulares foram quantificados pelo método de BCA (Pierce ${ }^{\circledast}$ BCA Protein Assay Kit, Thermo Scientific, EUA) segundo especificações do fabricante. Após a quantificação, $25 \mu \mathrm{g}$ de cada amostra de proteína foram colocadas em solução de dodecil sulfato de sódio (SDS) loading com azul de bromofenol para a realização da corrida eletroforética, em uma proporção de 3:1, respectivamente. Em seguida, para otimizar a separação durante a eletroforese, as amostras foram aquecidas durante 5 minutos a $100^{\circ} \mathrm{C}$ para desnaturação das proteínas, seguido de banho de gelo para manutenção da forma desnaturada.

As amostras foram aplicadas em gel de acrilamida (30\% Acrylamide/Bis Solution 29:1, Bio-Rad) com $1 \%$ de SDS e então foi realizada a eletroforese em tampão de corrida ( $\mathrm{pH}=8,4 ; 24,8 \mathrm{mM}$ Tris, $193 \mathrm{mM}$ glicina, 3,5 mM SDS) por aproximadamente 2 horas a $100 \mathrm{~V}$. Ao término da eletroforese, procedeu-se a transferência das proteínas para membrana de fluoreto de polivinilideno (PVDF) (Amersham Hybond ${ }^{T M}-P$, GE Healthcare, São Paulo - Brasil) com tampão de transferência ( $\mathrm{pH}=8,3 ; 25 \mathrm{mM}$ Tris, $192 \mathrm{mM}$ glicina, 20\% metanol) durante 2 horas a $0,30 \mathrm{~A}$.

Após o término da transferência, a membrana foi bloqueada por 2 horas com tampão tris-salina-Tween-20 (TBS-T, pH = 7,6) acrescido de 5\% de albumina de soro bovino (BSA) com $0,01 \%$ de azida sódica. Na sequência, incubou-se a membrana com anticorpos primários overnight. Então se procedeu com a lavagem da membrana por meia hora com TBS-T e posterior incubação com anticorpo 
secundário conjugado com peroxidase durante uma hora. A tabela 4 descreve os anticorpos utilizados para marcação das proteínas e suas concentrações de uso.

Após incubação com anticorpo secundário, a membrana foi novamente lavada com TBS-T por meia hora e, posteriormente, tratada com kit ECL (Amersham ${ }^{T M}$ $E C L^{T M}$ Prime Western Blotting Detection Reagent, GE Healthcare, São Paulo Brasil) para detecção das bandas proteicas marcadas com os anticorpos. A marcação das proteínas da membrana foi revelada em filme fotográfico (Amersham Hyperfilm $^{T M}$ ECL, GE Healthcare, Reino Unido) com revelador e fixador Kodak, em sala com luminosidade apropriada.

Tabela 4. Anticorpos e diluições utilizados para Western-blotting.

\begin{tabular}{|c|c|c|}
\hline ANTICORPO & ESPECIFICIDADE & DILUIÇÃO (Anticorpo:TBS-T) \\
\hline $\begin{array}{c}\text { Anti- } \gamma \text {-Tubulina } \\
\text { (Sigma-Aldrich, EUA) }\end{array}$ & $\begin{array}{l}\text { Ac primário policlonal } \\
\text { de coelho }\end{array}$ & $1: 5.000$ \\
\hline $\begin{array}{c}\text { Anti-cABL } \\
\left(\text { (Cell Signaling Technology }{ }^{\circledR} \text { ) }\right.\end{array}$ & $\begin{array}{l}\text { Ac primário policlonal } \\
\text { de coelho }\end{array}$ & $1: 1.000$ \\
\hline $\begin{array}{c}\text { Anti-Fosfotirosina } \\
\left(\text { Cell Signaling Technology }{ }^{\circledR}\right)\end{array}$ & $\begin{array}{l}\text { Ac primário monoclonal } \\
\text { de camundongo }\end{array}$ & $1: 1.000$ \\
\hline $\begin{array}{c}\mathrm{ECL}^{\mathrm{TM}} \text { Anti-mouse IgG } \\
\text { (GE Healthcare, Reino Unido) }\end{array}$ & Ac secundário & $1: 10.000$ \\
\hline $\begin{array}{c}\mathrm{ECL}^{\mathrm{TM}} \text { Anti-rabbit IgG } \\
\text { (GE Healthcare, Reino Unido) }\end{array}$ & Ac secundário & Variável de 1:2.000 a 1:7.000 \\
\hline
\end{tabular}

Ac: anticorpo.

\section{III.2.7 Cálculo do Índice de Sokal}

Descrito por Sokal et al. (1984), esse índice representa o escore prognóstico para pacientes com LMC, classificando-os em três grupos de risco que predizem a sobrevida global: alto risco (quando valor for $>1,20$ ), risco intermediário (valor de 0,80 a 1,20 ) e baixo risco (quando valor for $<0,80$ ). Para o cálculo do índice de Sokal, consideram-se como parâmetros a idade do paciente em anos, tamanho do baço em $\mathrm{cm}$, a contagem total de plaquetas em $10^{9} / \mathrm{L}$ e a porcentagem de blastos no sangue periférico dos pacientes ao diagnóstico. A fórmula utilizada para obtenção do escore prognóstico é a seguinte: 
ESCORE DE SOKAL $=\exp [0,0116 \times($ idade $-43,4)]+0,0345 \times($ baço $-7,51)+$ $0,01880 \times\left[(\text { plaquetas } / 700)^{2}-0,563\right]+0,0887 \times(\%$ blastos $-2,10)$

Nesse estudo, os índices referentes a cada paciente foram calculados pela fórmula acima e online, pelo site da European LeukemiaNet (EUROPEAN LEUKEMIA-NET, 2010). Os prontuários médicos dos pacientes foram pesquisados para obtenção dos dados necessários para o cálculo do índice de Sokal.

\section{III.2.8 Análise Estatística}

Todas as análises estatísticas foram realizadas por meio do Software GraphPad Prism ${ }^{\circledR}$ versão 5.0.

As análises comparativas da expressão dos transcritos Dido 1, 2, 3, $P P$ e $P D$ entre controles e pacientes com LMC nas diferentes fases da doença, respondedores e não respondedores aos TKIs, foram realizadas pelo teste estatístico não paramétrico de Mann-Whitney.

A correlação entre os valores de expressão $D I D O 1,2,3, P P$, e $P D$ e os valores do índice de Sokal, bem como a correlação entre os valores de expressão de $B C R-A B L 1$ e de DIDO 1, 2, 3, $P P$, e $P D$ de cada paciente foi realizada pelo teste de Spearman.

Valores de $p<0,05$ foram considerados significantes. 
IV. Resultados 


\title{
IV.1 Expressão gênica de DIDO 1, DIDO 2, DIDO 3, DIDO PP e DIDO PD em pacientes e controles
}

\author{
IV.1.1 Expressão gênica de DIDO 1, DIDO 2, DIDO 3, DIDO PP e DIDO PD em \\ controles, pacientes na fase crônica e nas fases avançadas (fase acelerada e \\ crise blástica) da LMC
}

As figuras de 5 à 7 referem-se às análises de expressão gênica das isoformas de DIDO que apresentaram significância estatística. As medianas da URE dos genes DIDO 1, DIDO 2, DIDO 3, DIDO PP e DIDO PD dos grupos de pacientes na fase crônica sem tratamento, pacientes nas fases avançadas da LMC e controles estão relatadas nas tabelas 5 e 6 .

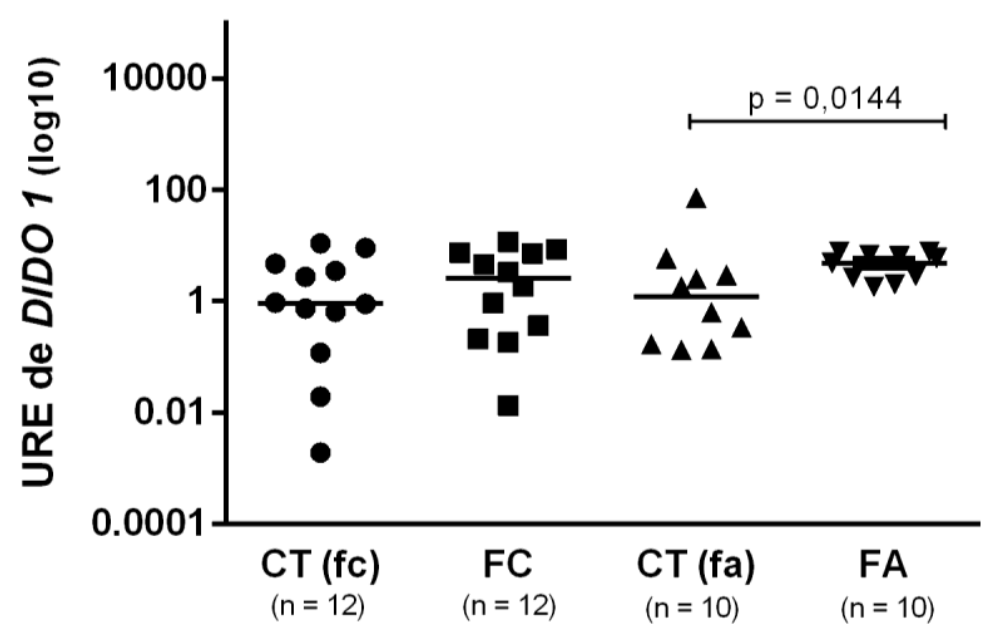

Figura 5. Expressão de DIDO 1 em controles, pacientes com LMC na fase crônica sem tratamento e pacientes com LMC nas fases avançadas da doença (fase acelerada e crise blástica). As linhas horizontais representam o valor da mediana da URE de cada grupo (CT (fc) = 0,964; $\mathrm{FC}=2,566 ; \mathrm{CT}(\mathrm{fa})=1,212 ; \mathrm{FA}=5,393)$. A expressão de DIDO 1 foi semelhante entre o grupo de pacientes na fase crônica sem tratamento e o grupo controle. Da mesma forma, a expressão de DIDO 1 foi semelhante entre o grupo de pacientes na fase crônica e pacientes nas fases avançadas da LMC. Por outro lado, a expressão gênica de DIDO 1 foi maior nos pacientes em fases avançadas da LMC do que nos controles ( $p=0,0144)$. CT ( $f c)$ : controles da fase crônica; FC: pacientes em fase crônica; CT (fa): controles das fases avançadas; FA: pacientes em fases avançadas. 


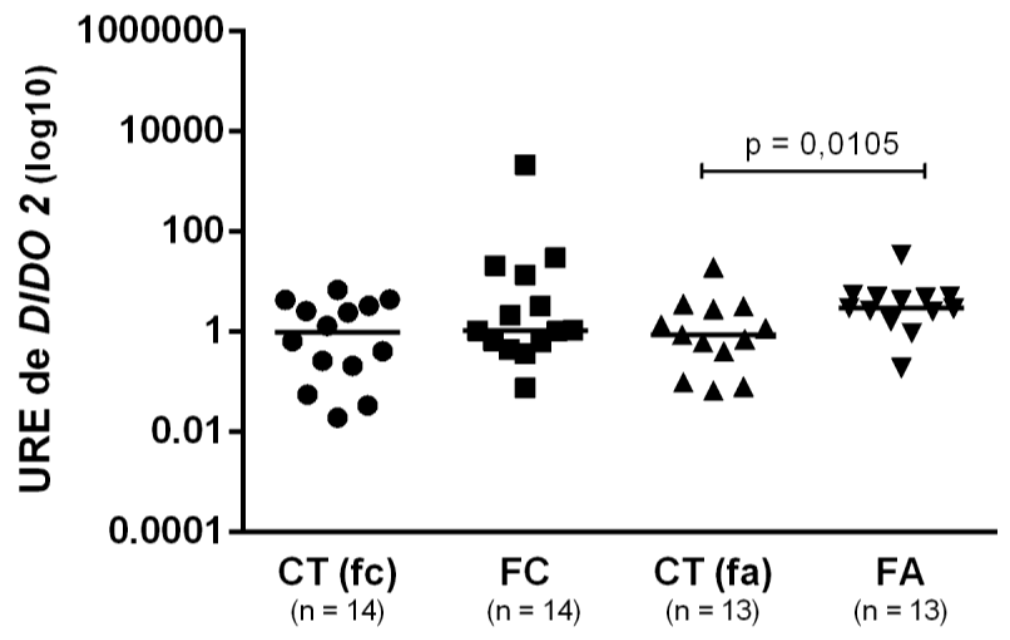

Figura 6. Expressão de DIDO 2 em controles, pacientes com LMC na fase crônica sem tratamento e pacientes com LMC nas fases avançadas da doença (fase acelerada e crise blástica). As linhas horizontais representam o valor da mediana da URE de cada grupo (CT (fc) = 0,$965 ; \mathrm{FC}=1,030 ; \mathrm{CT}(\mathrm{fa})=0,785 ; \mathrm{FA}=3,549$ ). A expressão de DIDO 2 foi semelhante entre o grupo de pacientes na fase crônica sem tratamento e o grupo controle. Da mesma forma, a expressão de DIDO 2 foi semelhante entre o grupo de pacientes na fase crônica e o grupo de pacientes nas fases avançadas da LMC. Por outro lado, a expressão gênica de DIDO 2 foi maior nos pacientes em fases avançadas da LMC do que nos controles $(p=0,0105)$. CT (fc): controles da fase crônica; FC: pacientes em fase crônica; CT (fa): controles das fases avançadas; FA: pacientes em fases avançadas.

Tabela 5. Medianas e valores de $\mathrm{p}$ da expressão gênica das isoformas de DIDO entre o grupo de pacientes na fase crônica da LMC sem tratamento e controles e entre o grupo de pacientes nas fases avançadas da LMC (fase acelerada e crise blástica) e controles.

\begin{tabular}{c|ccc|ccc}
\hline GENE & CT (md) & $\begin{array}{c}\text { FC S/T } \\
(\mathbf{m d})\end{array}$ & $\begin{array}{c}\mathbf{p} \\
\text { VALOR }\end{array}$ & $\mathbf{C T}(\mathbf{m d})$ & $\begin{array}{c}\text { FA } \\
(\mathbf{m d})\end{array}$ & $\begin{array}{c}\mathbf{p} \\
\text { VALOR }\end{array}$ \\
\hline DIDO 1 & 0,964 & 2,566 & 0,1851 & 1,212 & 5,393 & 0,0144 \\
DIDO 2 & 0,965 & 1,030 & 0,1401 & 0,7850 & 3,549 & 0,0105 \\
DIDO 3 & 8,705 & 2,338 & 0,0952 & 4,435 & 6,639 & 0,1499 \\
DIDO PP & 45,780 & 29,130 & 0,1032 & 43,760 & 38,860 & 0,1191 \\
DIDO PD & 6,095 & 3,331 & 0,1296 & 4,819 & 8,328 & 0,2525 \\
\hline
\end{tabular}

CT: controles; FC S/T: pacientes na fase crônica sem tratamento; FA: pacientes nas fases avançadas; md: mediana. 
Tabela 6. Medianas e valores de $\mathrm{p}$ da expressão gênica das isoformas de DIDO entre o grupo de pacientes na fase crônica da LMC sem tratamento e o grupo de pacientes nas fases avançadas da LMC (fase acelerada e crise blástica).

\begin{tabular}{c|c|c|c}
\hline GENE & $\begin{array}{c}\text { FC S/T } \\
(\mathbf{m d})\end{array}$ & $\begin{array}{c}\text { FA } \\
(\mathbf{m d})\end{array}$ & $\begin{array}{c}\mathbf{p} \\
\text { VALOR }\end{array}$ \\
\hline DIDO 1 & 2,566 & 5,393 & 0,1695 \\
DIDO 2 & 1,030 & 3,549 & 0,1484 \\
DIDO 3 & 2,338 & 6,639 & 0,0556 \\
DIDO PP & 29,130 & 38,860 & 0,2721 \\
DIDO PD & 3,331 & 8,328 & 0,0620 \\
\hline
\end{tabular}

FC S/T: pacientes na fase crônica sem tratamento; FA: pacientes nas fases avançadas; md: mediana.

Não houve diferença de expressão dos genes DIDO 1, DIDO 2, DIDO 3, $D I D O P P$ e DIDO PD entre o grupo de pacientes na fase crônica sem tratamento e controles.

$\mathrm{Na}$ análise entre pacientes nas fases avançadas da LMC (fase acelerada e crise blástica) e controles, não houve diferença de expressão dos genes DIDO 3 , DIDO PP e DIDO PD. A expressão dos genes DIDO 1 e DIDO 2 foi maior nos pacientes em fases avançadas do que nos controles (DIDO 1: $p=0,0144$; mediana da URE dos controles $=1,212$; mediana da URE dos pacientes $=5,393 ;$ DIDO 2: $p=$ 0,0105 ; mediana da URE dos controles $=0,785$; mediana da URE dos pacientes $=$ 3,549).

Não houve diferença de expressão dos genes DIDO 1, DIDO 2, DIDO 3, DIDO PP e DIDO PD entre o grupo de pacientes na fase crônica da LMC sem tratamento e o grupo de pacientes nas fases avançadas (fase acelerada e crise blástica) da doença.

\section{IV.1.2 Expressão gênica de DIDO 1, DIDO 2, DIDO 3, DIDO PP e DIDO PD em controles e em pacientes com LMC na fase crônica tratados com mesilato de imatinibe ou dasatinibe}

As análises significativas das expressões gênicas entre pacientes na fase crônica da LMC tratados com mesilato de imatinibe e controles estão representadas pelas figuras 7 e 8 . 


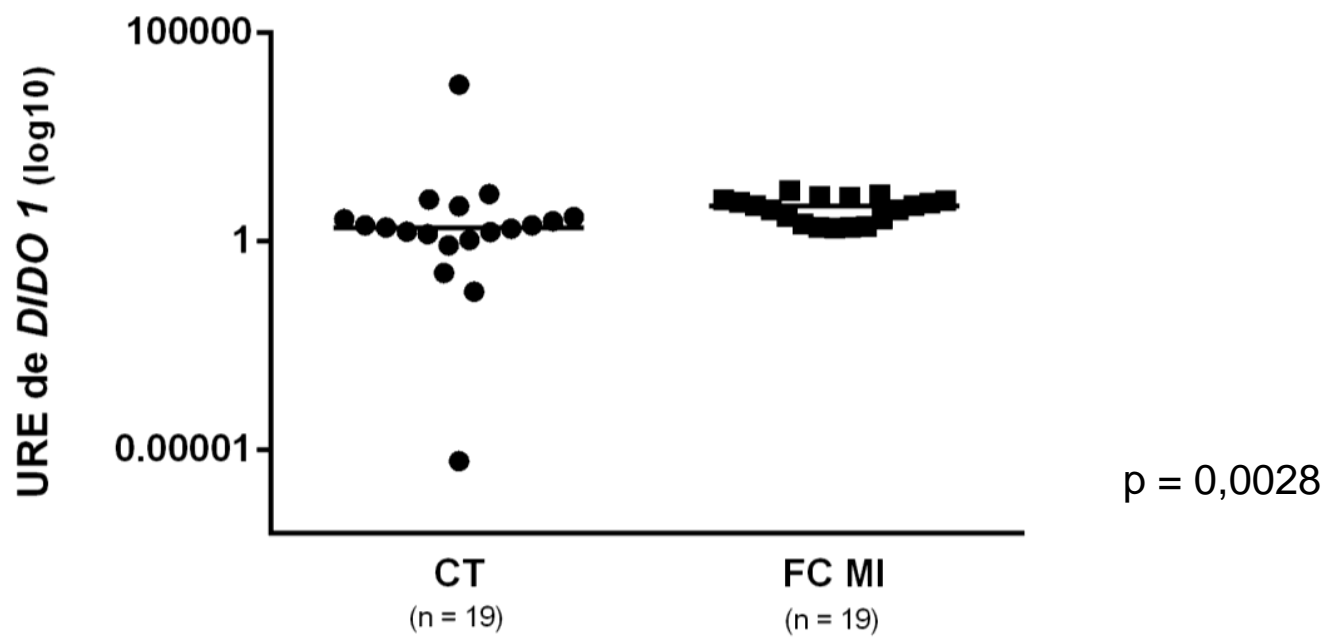

Figura 7. Expressão de DIDO 1 em pacientes com LMC na fase crônica tratados com mesilato de imatinibe e controles. As linhas horizontais representam o valor da mediana da URE de cada grupo $(\mathrm{CT}=2,092 ; \mathrm{FC} \mathrm{Ml}=6,921) ; \mathrm{p}=0,0028 ; \mathrm{CT}$ : controles; $\mathrm{FC} \mathrm{Ml}$ : pacientes na fase crônica tratados com mesilato de imatinibe.

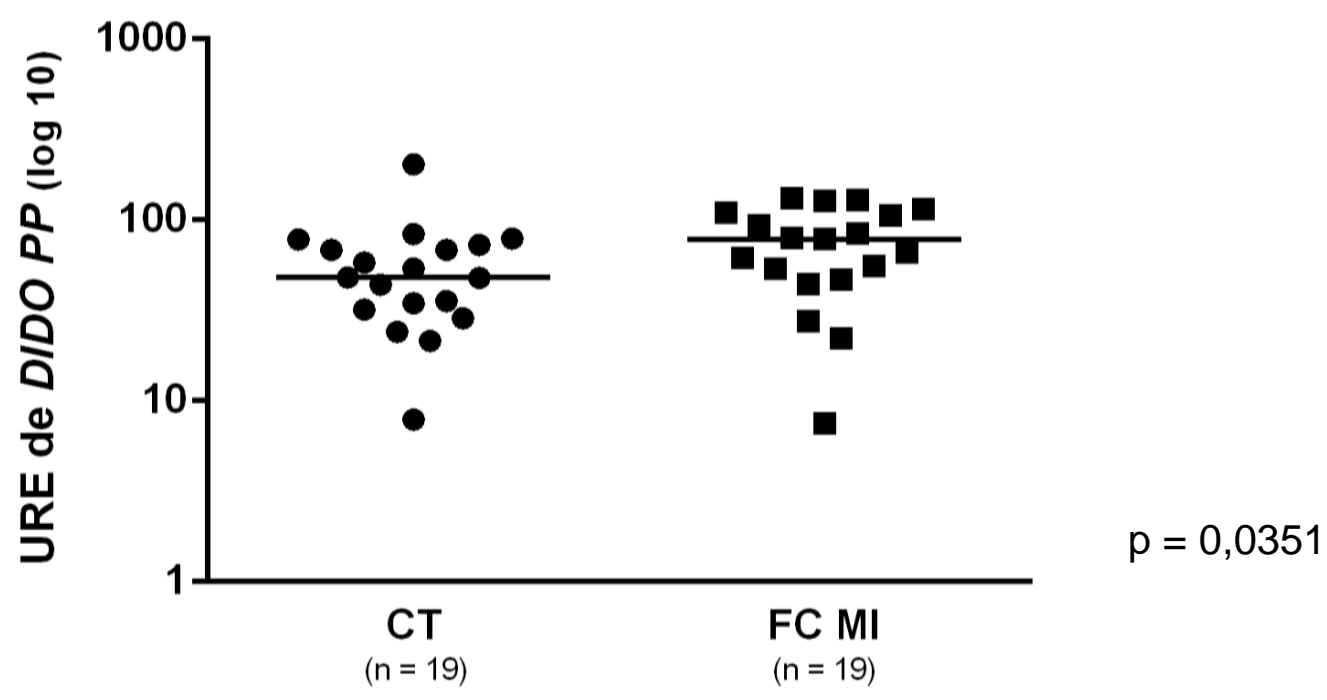

Figura 8. Expressão de DIDO PP em pacientes com LMC na fase crônica tratados com mesilato de imatinibe e controles. As linhas horizontais representam o valor da mediana da URE de cada grupo (CT $=47,740 ; \mathrm{FC} \mathrm{MI}=77,980) ; p=0,0351$; $\mathrm{CT}$ : controles; $\mathrm{FC}(\mathrm{MI})$ : pacientes na fase crônica tratados com mesilato de imatinibe.

Não houve diferença de expressão dos genes DIDO 2, DIDO 3 e DIDO PD entre pacientes na fase crônica da LMC tratados com mesilato de imatinibe e controles. A expressão do gene DIDO 1 foi maior nos pacientes em fase crônica tratados com MI do que nos controles $(p=0,0028$; mediana da URE dos controles $=$ 2,092; mediana da URE dos pacientes $=6,921$ ); a expressão de DIDO $P P$ também foi maior nos pacientes em fase crônica tratados com Ml do que nos controles $(p=$ 
0,0351; mediana da URE dos controles $=47,740$; mediana da URE dos pacientes $=$ $77,980)$.

Com relação aos pacientes na fase crônica da $L M C$ tratados com dasatinibe, as expressões dos genes DIDO 1, DIDO 2, DIDO PP e DIDO PD foram maiores no grupo de pacientes do que no grupo controle, conforme relatado na tabela 7 .

Tabela 7. Medianas e valores de $p$ da expressão das diferentes isoformas de DIDO que foram diferentes entre o grupo de pacientes na fase crônica da LMC tratados com dasatinibe e o grupo controle.

\begin{tabular}{cccc}
\hline GENE & CT $(\mathbf{m d})$ & DAS $(\mathbf{m d})$ & p VALOR \\
\hline$D I D O 1$ & 0,260 & 5,271 & 0,0143 \\
$D I D O 2$ & 0,576 & 4,743 & 0,0286 \\
$D I D O P P$ & 38,780 & 82,070 & 0,0159 \\
$D I D O P D$ & 4,101 & 73,850 & 0,0278 \\
\hline
\end{tabular}

CT: controles; DAS: dasatinibe; md: mediana; $\mathrm{n} \mathrm{CT}=5 ; \mathrm{n} \mathrm{DAS}=5$.

Não houve diferença de expressão do gene DIDO 3 entre o grupo de pacientes na fase crônica da $L M C$ tratados com dasatinibe e o grupo controle. As expressões dos genes DIDO 1 e DIDO 2 foram maiores nos pacientes em fase crônica tratados com dasatinibe do que nos controles (DIDO 1: $p=0,0143$; mediana da URE dos controles $=0,2604$; mediana da URE dos pacientes $=5,271 ;$ DIDO 2: $p$ $=0,0286$; mediana da URE dos controles $=0,576$; mediana da URE dos pacientes $=$ 4,743); as expressões de DIDO PP e DIDO $P D$ também foram maiores nos pacientes em fase crônica tratados com dasatinibe do que nos controles (DIDO PP: $p=0,0159$; mediana da URE dos controles $=38,780$; mediana da URE dos pacientes = 82,070; DIDO PD: $p=0,0278$; mediana da URE dos controles $=4,101$; mediana da URE dos pacientes $=73,850$ ).

A tabela 8 relata as medianas da URE dos genes DIDO 1, DIDO 2, DIDO 3, DIDO PP e DIDO PD dos grupos de pacientes na fase crônica da LMC tratados com mesilato de imatinibe, pacientes na fase crônica da LMC tratados com dasatinibe e no grupo controle. 
Tabela 8. Medianas e valores de $\mathrm{p}$ da expressão das isoformas de DIDO entre o grupo de pacientes na fase crônica da LMC tratados com mesilato de imatinibe e controles e entre pacientes na fase crônica tratados com dasatinibe e controles.

\begin{tabular}{|c|c|c|c|c|c|c|}
\hline GENE & CT (md) & $\begin{array}{c}\text { MI } \\
\text { (md) }\end{array}$ & $\begin{array}{c}\mathbf{P} \\
\text { VALOR }\end{array}$ & $\mathrm{CT}(\mathrm{md})$ & $\begin{array}{l}\text { DAS } \\
\text { (md) }\end{array}$ & $\begin{array}{c}\mathbf{p} \\
\text { VALOR }\end{array}$ \\
\hline DIDO 1 & 2,092 & 6,921 & 0,0028 & 0,260 & 5,271 & 0,0143 \\
\hline DIDO 2 & 2,187 & 1,270 & 0,0683 & 0,576 & 4,743 & 0,0286 \\
\hline DIDO 3 & 7,816 & 7,124 & 0,3098 & 2,925 & 8,317 & 0,1111 \\
\hline$D I D O P P$ & 47,740 & 77,980 & 0,0351 & 38,780 & 82,070 & 0,0159 \\
\hline DIDO PD & 7,084 & 9,454 & 0,0587 & 4,101 & 73,850 & 0,0278 \\
\hline
\end{tabular}

CT: controle; MI: mesilato de imatinibe; DAS: dasatinibe; md: mediana.

\section{IV.1.3 Expressão dos genes DIDO 1, DIDO 2, DIDO 3, DIDO PP e DIDO PD em pacientes com LMC na fase crônica sem tratamento e pacientes na fase crônica tratados com mesilato de imatinibe}

As figuras de 9 a 12 referem-se às análises de expressão gênica das isoformas de DIDO que apresentaram significância estatística. As medianas da URE dos genes DIDO 1, DIDO 2, DIDO 3, DIDO PP e DIDO PD de pacientes na fase crônica da LMC sem tratamento e de pacientes na fase crônica da LMC tratados com mesilato de imatinibe estão relatadas na tabela 9 .

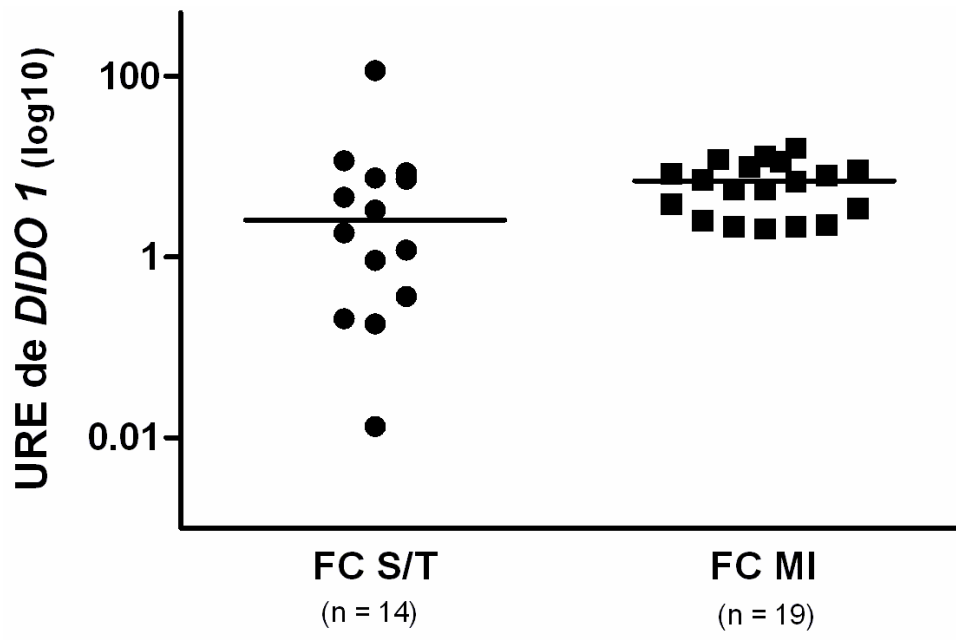$$
p=0,0303
$$

$(n=14)$ $(\mathrm{n}=19)$

Figura 9. Expressão de DIDO 1 em pacientes com LMC na fase crônica sem tratamento e pacientes com LMC na fase crônica tratados com mesilato de imatinibe. As linhas horizontais representam o valor da mediana da URE de cada grupo ( $F C S / T=2,566 ; F C ~ M I=6,921) ; p=0,0303$; FC S/T: pacientes na fase crônica sem tratamento; FC MI: pacientes na fase crônica tratados com mesilato de imatinibe. 


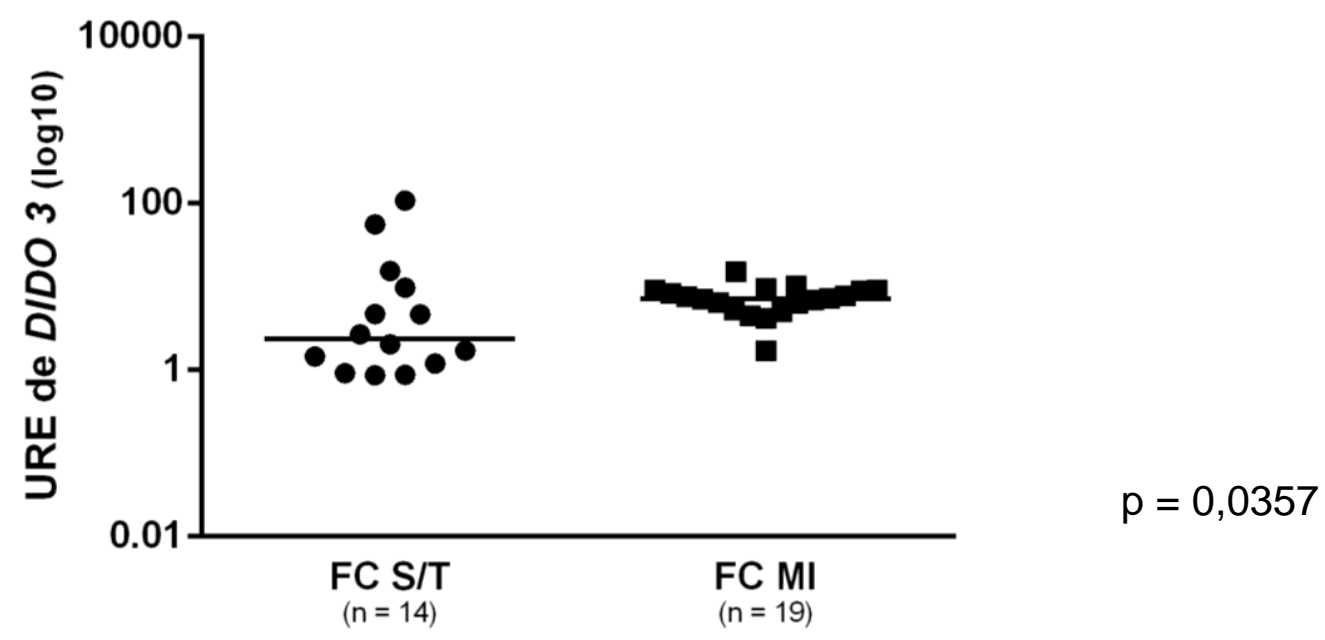

Figura 10. Expressão de DIDO $3 \mathrm{em}$ pacientes com LMC na fase crônica sem tratamento e pacientes com LMC na fase crônica tratados com mesilato de imatinibe. As linhas horizontais representam o valor da mediana da URE de cada grupo ( $F C S / T=2,338 ; \mathrm{FC} \mathrm{MI}=7,124) ; p=0,0357$; FC S/T: pacientes na fase crônica sem tratamento; FC MI: pacientes na fase crônica tratados com mesilato de imatinibe.

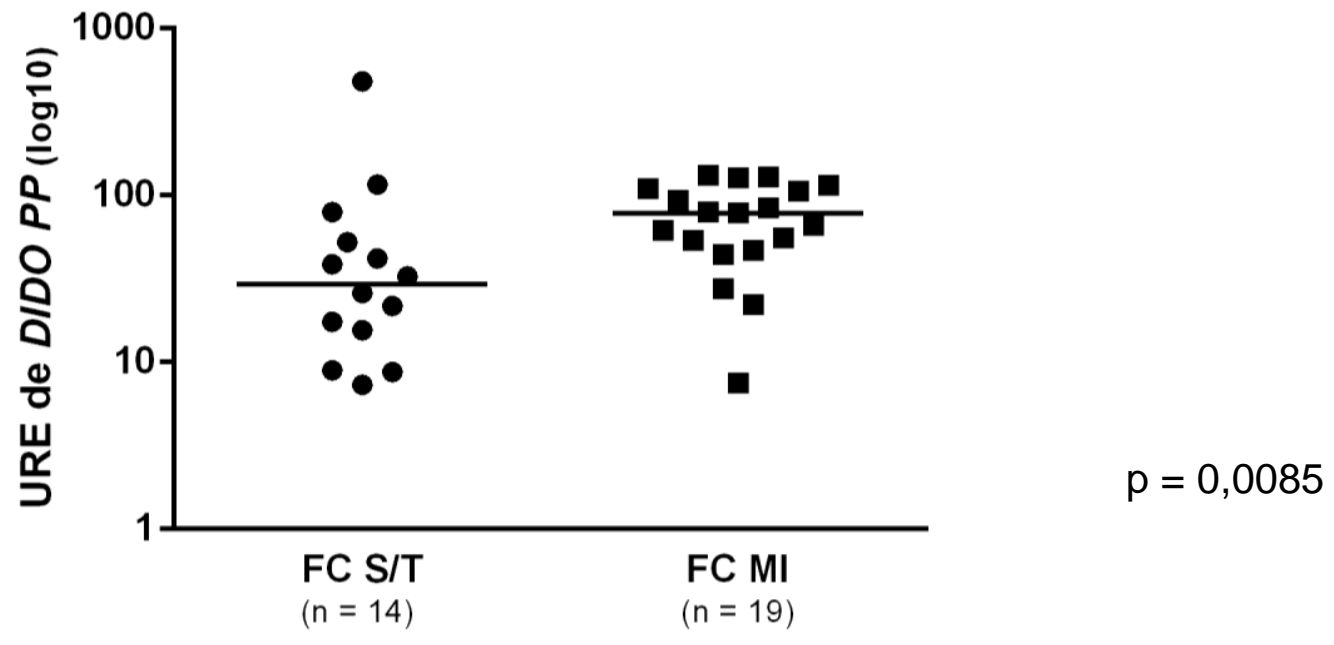

Figura 11. Expressão de DIDO PP em pacientes com LMC na fase crônica sem tratamento e pacientes com LMC na fase crônica tratados com mesilato de imatinibe. As linhas horizontais representam o valor da mediana da URE de cada grupo ( $F C S / T=29,13 ; \mathrm{FC} \mathrm{MI}=77,98$ ); $p=0,0085$; FC S/T: pacientes na fase crônica sem tratamento; FC MI: pacientes na fase crônica tratados com mesilato de imatinibe. 


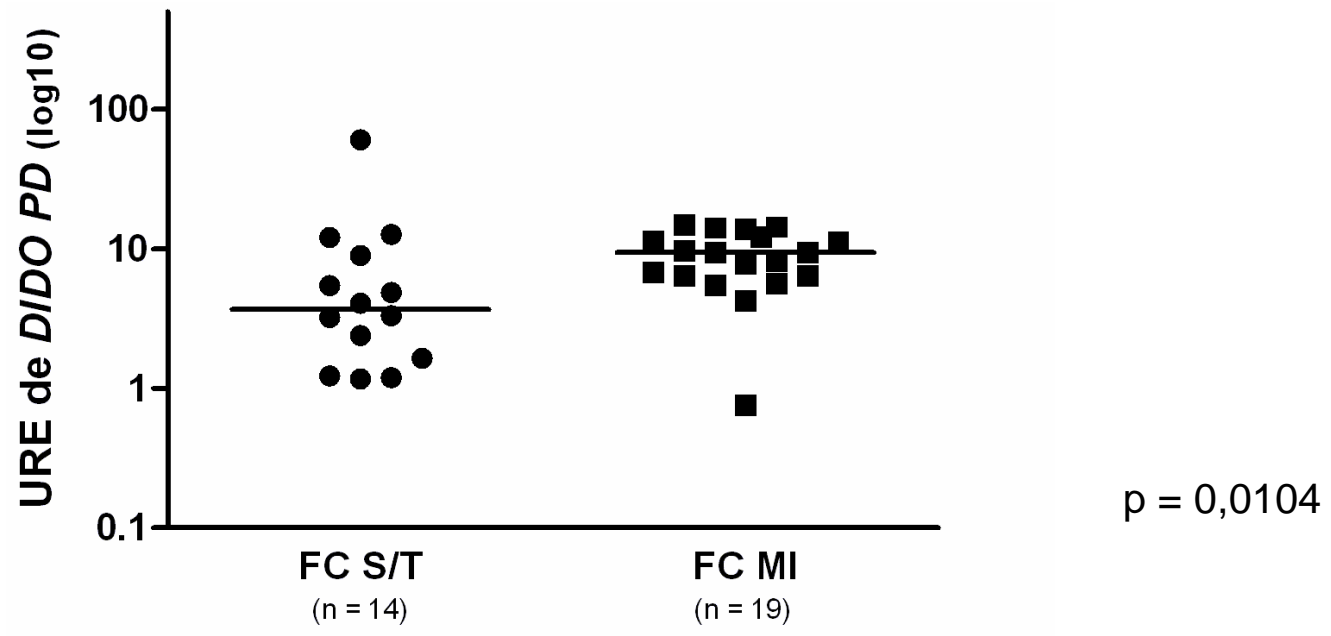

Figura 12. Expressão de DIDO PD em pacientes com LMC na fase crônica sem tratamento e pacientes com LMC na fase crônica tratados com mesilato de imatinibe. As linhas horizontais representam o valor da mediana da URE de cada grupo ( $F C S / T=3,700 ; F C ~ M I=9,414) ; p=0,0104$; FC S/T: pacientes na fase crônica sem tratamento; FC MI: pacientes na fase crônica tratados com MI.

Tabela 9. Medianas e valores de $\mathrm{p}$ da expressão das isoformas de DIDO entre o grupo de pacientes na fase crônica da LMC sem tratamento e o grupo de pacientes na fase crônica da LMC tratados com mesilato de imatinibe.

\begin{tabular}{c|c|c|c}
\hline GENE & $\begin{array}{c}\text { FC S/T } \\
(\mathbf{m d})\end{array}$ & $\begin{array}{c}\text { FC MI } \\
(\mathbf{m d})\end{array}$ & $\begin{array}{c}\text { p } \\
\text { VALOR }\end{array}$ \\
\hline DIDO 1 & 2,566 & 6,921 & 0,0303 \\
DIDO 2 & 0,824 & 1,270 & 0,0955 \\
DIDO 3 & 2,338 & 7,124 & 0,0357 \\
DIDO PP & 29,130 & 77,980 & 0,0085 \\
DIDO PD & 3,700 & 9,414 & 0,0025 \\
\hline
\end{tabular}

FC S/T: pacientes na fase crônica sem tratamento; FC MI: pacientes na fase crônica tratados com mesilato de imatinibe; md: mediana.

Não houve diferença de expressão do gene DIDO 2 entre o grupo de pacientes na fase crônica da LMC sem tratamento e o grupo de pacientes na fase crônica da LMC tratados com mesilato de imatinibe. As expressões de DIDO $1 \mathrm{e}$ DIDO 3 foram maiores nos pacientes com LMC na fase crônica tratados com mesilato de imatinibe do que nos pacientes com LMC na fase crônica sem tratamento (DIDO 1: $\mathrm{p}=0,0303$; mediana da URE dos pacientes sem tratamento $=$ 2,566; mediana da URE dos pacientes tratados com MI = 6,921; DIDO 3: $p=0,0357$; mediana da URE dos pacientes sem tratamento $=2,338$; mediana da URE dos pacientes tratados com $\mathrm{MI}=7,124)$. As expressões de DIDO PP e DIDO PD também 
foram maiores nos pacientes na fase crônica tratados com mesilato de imatinibe do que nos pacientes na fase crônica sem tratamento (DIDO PP: $p=0,0085$; mediana da URE dos pacientes sem tratamento $=29,13$; mediana da URE dos pacientes tratados com $\mathrm{MI}=77,98 ;$ DIDO PD: $\mathrm{p}=0,0104$; mediana da URE dos pacientes sem tratamento $=3,700$; mediana da URE dos pacientes tratados com $\mathrm{MI}=9,414$ ).

\section{IV.1.4 Expressão dos genes DIDO 1, DIDO 2, DIDO 3, DIDO PP e DIDO PD em pacientes com LMC antes do tratamento e tratados com mesilato de imatinibe}

A expressão de DIDO PD foi maior no grupo de pacientes após 12 meses de tratamento com mesilato de imatinibe do que no grupo de pacientes antes do tratamento e está relatada na figura 13. As medianas da URE dos genes DIDO 1, DIDO 2, DIDO 3, DIDO PP e DIDO PD dos grupos de pacientes após 12 meses de tratamento com Ml e pacientes antes do tratamento estão relatadas na tabela 10.

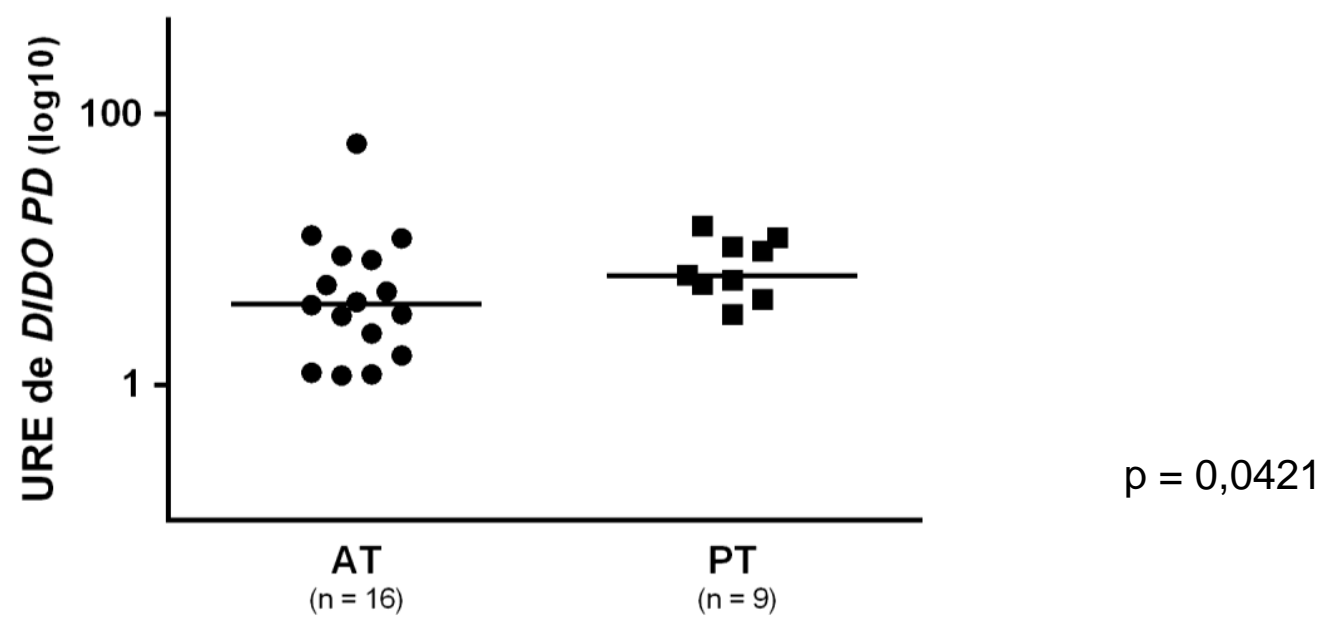

Figura 13. Expressão de DIDO PD em pacientes com LMC antes do tratamento e após 12 meses de tratamento com MI. As linhas horizontais representam o valor da mediana de cada grupo $(\mathrm{AT}=3,973 ; \mathrm{PT}=6,412) ; \mathrm{p}=0,0421 ; \mathrm{AT}$ : antes do tratamento; PT: após 12 meses de tratamento com MI. 
Tabela 10. Medianas e valores de $\mathrm{p}$ da expressão das isoformas de DIDO entre o grupo de pacientes antes do tratamento e o grupo de pacientes 12 meses após 0 tratamento com mesilato de imatinibe.

\begin{tabular}{c|c|c|c}
\hline GENE & AT $(\mathbf{m d})$ & PT $(\mathbf{m d})$ & $\begin{array}{c}\mathbf{p} \\
\text { VALOR }\end{array}$ \\
\hline DIDO 1 & 1,820 & 2,399 & 0,1014 \\
DIDO 2 & 1,030 & 1,902 & 0,2396 \\
DIDO 3 & 2,878 & 6,227 & 0,1901 \\
DIDO PP & 30,830 & 43,700 & 0,0598 \\
DIDO PD & 3,973 & 6,412 & 0,0421 \\
\hline
\end{tabular}

AT: antes do tratamento com Ml; PT: após 12 meses de tratamento com Ml; md: mediana.

Não houve diferença de expressão dos genes DIDO 1, DIDO 2, DIDO 3 e DIDO PP entre o grupo de pacientes antes do tratamento com mesilato de imatinibe e o grupo de pacientes após 12 meses de tratamento com esse inibidor de tirosinaquinase. A expressão de DIDO PD foi maior no grupo de pacientes após 12 meses de tratamento com $\mathrm{Ml}$ do que no grupo de pacientes antes do tratamento $(p=$ 0,0421; mediana da URE nos pacientes antes do tratamento $=3,973$; mediana da URE nos pacientes após 12 meses de tratamento $=6,412$ ).

\section{IV.1.5 Expressão dos genes DIDO 1, DIDO 2, DIDO 3, DIDO PP e DIDO PD em pacientes com LMC tratados com mesilato de imatinibe que atingiram a resposta citogenética completa $(\mathrm{RCC})$ e em pacientes resistentes à terapia}

As medianas da URE de DIDO 1, DIDO 2, DIDO 3, DIDO PP e DIDO PD dos grupos de pacientes tratados com mesilato de imatinibe que atingiram a RCC e pacientes resistentes à terapia com esse inibidor estão relatadas na tabela 11. 
Tabela 11. Medianas e valores de $\mathrm{p}$ da expressão de DIDO entre os grupos de pacientes que atingiram a RCC ou foram resistentes à terapia com Ml.

\begin{tabular}{c|c|c|c}
\hline GENE & RCC MI (md) & RES MI (md) & $\begin{array}{c}\text { P } \\
\text { VALOR }\end{array}$ \\
\hline DIDO 1 & 6,268 & 5,945 & 0,1431 \\
DIDO 2 & 1,319 & 2,481 & 0,0622 \\
DIDO 3 & 7,338 & 5,954 & 0,0532 \\
DIDO PP & 71,980 & 54,750 & 0,1634 \\
DIDO PD & 8,792 & 7,095 & 0,0667 \\
\hline
\end{tabular}

RCC Ml: pacientes tratados com mesilato de imatinibe que atingiram remissão citogenética completa; RES MI: pacientes resistentes ao tratamento com mesilato de imatinibe.

Não houve diferença de expressão de DIDO 1, DIDO 2, DIDO 3, DIDO PP e $D I D O P D$ entre o grupo de pacientes tratados com mesilato de imatinibe que atingiram a RCC e o grupo de pacientes resistentes à terapia com esse inibidor de tirosina-quinase.

\section{IV.1.6 Expressão dos transcritos do gene $B C R-A B L 1$ com junções b2a2 e b3a2}

A tabela 12 relaciona os transcritos b2a2 e b3a2 com as fases da doença e a resposta ao tratamento com inibidores de TK dos pacientes com LMC estudados.

Tabela 12. Relação entre a expressão gênica de $B C R-A B L 1$ com junções b2a2 e b3a2, fases da doença e respostas ao tratamento com os TKIs dos pacientes.

\begin{tabular}{|c|c|c|c|c|c|}
\hline & b2a2/b3a3 & b2a2 & b3a2 & SEM \\
\hline \multirow{3}{*}{$\begin{array}{l}\text { FASE DA } \\
\text { DOENÇA }\end{array}$} & Fase crônica & 17 & 8 & 2 & 14 \\
\hline & Fase acelerada & 3 & 2 & 0 & 5 \\
\hline & Crise blástica & 7 & 1 & 0 & 1 \\
\hline \multirow{3}{*}{$\begin{array}{l}\text { RESPOSTA AO } \\
\text { TRATAMENTO }\end{array}$} & $\begin{array}{c}\text { Resistentes ao } \\
\text { MI }\end{array}$ & 11 & 4 & 0 & 7 \\
\hline & RCC MI & 3 & 3 & 1 & 11 \\
\hline & RCC DAS & 1 & 1 & 0 & 1 \\
\hline
\end{tabular}

b2a2/b3a3: pacientes que apresentaram amplificação de $B C R-A B L 1$ tanto para a junção b2a2 quanto para a junção b3a2. 
Dos 60 pacientes estudados, 27 pacientes apresentaram amplificação de $B C R-A B L 1$ tanto para a junção b2a2 quanto para a junção b3a2. Onze pacientes apresentaram amplificação somente para a junção b2a2. Somente 2 pacientes, dentre os 60 estudados, apresentaram amplificação somente para a junção b3a2. Vinte pacientes não apresentaram amplificação para nenhuma das junções pesquisadas e dentre eles, 12 estavam em RCC.

Com relação à fase da doença em que se encontram, dentre os 41 pacientes na fase crônica da LMC, 17 apresentaram amplificação tanto para a junção b2a2 quanto para b3a2, 8 apresentaram amplificação somente para b2a2, 2 apresentaram amplificação somente para b3a2 e 14 pacientes não apresentaram amplificação de $B C R-A B L 1$ para nenhuma das junções pesquisadas. No grupo dos 10 pacientes na fase acelerada da LMC, 3 apresentaram amplificação tanto para b2a2 quanto para b3a2, 2 apresentaram amplificação somente para b2a2 e cinco pacientes não apresentaram amplificação para nenhuma dessas duas junções; nenhum paciente apresentou amplificação somente para b3a2. Dentre os 9 pacientes na crise blástica da LMC, 7 apresentaram amplificação tanto para b2a2 quanto para b3a2, 1 paciente apresentou amplificação somente para a junção b2a2 e 1 paciente não apresentou amplificação para nenhuma das regiões pesquisadas; nenhum paciente apresentou amplificação somente para a junção b3a2.

Com relação ao critério de resposta ao tratamento, dentre os 22 pacientes que foram resistentes à terapia com mesilato de imatinibe, 11 amplificaram tanto para a junção b2a2 quanto para b3a2, 4 amplificaram somente para a junção b2a2 e 7 pacientes não apresentaram amplificação para nenhum dos transcritos pesquisados; nenhum paciente apresentou amplificação somente para a região b3a2. No grupo dos 18 pacientes que atingiram a RCC à terapia com mesilato de imatinibe, 3 apresentaram amplificação tanto para b2a2 quanto para b3a2, 3 amplificaram somente para b2a2, um apresentou amplificação somente para b3a2 e 11 pacientes não apresentaram amplificação para nenhuma das junções pesquisadas. Quanto aos 3 pacientes que atingiram RCC à terapia com dasatinibe, um apresentou amplificação tanto para b2a2 quanto para b3a2, um apresentou amplificação somente para b2a2 e um não amplificou para nenhum dos transcritos pesquisados. 


\section{IV.1.7 Correlações entre a expressão gênica de BCR-ABL1 e dos genes DIDO 1, DIDO 2, DIDO 3, DIDO PP e DIDO PD dos pacientes com LMC}

Houve uma correlação positiva entre a expressão gênica de $B C R-A B L 1$, junção b2a2, e de DIDO 2 nos pacientes com LMC sem tratamento (figura 14), com um valor de $r_{s}=0,5824(p=0,0184)$.

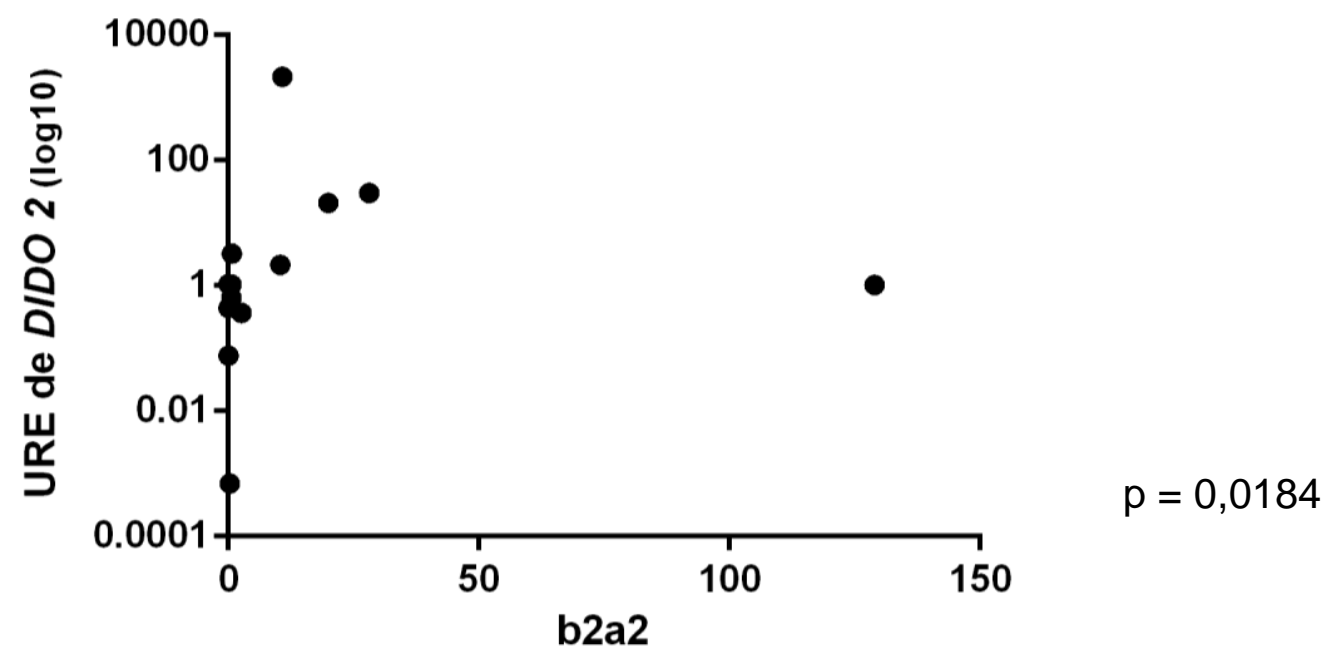

Figura 14. Correlação entre a expressão de $B C R-A B L 1$ com a junção b2a2 e a expressão de DIDO 2 dos pacientes na fase crônica da LMC sem tratamento. $r_{s}=0,5824 ; p=0,0184 ; n=13$.

A tabela 13 refere-se às correlações entre a expressão gênica de $B C R-A B L 1$ e a expressão de DIDO 1, DIDO 2, DIDO 3, DIDO PP e DIDO PD dos pacientes na fase crônica da LMC sem tratamento.

Tabela 13. Correlações entre as expressões de $B C R-A B L 1$ (junções b2a2 e b3a2) e a expressão de DIDO nos pacientes na fase crônica da LMC sem tratamento.

\begin{tabular}{c|cc|cc}
\hline GENE & $\begin{array}{c}\mathbf{r}_{\mathbf{s}} \\
\text { (b2a2 versus FC S/T) }\end{array}$ & p VALOR & $\begin{array}{c}\mathbf{r}_{\mathbf{s}} \\
\text { (b3a2 versus } \mathrm{FC} / \mathbf{T})\end{array}$ & $\mathbf{p ~ V A L O R}$ \\
\hline DIDO 1 & 0,3495 & 0,1103 & 0,2378 & 0,2284 \\
DIDO 2 & 0,5824 & 0,0184 & 0,3818 & 0,1233 \\
DIDO 3 & 0,3890 & 0,0846 & 0,4266 & 0,0833 \\
DIDO PP & 0,1516 & 0,3024 & 0,3217 & 0,1540 \\
DIDO PD & 0,1474 & 0,3075 & 0,2378 & 0,2284 \\
\hline
\end{tabular}

$r_{s}$ : valor da correlação entre as expressões de b2a2 ou b3a2 e as expressões das diferentes isoformas de DIDO dos pacientes na fase crônica da LMC sem tratamento; FC S/T: pacientes na fase crônica sem tratamento. 
As correlações entre a expressão gênica de $B C R-A B L 1$, junção b2a2, e a expressão de DIDO 1, DIDO 3, DIDO PP e DIDO PD dos pacientes na fase crônica da LMC sem tratamento não foram significativas. Da mesma forma, as correlações entre a expressão gênica de $B C R-A B L 1$, junção b3a2, e a expressão de DIDO 1 , DIDO 2, DIDO 3, DIDO PP e DIDO PD dos pacientes na fase crônica da LMC sem tratamento não foram significativas.

A tabela 14 refere-se às correlações entre a expressão gênica de $B C R-A B L 1$ e a expressão de DIDO 1, DIDO 2, DIDO 3, DIDO PP e DIDO PD dos pacientes na fase crônica da LMC tratados com mesilato de imatinibe.

Tabela 14. Correlações entre as expressões de $B C R-A B L 1$ (junções b2a2 e b3a2) e de DIDO dos pacientes na fase crônica da LMC tratados com mesilato de imatinibe.

\begin{tabular}{c|cc|cc}
\hline GENE & $\begin{array}{c}\mathbf{r}_{\mathbf{s}} \\
\text { (b2a2 versus FC MI) }\end{array}$ & p VALOR & $\begin{array}{c}\mathbf{r}_{\mathbf{s}} \\
\text { (b3a2 versus FC MI) }\end{array}$ & p VALOR \\
\hline DIDO 1 & $-0,5238$ & 0,0983 & $-0,8000$ & 0,1667 \\
DIDO 2 & $-0,1429$ & 0,3760 & 0,8000 & 0,1667 \\
DIDO 3 & $-0,1667$ & 0,3517 & 0,4000 & 0,3750 \\
DIDO PP & $-0,5000$ & 0,1081 & $-0,4000$ & 0,3750 \\
DIDO PD & $-0,0714$ & 0,4410 & 0,2000 & 0,4583 \\
\hline
\end{tabular}

$r_{s}$ : valor da correlação entre as expressões de b2a2 ou b3a2 e as expressões das diferentes isoformas de DIDO dos pacientes na fase crônica da LMC tratados com mesilato de imatinibe; FC MI: pacientes na fase crônica tratados com mesilato de imatinibe.

As correlações entre a expressão gênica de $B C R-A B L 1$ (tanto junção b2a2, quanto junção b3a2) e dos genes DIDO 1, DIDO 2, DIDO 3, DIDO PP e DIDO PD dos pacientes na fase crônica da LMC tratados com mesilato de imatinibe não foram significativas.

A tabela 15 refere-se às correlações entre a expressão gênica de $B C R-A B L 1$ e de DIDO 1, DIDO 2, DIDO 3, DIDO PP e DIDO PD dos pacientes nas fases avançadas (fase acelerada e crise blástica) da LMC. 
Tabela 15. Correlações entre as expressões de $B C R-A B L 1$ (junções b2a2 e b3a2) e de DIDO dos pacientes nas fases avançadas da LMC.

\begin{tabular}{c|cc|cc}
\hline GENE & $\begin{array}{c}\mathbf{r}_{\mathbf{s}} \\
\text { (b2a2 versus FA) }\end{array}$ & p VALOR & $\begin{array}{c}\mathbf{r}_{\mathbf{s}} \\
\text { (b3a2 versus FA) }\end{array}$ & p VALOR \\
\hline DIDO 1 & $-0,1273$ & 0,3665 & 0,1786 & 0,3508 \\
$D I D O 2$ & 0,5500 & 0,0664 & 0,3571 & 0,2158 \\
$D I D O 3$ & 0,1000 & 0,3849 & $-0,0476$ & 0,4554 \\
DIDO PP & $-0,2098$ & 0,2564 & $-0,4333$ & 0,1220 \\
DIDO PD & 0,1364 & 0,3447 & $-0,3333$ & 0,2099 \\
\hline
\end{tabular}

$r_{s}$ : valor da correlação entre as expressões de b2a2 ou b3a2 e as expressões das diferentes isoformas de DIDO dos pacientes nas fases avançadas da LMC (fase acelerada ou crise blástica); FA: fases avançadas.

As correlações entre a expressão gênica de $B C R-A B L 1$ (tanto junção b2a2, quanto junção b3a2) e dos genes DIDO 1, DIDO 2, DIDO 3, DIDO PP e DIDO PD dos pacientes nas fases avançadas da LMC (fase acelerada e crise blástica) não foram significativas.

IV.1.8 Correlações entre os índices de Sokal e a expressão dos genes DIDO 1, DIDO 2, DIDO 3, DIDO PP e DIDO PD dos pacientes com LMC

A figura 15 corresponde à correlação entre o índice de Sokal e a expressão de DIDO 2 dos pacientes com LMC. As correlações entre os índices de Sokal e a expressão das diferentes isoformas do gene DIDO estão relatadas na tabela 16.

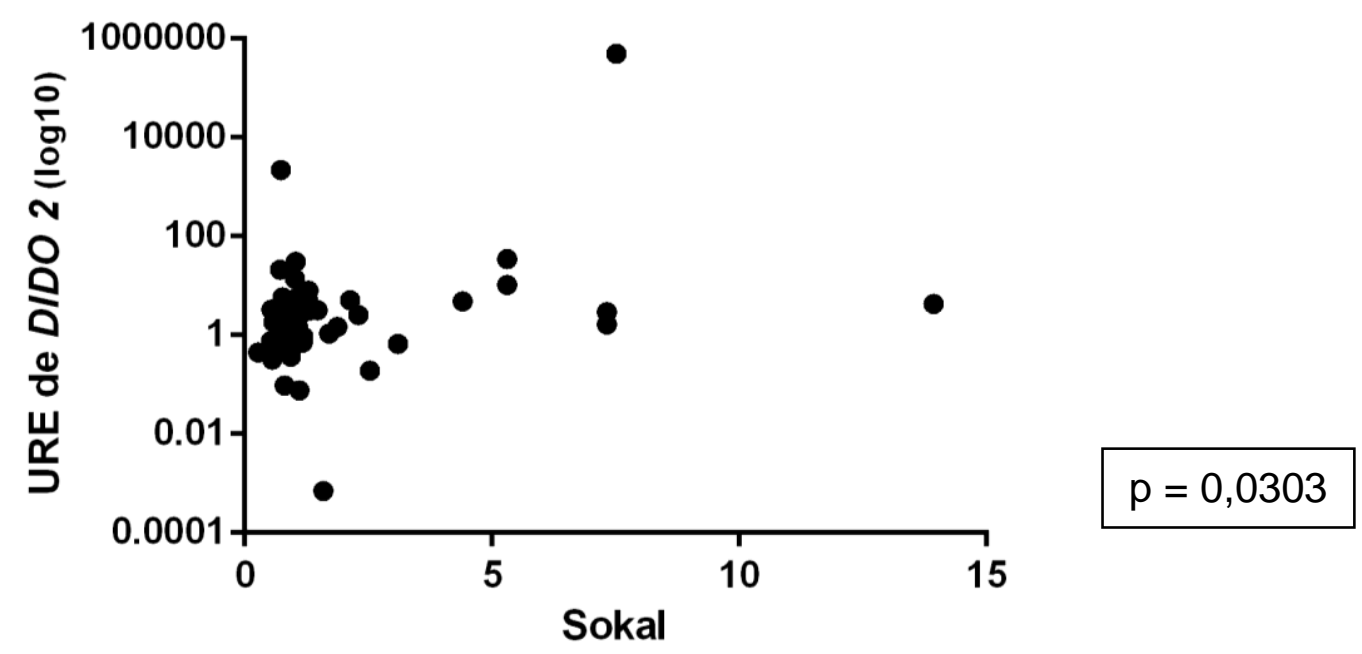

Figura 15. Correlação entre o índice de Sokal e a expressão de DIDO 2 dos pacientes com LMC. $r_{s}=0,2595 ; p=0,0303 ; n=55$. 
Tabela 16. Correlação entre o índice de Sokal e as expressões da diferentes isoformas de DIDO dos pacientes com LMC.

\begin{tabular}{ccc}
\hline GENE & $\mathbf{r}_{\mathbf{s}}$ & $\mathbf{p ~ V A L O R}$ \\
\hline DIDO 1 & 0,1308 & 0,1706 \\
$D I D O 2$ & 0,2595 & 0,0303 \\
$D I D O 3$ & 0,1460 & 0,1415 \\
$D I D O P P$ & 0,1106 & 0,2063 \\
DIDO PD & 0,0528 & 0,3496 \\
\hline
\end{tabular}

$r_{s}$ : valor da correlação entre $o$ índice de Sokal e as expressões gênicas das diferentes isoformas de DIDO.

A correlação entre o valor do índice de Sokal e a expressão do gene DIDO 2 apresentou um valor de $r_{s}=0,2595$ ( $p=0,0303$ ), o que indica uma correlação positiva entre o índice de Sokal e a expressão de DIDO 2 dos pacientes com LMC. Por outro lado, as correlações entre os valores do índice de Sokal e as expressões dos genes DIDO 1, DIDO3, DIDO PP e DIDO PD dos pacientes com LMC não foram significativas.

Como a correlação entre o índice de Sokal e a expressão de DIDO 2 foi positiva, buscou-se avaliar se os pacientes com maior expressão gênica de DIDO 2 apresentam, de fato, altos valores de índice de Sokal. Dessa forma, foram avaliados os índices de Sokal de todos os pontos que se encontravam acima do percentil $75 \%$ na curva de distribuição dos valores de expressão de DIDO 2 dos pacientes estudados. Dentre os 13 pontos presentes acima do percentil $75 \%$, que são os que correspondem às maiores expressões gênicas de DIDO 2, 7 pontos foram de pacientes com índices de Sokal de alto risco (valor > 1,20); 3 pontos foram de pacientes com índices de Sokal de risco intermediário (valor de 0,80 a 1,20) e 3 pontos foram de pacientes com índices de Sokal de baixo risco (valor $<0,80$ ), confirmando, portanto, que os pacientes com maior expressão gênica de DIDO 2 realmente apresentam altos valores de índice de Sokal. 
IV.2 Expressão gênica de DIDO 1, DIDO 2, DIDO 3, DIDO PP e DIDO PD em linhagens celulares

IV.2.1 Expressão dos genes DIDO 1, DIDO 2, DIDO 3, DIDO PP e DIDO PD em HL-60 após tratamento com Inibidores de Tirosina-quinase

A figura 16 refere-se à expressão gênica de $D I D O$ 1, DIDO 2, DIDO 3, DIDO $P P$ e $D I D O P D$ na linhagem $\mathrm{HL}-60$ após $4 \mathrm{~h}$ de tratamento com inibidores de tirosina-quinase mesilato de imatinibe, dasatinibe e nilotinibe.
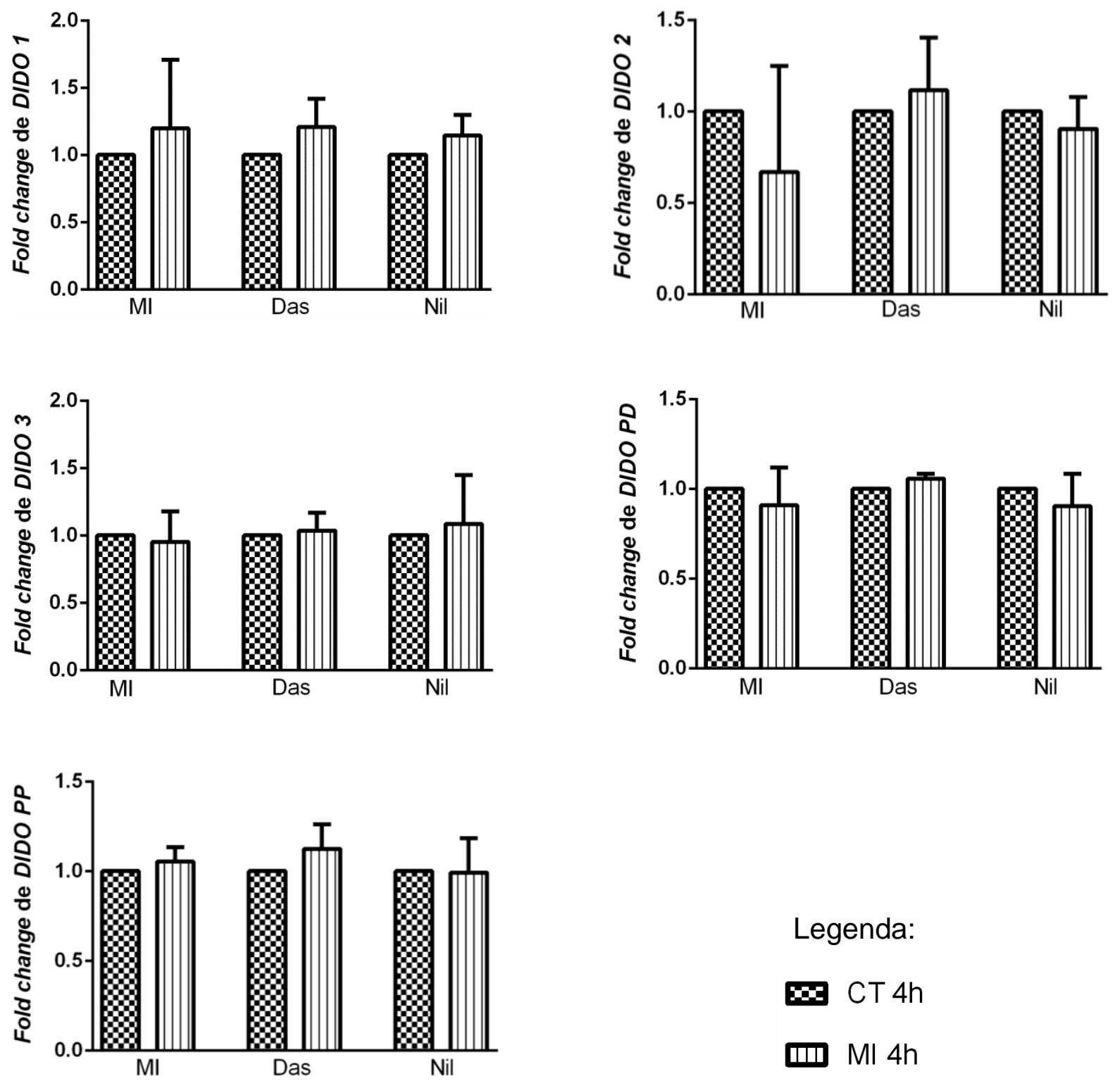

Legenda:

E CT $4 \mathrm{~h}$

血 $\mathrm{Ml}$ 4h

Figura 16. Expressão de DIDO 1, DIDO2, DIDO 3, DIDO PP e DIDO PD na linhagem HL-60 após 4h de tratamento com inibidores de tirosina-quinase. CT: controle; MI: mesilato de imatinibe; Das: dasatinibe; Nil: nilotinibe. 
A tabela 17 traz as médias entre os valores de fold change (triplicatas) das expressões de DIDO após as $4 \mathrm{~h}$ de tratamento com os inibidores de tirosina quinase na linhagem HL-60.

Tabela 17. Médias entre os valores de fold change da expressão gênica de DIDO na linhagem celular HL-60 após $4 \mathrm{~h}$ de tratamento com inibidores de tirosina-quinase.

\begin{tabular}{c|cccccc}
\hline GENE & CT $(\bar{x})$ & MI $(\bar{x})$ & CT $(\bar{x})$ & DAS $(\bar{x})$ & CT $(\bar{x})$ & NIL $(\bar{x})$ \\
\hline DIDO 1 & 1,0000 & 1,1970 & 1,0000 & 1,2080 & 1,0000 & 1,1440 \\
DIDO 2 & 1,0000 & 0,6678 & 1,0000 & 1,1160 & 1,0000 & 0,9041 \\
DIDO 3 & 1,0000 & 0,9519 & 1,0000 & 1,0360 & 1,0000 & 1,0840 \\
DIDO PP & 1,0000 & 1,0530 & 1,0000 & 1,1250 & 1,0000 & 0,9920 \\
DIDO PD & 1,0000 & 0,9086 & 1,0000 & 1,0570 & 1,0000 & 0,9031 \\
\hline
\end{tabular}

$\bar{x}$ : média entre os valores de fold change das expressões gênicas das diferentes isoformas de DIDO na linhagem celular HL-60 após 4h de tratamento com TKIs; CT: controle; MI: mesilato de imatinibe; DAS: dasatinibe; NIL: nilotinibe.

A expressão dos genes DIDO 1, DIDO 2, DIDO 3, DIDO PP e DIDO PD na linhagem celular HL-60 não foi diferente entre os controles (células não tratadas) e células tratadas por $4 \mathrm{~h}$ com os inibidores de tirosina-quinase mesilato de imatinibe, dasatinibe e nilotinibe.

\section{IV.2.2 Expressão dos genes DIDO 1, DIDO 2, DIDO 3, DIDO PP e DIDO PD em HL-60.Bcr-Abl ${ }^{+}$após tratamento com Inibidores de Tirosina-quinase}

A figura 17 refere-se à expressão gênica de DIDO 1, DIDO 2, DIDO 3, DIDO $P P$ e DIDO PD na linhagem HL-60.Bcr-Abl ${ }^{+}$após $4 \mathrm{~h}$ de tratamento com inibidores de tirosina-quinase. A tabela 18 traz as médias entre os valores de fold change (triplicatas) da expressão gênica de DIDO 1, DIDO 2, DIDO 3, DIDO PP e DIDO PD na linhagem HL-60.Bcr-Abl ${ }^{+}$após o tratamento com os inibidores. 

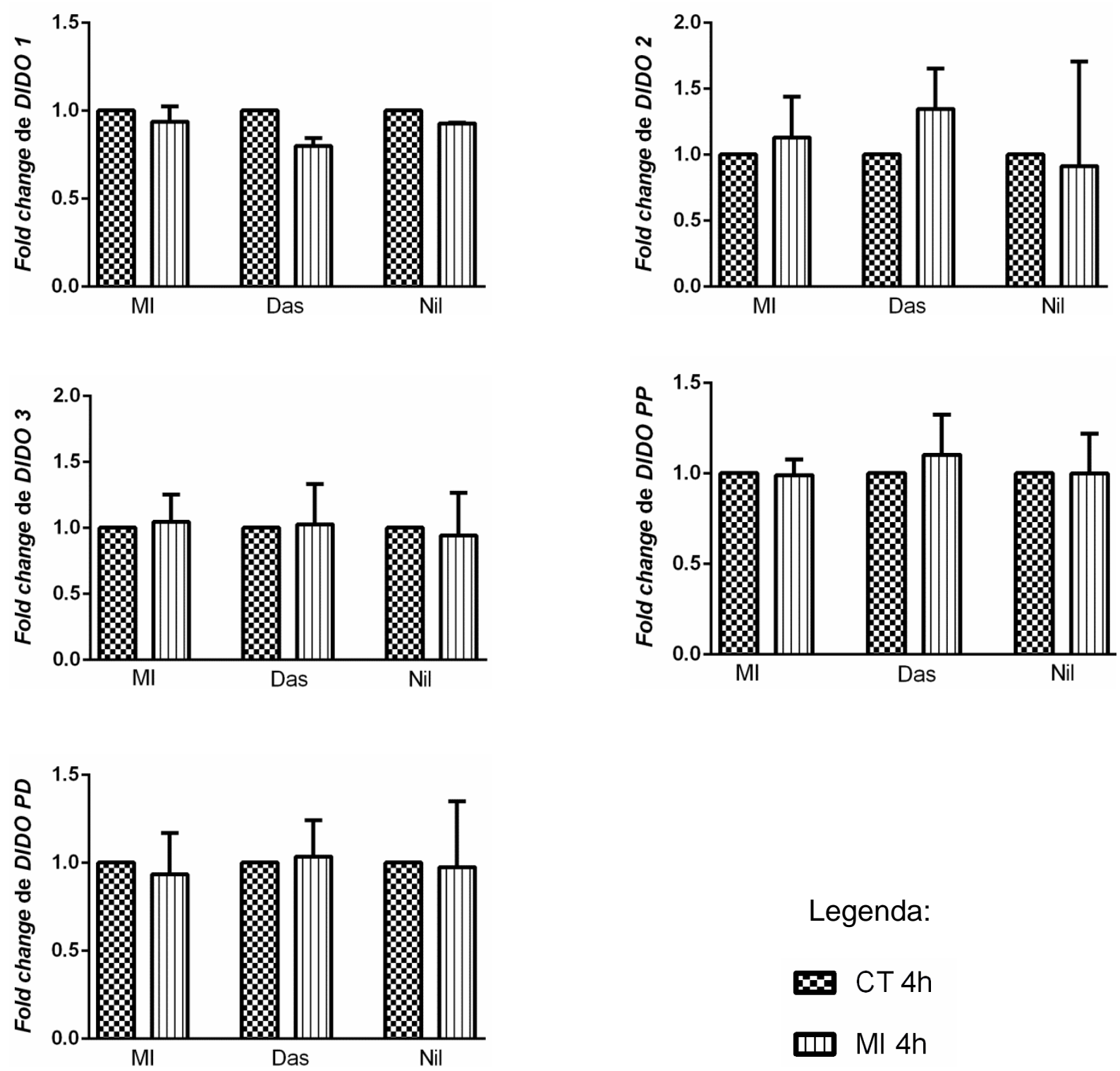

\section{Legenda: \\ ET CT $4 \mathrm{~h}$ \\ Ul $4 h$}

Figura 17. Expressão de DIDO 1, DIDO2, DIDO 3, DIDO PP e DIDO PD na linhagem HL-60.Bcr$\mathrm{Abl}^{+}$após $4 \mathrm{~h}$ de tratamento com inibidores de tirosina-quinase. CT: controle; Ml: mesilato de imatinibe; Das: dasatinibe; Nil: nilotinibe.

Tabela 18. Médias entre os valores de fold change da expressão gênica de DIDO na linhagem celular HL-60.Bcr-Abl ${ }^{+}$após $4 \mathrm{~h}$ de tratamento com inibidores de tirosinaquinase.

\begin{tabular}{c|cccccc}
\hline GENE & CT $(\bar{x})$ & MI $(\bar{x})$ & CT $(\bar{x})$ & DAS $(\bar{x})$ & CT $(\bar{x})$ & NIL $(\bar{x})$ \\
\hline DIDO 1 & 1,0000 & 0,9369 & 1,0000 & 0,7987 & 1,0000 & 0,9268 \\
DIDO 2 & 1,0000 & 1,1300 & 1,0000 & 1,3460 & 1,0000 & 0,9124 \\
DIDO 3 & 1,0000 & 1,0440 & 1,0000 & 1,0250 & 1,0000 & 0,9404 \\
DIDO PP & 1,0000 & 0,9899 & 1,0000 & 1,1020 & 1,0000 & 0,9981 \\
DIDO PD & 1,0000 & 0,9334 & 1,0000 & 1,0340 & 1,0000 & 0,9741 \\
\hline
\end{tabular}

$\bar{x}$ : média entre os valores de fold change das expressões gênicas das diferentes isoformas de DIDO na linhagem celular $\mathrm{HL}-60 . \mathrm{Bcr}_{-} \mathrm{Abl}^{+}$após $4 \mathrm{~h}$ de tratamento com TKIs; CT: controle; MI: mesilato de imatinibe; DAS: dasatinibe; NIL: nilotinibe. 
Não houve diferença de expressão dos genes DIDO 1, DIDO 2, DIDO 3, $D I D O P P$ e DIDO PD na linhagem celular HL-60.Bcr-Abl ${ }^{+}$entre os controles (células não tratadas) e células tratadas por $4 \mathrm{~h}$ com os inibidores de TK utilizados.

IV.2.3 Expressão dos genes DIDO 1, DIDO 2, DIDO 3, DIDO PP e DIDO PD em KCL 22 S, KCL 22 R, LAMA 84 S e LAMA 84 R

A figura 18 refere-se à expressão gênica de DIDO 1, DIDO 2, DIDO 3, DIDO $P P$ e DIDO PD entre as linhagens KCL22 S e KCL $22 \mathrm{R}$ e entre LAMA $84 \mathrm{~S}$ e LAMA $84 \mathrm{R}$.
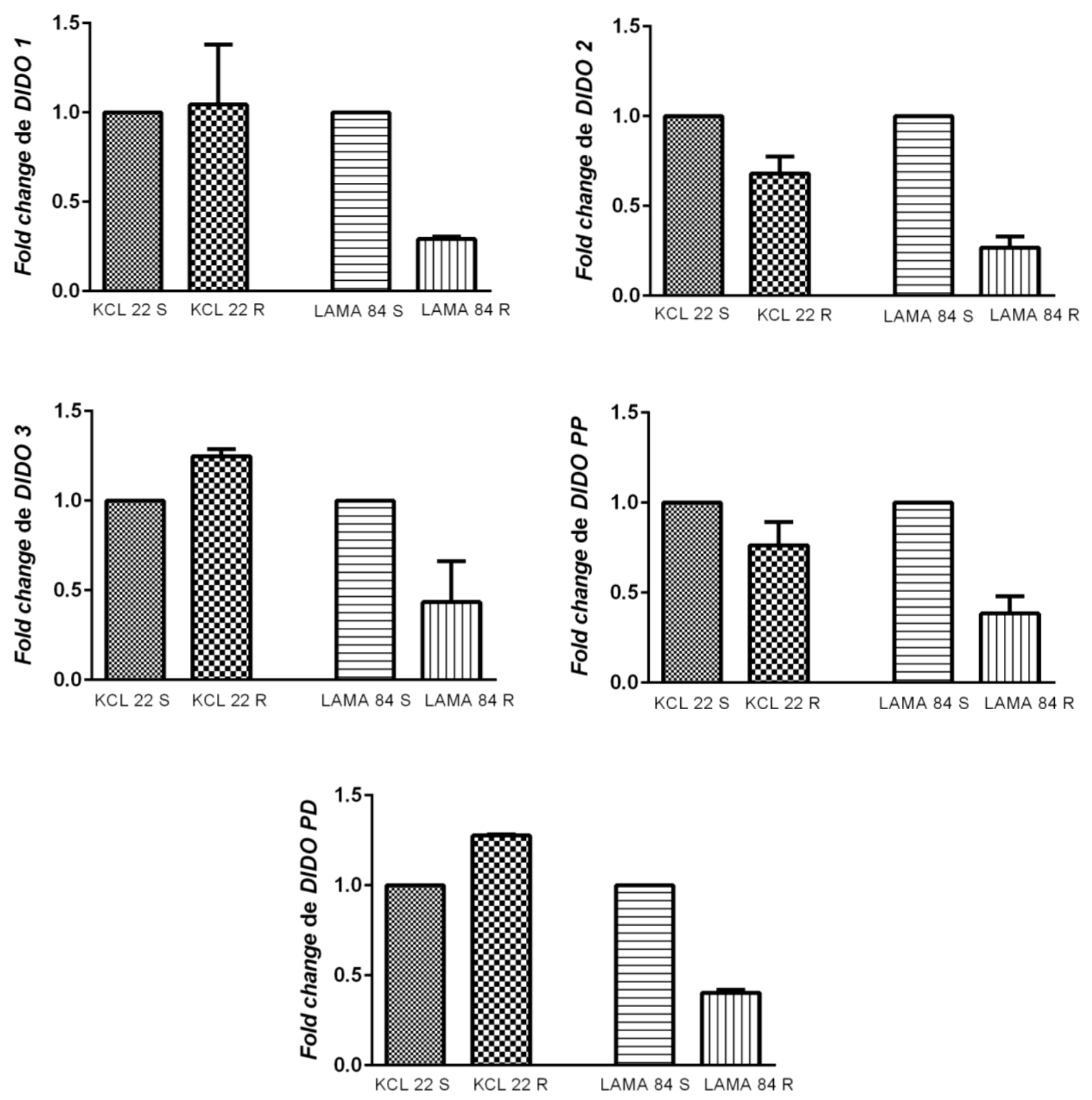

Figura 18. Expressão de DIDO 1, DIDO2, DIDO 3, DIDO PP e DIDO PD nas linhagens KCL22 S, KCL 22 R, LAMA 84 S e LAMA 84 R. 
A tabela 19 traz as médias entre os valores de fold change (triplicatas) da expressão gênica de DIDO 1, DIDO 2, DIDO 3, DIDO PP e DIDO PD nas linhagens KCL 22 S, KCL 22 R, LAMA 84 S e LAMA 84 R.

Tabela 19. Médias entre os valores de fold change da expressão gênica de DIDO nas linhagens celulares KCL 22 S, KCL 22 R, LAMA 84 S e LAMA 84 R.

\begin{tabular}{c|cc|cc}
\hline GENE & KCL 22 S $(\overline{\boldsymbol{x}})$ & KCL 22 R $(\overline{\boldsymbol{x}})$ & LAMA 84 S $(\overline{\boldsymbol{x}})$ & LAMA 84 R $(\overline{\boldsymbol{x}})$ \\
\hline DIDO 1 & 1,0000 & 1,0440 & 1,0000 & 0,2913 \\
DIDO 2 & 1,0000 & 0,6804 & 1,0000 & 0,2679 \\
DIDO 3 & 1,0000 & 1,2480 & 1,0000 & 0,4342 \\
DIDO PP & 1,0000 & 0,7637 & 1,0000 & 0,3845 \\
DIDO PD & 1,0000 & 1,2770 & 1,0000 & 0,4029 \\
\hline
\end{tabular}

$\bar{x}$ : média entre os valores de fold change das expressões gênicas das diferentes isoformas de DIDO nas linhagens celulares KCL $22 \mathrm{~S}, \mathrm{KCL} 22 \mathrm{R}$, LAMA 84 S e LAMA 84 R.

Em KCL 22 R, a expressão gênica de DIDO 1 não foi diferente de KCL 22 S, enquanto que em LAMA $84 \mathrm{R}$, a expressão de DIDO 1 foi 2,4 vezes menor do que em LAMA 84 S. Com relação à expressão gênica de DIDO 2, em KCL $22 \mathrm{R}$ foi aproximadamente a 0,5 vezes menor do que em KCL 22 S; já em LAMA 84 R, a expressão DIDO 2 foi aproximadamente 2,7 vezes menor do que em LAMA 84 S. Quanto a expressão de DIDO 3, em KCL 22 R foi 0,25 vezes maior do que em KCL $22 \mathrm{~S}$, mas em LAMA $84 \mathrm{R}$ a expressão de DIDO 3 foi 1,3 vezes menor do que em LAMA $84 \mathrm{~S}$.

A expressão de DIDO PP em KCL $22 \mathrm{R}$ foi 0,3 vezes menor do que em KCL $22 \mathrm{~S}$ e em LAMA $84 \mathrm{R}$, a expressão de DIDO PP foi 1,6 vezes menor do que em LAMA 84 S. Já a expressão de DIDO PD foi aproximadamente 0,3 vezes maior em KCL $22 \mathrm{R}$ do que em KCL $22 \mathrm{~S}$, mas a expressão de DIDO PD em LAMA $84 \mathrm{R}$ foi aproximadamente 1,5 vezes menor do que em LAMA $84 \mathrm{~S}$.

IV.2.4 Expressão dos genes DIDO 1, DIDO 2 e DIDO 3 em KCL 22 S, KCL 22 R, LAMA 84 S e LAMA 84 R após tratamento com mesilato de Imatinibe

A figura 19 refere-se à expressão gênica de DIDO 1, DIDO 2 e DIDO 3 entre controles e células tratadas das linhagens KCL22 S e KCL 22 R após 4h de tratamento com mesilato de imatinibe. 

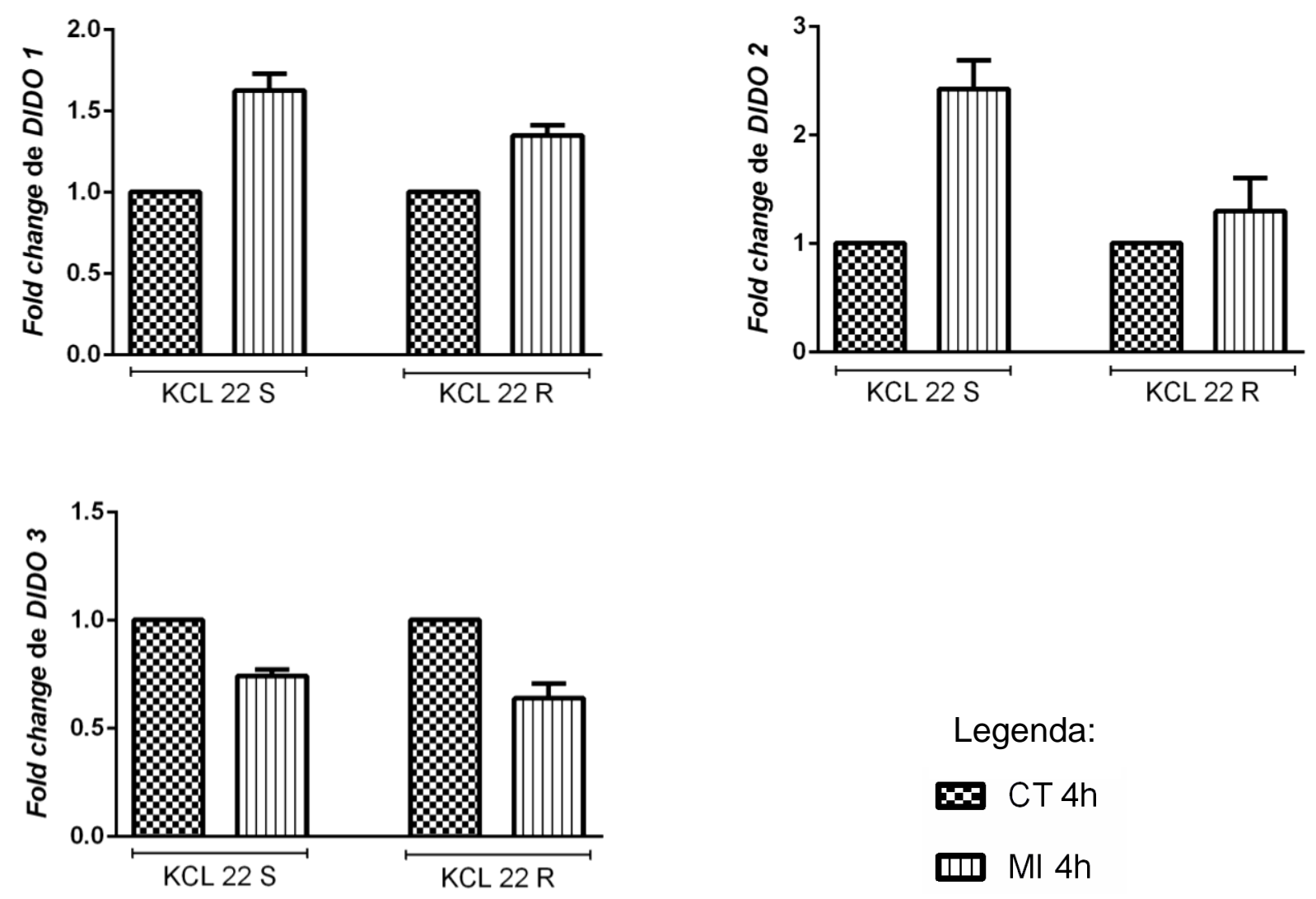

Legenda:

$\mathbf{E}$ CT $4 \mathrm{~h}$

سI $\mathrm{Ml} 4 \mathrm{~h}$

Figura 19. Expressão gênica de DIDO 1, DIDO2 e DIDO 3 em KCL 22 S e KCL 22 R após 4h de tratamento com o inibidor de tirosina-quinase mesilato de imatinibe. CT: controle; MI: mesilato de imatinibe.

A expressão de DIDO 1 em KCL 22 S e KCL $22 \mathrm{R}$ após 4h de tratamento com mesilato de imatinibe foi discretamente maior do que nos controles (células sem tratamento). Em KCL $22 \mathrm{~S}$, o aumento na expressão de DIDO 1 após 4h de tratamento com MI foi de aproximadamente 0,6 vezes, enquanto que em KCL $22 \mathrm{R}$ esse aumento foi de aproximadamente 0,3 vezes. A expressão de DIDO 2 em KCL $22 \mathrm{~S}$ após $4 \mathrm{~h}$ de tratamento com mesilato de imatinibe foi 1,4 vezes maior do que no controle, enquanto que a expressão de DIDO 2 em KCL $22 \mathrm{R}$ após 4h de tratamento com Ml foi discreta, da ordem de 0,3 vezes maior do que no controle.

Ao contrário do observado para a expressão de DIDO 1 e DIDO 2, a expressão gênica de DIDO 3 foi menor nas linhagens KCL 22 S e KCL 22 R após 4h de tratamento com $\mathrm{Ml}$ em relação aos controles, no entanto, essa redução de expressão foi discreta; na linhagem KCL $22 \mathrm{~S}$, a redução na expressão de DIDO 3 após $4 \mathrm{~h}$ de tratamento foi aproximadamente 0,3 vezes menor do que no controle, enquanto que na linhagem KCL $22 \mathrm{R}$, a expressão de DIDO 3 foi aproximadamente 0,6 vezes menor do que no controle. 
A figura 20 refere-se à expressão gênica de DIDO 1, DIDO 2 e DIDO 3 entre controles e células tratadas das linhagens LAMA $84 \mathrm{~S}$ e LAMA $84 \mathrm{R}$ após $4 \mathrm{~h}$ de tratamento com mesilato de imatinibe.
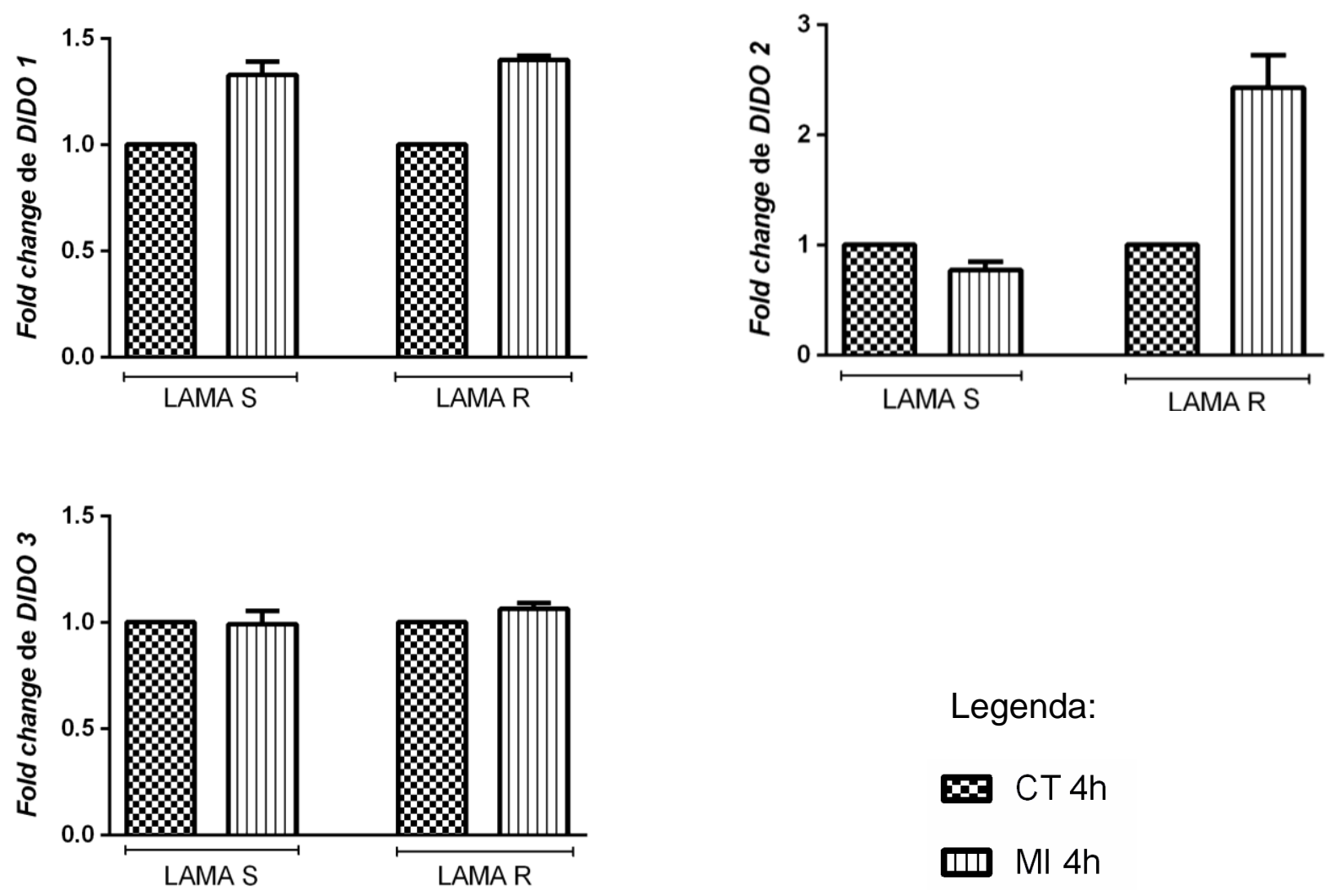

Legenda:

CT $4 \mathrm{~h}$

四 Ml 4h

Figura 20. Expressão gênica de DIDO 1, DIDO2 e DIDO 3 em LAMA 84 S e LAMA 84 R após 4h de tratamento com o inibidor de tirosina-quinase mesilato de imatinibe. CT: controle; $\mathrm{Ml}$ : mesilato de imatinibe.

Nas linhagens LAMA $84 \mathrm{~S}$ e LAMA $84 \mathrm{R}$, a expressão de DIDO 1 aumentou discretamente nas células tratadas por $4 \mathrm{~h}$ com mesilato de imatinibe em relação aos controles. Em LAMA $84 \mathrm{~S}$, a expressão de DIDO 1 foi 0,3 vezes maior do que no controle, enquanto que em LAMA $84 \mathrm{R}$, a expressão de DIDO 1 foi aproximadamente 0,4 vezes maior do que no controle. Quanto a expressão de DIDO 2 após $4 \mathrm{~h}$ de tratamento com MI, em LAMA $84 \mathrm{~S}$ foi discretamente menor do que no controle, da ordem de 0,3 vezes, enquanto que em LAMA $84 \mathrm{R}$ a expressão de DIDO 2 foi 1,4 vezes maior do que no controle. A expressão de DIDO 3 não foi diferente em LAMA $84 \mathrm{~S}$ e em LAMA $84 \mathrm{R}$ após $4 \mathrm{~h}$ de tratamento com mesilato de imatinibe quando em comparação aos controles. 
A tabela 20 traz as médias dos valores de fold change da expressão gênica de DIDO 1, DIDO 2 e DIDO 3 nas linhagens KCL 22 S, KCL 22 R, LAMA 84 S e LAMA $84 \mathrm{R}$ entre controles e células tratadas por $4 \mathrm{~h}$ com mesilato de imatinibe.

Tabela 20. Média dos valores de fold change da expressão gênica de DIDO 1, DIDO 2 e DIDO 3 nas linhagens celulares KCL $22 \mathrm{~S}, \mathrm{KCL} 22 \mathrm{R}$, LAMA 84 S e LAMA $84 \mathrm{R}$ após $4 \mathrm{~h}$ de tratamento com mesilato de imatinibe.

\begin{tabular}{c|cc|cc|cc|cc}
\hline \multirow{2}{*}{ GENE } & \multicolumn{2}{|c|}{ KCL 22 S } & \multicolumn{2}{c|}{ KCL 22 R } & \multicolumn{2}{c|}{ LAMA 84 S } & \multicolumn{2}{c}{ LAMA 84 R } \\
\cline { 2 - 9 } & CT 4h $(\bar{x})$ & MI 4h $(\bar{x})$ & CT 4h $(\bar{x})$ & MI 4h $(\bar{x})$ & CT 4h $(\bar{x})$ & MI 4h $(\bar{x})$ & CT 4h $(\bar{x})$ & MI 4h $(\bar{x})$ \\
\hline DIDO 1 & 1,0000 & 1,6240 & 1,0000 & 1,3500 & 1,0000 & 1,3280 & 1,0000 & 1,398 \\
DIDO 2 & 1,0000 & 2,4250 & 1,0000 & 1,2960 & 1,0000 & 0,7706 & 1,0000 & 2,4290 \\
DIDO 3 & 1,0000 & 0,7415 & 1,0000 & 0,6378 & 1,0000 & 0,9924 & 1,0000 & 1,0630 \\
\hline
\end{tabular}

$\bar{x}$ : média dos valores de fold change das expressões gênicas das diferentes isoformas de DIDO após 4h de tratamento com mesilato de imatinibe, CT: controle; MI: mesilato de imatinibe.

\section{IV.3 Expressão proteica de Bcr-Abl e fosfotirosina}

A expressão proteica de fosfotirosina, c-abl e Bcr-Abl na linhagem celular HL60.Bcr-Abl ${ }^{+}$sem tratamento e tratada com os inibidores de tirosina-quinase mesilato de imatinibe, dasatinibe e nilotinibe foi determinada por western-blotting e está demonstrada na figura 21.

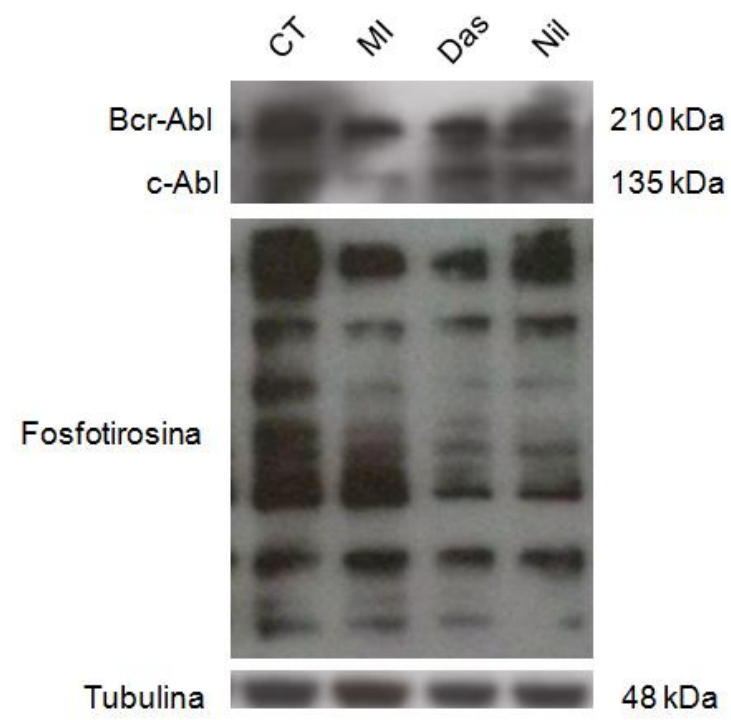

Figura 21. Expressão de tubulina, fosfotirosina, c-Abl e Bcr-Abl em HL60.Bcr-Abl ${ }^{+}$após $4 \mathrm{~h}$ de tratamento com TKIs. CT: controle; MI: mesilato de imatinibe; Das: dasatinibe; Nil: nilotinibe. 
Após $4 \mathrm{~h}$ de tratamento com os inibidores de tirosina-quinase mesilato de imatinibe, dasatinibe e nilotinibe, as células da linhagem $\mathrm{HL}-60 . \mathrm{Bcr}^{-\mathrm{Abl}^{+}}$ apresentaram redução na expressão de proteínas fosforiladas quando comparadas às células não tratadas (controle). Essa redução na expressão proteica de proteínas fosforiladas foi menor nas células tratadas com dasatinibe e nilotinibe do que nas células tratadas com mesilato de imatinibe.

Como controle de expressão de Bcr-Abl e da atividade de fosfotirosina, os lisados proteicos das linhagens celulares KCL22 S, KCL 22 R, LAMA 84 S e LAMA $84 \mathrm{R}$ foram também submetidos ao western-blotting (figuras 22 e 23).

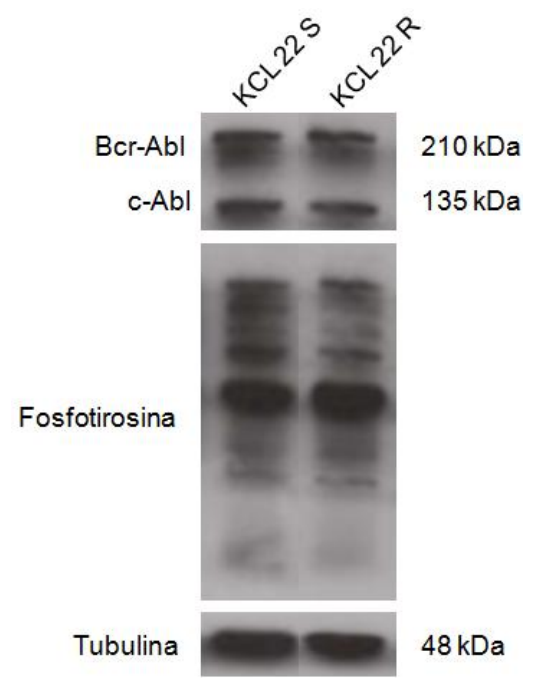

Figura 22. Expressão de tubulina, fosfotirosina, c-Abl e Bcr-Abl nas linhagens KCL $22 \mathrm{~S}$ e KCL 22 R.

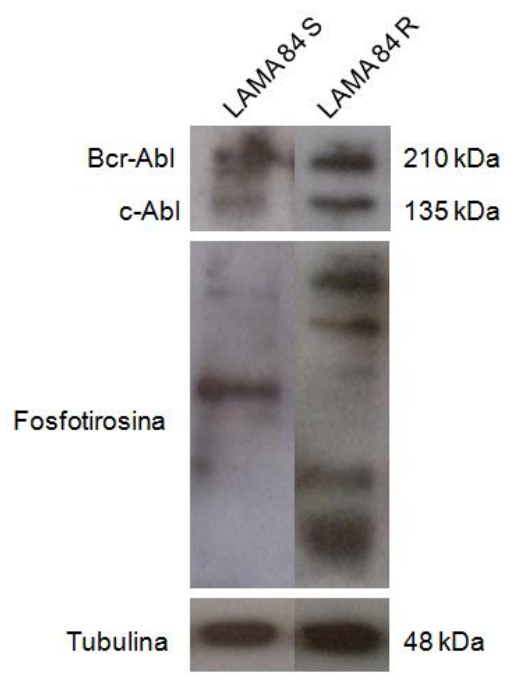

Figura 23. Expressão de tubulina, fosfotirosina, c-Abl e Bcr-Abl nas linhagens celulares LAMA 84 S e LAMA 84 R. 
A expressão de c-Abl e de Bcr-Abl não foi diferente entre KCL 22 S e KCL 22 R. Tais linhagens também não apresentaram diferença na expressão de proteínas fosforiladas. No entanto, a expressão de c-Abl e de Bcr-Abl foi menor na linhagem LAMA $84 \mathrm{~S}$ do que na linhagem LAMA $84 \mathrm{R}$. Da mesma forma, a expressão de proteínas fosforiladas em LAMA $84 \mathrm{~S}$ foi menor do que em LAMA $84 \mathrm{R}$, confirmando a maior atividade fosforilativa da proteína Bcr-Abl na linhagem resistente do que na linhagem sensível.

\section{IV.4 Resultados compilados}

As tabelas 21 e 22 compilam os resultados da expressão gênica das isoformas de DIDO em pacientes e controles e das correlações entre a expressão de $B C R-A B L 1$ e de DIDO e entre índice de Sokal e expressão de DIDO dos pacientes. 
Tabela 21. Resultados das análises comparativas da expressão gênica das diferentes isoformas de DIDO em controles, pacientes nas diferentes fases da LMC e pacientes tratados com inibidores de tirosina-quinase.

\begin{tabular}{|c|c|c|c|}
\hline COMPARAÇÃO & GENE & p VALOR & md VALOR \\
\hline \multirow{2}{*}{$\begin{array}{l}\text { Controles versus } \\
\text { Pacientes nas fases } \\
\text { avançadas }\end{array}$} & DIDO 1 & 0,0144 & $\begin{array}{l}C T=1,212 \\
F A=5,933\end{array}$ \\
\hline & DIDO 2 & 0,0105 & $\begin{array}{l}C T=0,785 \\
F A=3,549\end{array}$ \\
\hline \multirow{2}{*}{$\begin{array}{l}\text { Controles versus } \\
\text { Pacientes na fase crônica } \\
\text { tratados com MI }\end{array}$} & DIDO 1 & 0,0028 & $\begin{array}{l}\mathrm{CT}=2,092 \\
\mathrm{FC} \mathrm{MI}=6,921\end{array}$ \\
\hline & DIDO PP & 0,0352 & $\begin{array}{l}\mathrm{CT}=47,740 \\
\mathrm{FC} \mathrm{MI}=77,980\end{array}$ \\
\hline \multirow{4}{*}{$\begin{array}{c}\text { Controles versus } \\
\text { Pacientes na fase crônica } \\
\text { tratados com DAS }\end{array}$} & DIDO 1 & 0,0143 & $\begin{array}{l}C T=0,260 \\
\text { FC DAS }=5,271\end{array}$ \\
\hline & DIDO 2 & 0,0286 & $\begin{array}{l}C T=0,576 \\
\text { FC DAS }=4,743\end{array}$ \\
\hline & DIDO PP & 0,0159 & $\begin{array}{l}C T=38,780 \\
F C D A S=82,070\end{array}$ \\
\hline & $D I D O P D$ & 0,0278 & $\begin{array}{l}C T=4,101 \\
F C D A S=73,850\end{array}$ \\
\hline \multirow{4}{*}{$\begin{array}{l}\text { Pacientes na fase crônica } \\
\text { sem tratamento versus } \\
\text { Pacientes na fase crônica } \\
\text { tratados com Ml }\end{array}$} & DIDO 1 & 0,0184 & $\begin{array}{l}\mathrm{FC} \mathrm{S} / \mathrm{T}=2,557 \\
\mathrm{FC} \mathrm{MI}=6,921\end{array}$ \\
\hline & DIDO 3 & 0,0357 & $\begin{array}{l}\mathrm{FC} \mathrm{S} / \mathrm{T}=2,338 \\
\mathrm{FC} \mathrm{MI}=7,124\end{array}$ \\
\hline & DIDO PP & 0,0085 & $\begin{array}{l}\mathrm{FC} \mathrm{S} / \mathrm{T}=29,130 \\
\mathrm{FC} \mathrm{MI}=77,980\end{array}$ \\
\hline & $D I D O P D$ & 0,0025 & $\begin{array}{l}\mathrm{FC} \mathrm{S} / \mathrm{T}=3,331 \\
\mathrm{FC} \mathrm{MI}=9,414\end{array}$ \\
\hline $\begin{array}{c}\text { Pacientes antes do } \\
\text { tratamento versus } \\
\text { Pacientes após } 12 \text { meses } \\
\text { de tratamento com Ml }\end{array}$ & $D I D O P D$ & 0,0421 & $\begin{array}{l}\text { AT }=3,973 \\
\mathrm{PT}=6,412\end{array}$ \\
\hline
\end{tabular}


Tabela 22. Resultados das correlações entre expressão de $B C R-A B L 1$ e expressão de DIDO e entre Índice de Sokal e expressão de DIDO nos pacientes com LMC.

\begin{tabular}{cccc}
\hline CORRELAÇÃO & GENE & $\mathbf{r}_{\mathbf{s}}$ & p VALOR \\
\hline $\begin{array}{c}\text { Expressão de BCR- } \\
\text { ABL1 (b2a2) versus } \\
\text { Expressão de DIDO }\end{array}$ & DIDO2 & 0,5824 & 0,0184 \\
\hline $\begin{array}{c}\text { Índice de Sokal versus } \\
\text { Expressão de DIDO }\end{array}$ & DIDO 2 & 0,2592 & 0,0303 \\
\hline
\end{tabular}

$r_{\mathrm{s}}$ : valor da correlação. 
V. Discussão 
$\mathrm{Na}$ leucemia mielóide crônica a proteína tirosina-quinase Bcr-Abl induz a mieloproliferação e resistência à apoptose, sendo a responsável pela leucemogênese (JABBOUR; KANTARJIAN, 2012; CHEREDA; MELO, 2015). Apesar de todos os conhecimentos acerca da fisiopatologia da $L M C$, a resistência da célula Bcr-Abl positiva à apoptose e novos alvos terapêuticos continuam sendo investigados.

Os inibidores de tirosina-quinase são capazes de induzir remissão citogenética completa na maioria dos pacientes com LMC na fase crônica. Apesar dos excelentes resultados obtidos com o tratamento com o $\mathrm{Ml}$, uma parcela desses pacientes tem se mostrado resistente à terapia, apresentando recaídas ou progressão da LMC para fase acelerada ou crise blástica (DRUKER, et al., 2006).

Estudos recentes têm demonstrado que a ativação compensatória de vias de sinalização intracelulares na LMC é um mecanismo comum de resistência aos TKls. Dessa maneira, as células Bcr-Abl positivas continuam a proliferar, mesmo com a inibição da atividade quinase de Bcr-Abl (BALBANOV; BRAIG; BRÜMMENDORF, 2014). Os mecanismos de resistência das células Bcr-Abl positivas à terapia com TKls são diversos e parcialmente compreendidos e, portanto, precisam ser estudados para a descrição de terapias mais eficazes.

O presente estudo investigou a associação da expressão das isoformas 1, 2, 3 e promotores do gene DIDO com as fases da LMC, atividade quinase de Bcr-Abl, níveis de expressão de Bcr-Abl, resposta (resistência e sensibilidade) ao mesilato de imatinibe e índice de Sokal.

Os promotores são regiões que se localizam upstream ao sítio de início da transcrição de genes e possuem papel de regulação gênica, uma vez que contém múltiplas regiões para ligação de fatores ativadores da transcrição (MASTON; EVANS; GREEN, 2006; ANDERSSON; SANDELIN; DANKO, 2015), por isso sua análise fou inclusa no estudo.

A literatura relata que DIDO 1 participa do processo de apoptose e que alterações na expressão de DIDO 2 e DIDO 3 podem estar associadas com 0 desenvolvimento de neoplasias mielóides (GARCÍA-DOMINGO et al., 1999, 2003; FÜTTERER et al. 2005). 


\section{V.1 Discussão dos resultados da expressão das diferentes isoformas de DIDO em pacientes e controles nas diferentes fases da doença}

O presente estudo detectou aumento dos níveis de expressão de DIDO $1 \mathrm{e}$ DIDO 2 em pacientes nas fases avançadas da leucemia mielóide crônica quando comparados aos controles e fase crônica da doença.

Braig e Bosserhoff (2013) avaliaram os níveis de expressão gênica de DIDO 1 em linhagens celulares de melanoma e verificaram que o gene estava mais expresso em linhagens celulares da doença do que em linhagens de melanócitos humanos normais. Observaram, ainda, que o silenciamento de DIDO por RNAs de interferência (siRNA) nas linhagens celulares de melanoma diminuía a progressão do tumor e o potencial proliferativo e invasivo das células. Esse estudo indica que no modelo de Melanoma, DIDO 1 contribui para a proliferação tumoral e progressão da doença.

Contudo, Fütterer et al. (2005) compararam a expressão de DIDO 1, DIDO 2 e DIDO 3 de células hematopoéticas de medula óssea entre indivíduos saudáveis e pacientes diagnosticados com doenças hematológicas, incluindo pacientes com síndromes mielodisplásicas, com doenças mieloproliferativas (neoplasias mielóide $\mathrm{Ph}$ negativas e leucemia mielóide crônica), com síndrome mielodisplásica/doença mieloproliferativa e com leucemia mielóide aguda. Os autores verificaram que parte dos pacientes com doenças hematológicas mielóides apresentaram redução nos níveis de expressão de DIDO, principalmente alterações de expressão de DIDO $2 \mathrm{e}$ DIDO 3.

Essa discrepância do nosso dado em relação ao que foi observado por Fütterer et al. (2005) parece estar associada às diferenças de desenho de estudo. Os autores citados estudaram células da medula óssea e não analisaram separadamente as desordens mielóides conforme os critérios da organização mundial da saúde. Portanto, nossas hipóteses são de que DIDO 1 e 2 contribuem para a progressão da LMC ou aumentam com a progressão da doença, indicando papel diferente do descrito por Futterer et al. nas demais doenças mielóides.

Estudos funcionais em linhagens, detecção proteica de Dido e estudo sobre sua relação com outros genes são necessários para confirmação de nossas hipóteses sobre o potencial papel de DIDO 1 e DIDO 2 na evolução clonal da LMC. 
Os resultados aqui obtidos também sugerem que os inibidores de tirosinaquinase, mesilato de imatinibe e dasatinibe, aumentam a expressão de DIDO. Os pacientes na fase crônica, quando comparados aos controles, apresentaram maior expressão de DIDO 1 e de DIDO PP quando tratados com mesilato de imatinibe e maior expressão de DIDO 1, DIDO 2, DIDO PP e DIDO PD quando tratados com dasatinibe. Já os pacientes na fase crônica tratados com Ml, quando comparados com pacientes na mesma fase da doença sem tratamento, apresentaram maior expressão de DIDO 1, DIDO 3, DIDO PP e DIDO PD.

García-Domingo et al. (2003) demonstraram em células de linhagens celulares do tipo pró-B de murinos, transfectadas com plasmídeo contendo o gene DIDO 1, a regulação positiva da apoptose e aumento nos níveis das caspases ativadas 3, 9, 6 e 2. Wang e colaboradores (2008) relataram o aumento de expressão da proteína Dido $1 \mathrm{em}$ linhagem tumoral de linfócitos $T$ cultivados com ácido gambógico, produto natural indutor da apoptose. O estudo descreveu a regulação positiva da expressão do gene DIDO 1 pós-cultivo das células com ácido gambógico, a qual foi acompanhada de regulação negativa da proteína antiapoptótica Bcl-2, com consequente ativação da pró-caspase 3.

Em nosso estudo, o aumento da expressão de DIDO 1 e promotores em pacientes na fase crônica da LMC tratados com MI ou Das em comparação aos controles pode ser explicado, pelo menos parcialmente, pelo envolvimento dessa isoforma no desencadeamento do processo apoptótico, sugerindo que a regulação positiva de DIDO 1 pode estar relacionada ao papel dos inibidores de tirosinaquinase em tentar reestabelecer nas células leucêmicas a sensibilidade à apoptose.

Além de DIDO 1, os inibidores de tirosina-quinase também pareceram modular positivamente a expressão dos genes DIDO 2 e DIDO 3. Entretanto, não há relatos na literatura sobre o envolvimento de DIDO 2 e 3 no processo apoptótico

A isoforma DIDO 3 já foi identificada como associada ao aparato do fuso mitótico in vitro e alterações na expressão do gene DIDO 3 estariam ligadas à amplificações de centrossomos e má formação do fuso mitótico, comprometendo a estabilidade dos cromossomos e favorecendo o processo de tumorigênese. As proteínas de DIDO 3 foram também associadas com a regulação da pluripotência de células embrionárias in vitro e in vivo (TRACHANA et al., 2007; GATCHALIAN et al., 2013). 
Nossos achados sugerem, portanto, que os inibidores de tirosina-quinase podem modular a expressão gênica de DIDO, sobretudo de DIDO 1. No entanto, não conseguimos confirmar a relação do aumento da expressão das isoformas de DIDO nas células das linhagens Bcr-Abl positivas estudadas após 4h de tratamento com inibidores de tirosina-quinase. Sendo assim, esses dados são insuficientes para respondermos se a expressão de DIDO é dependente da atividade quinase de BcrAbl.

Os pacientes com LMC são tratados continuamente com os inibidores de tirosina-quinase, o que nos permite especular que o tempo maior de inibição da atividade quinase da proteína Bcr-Abl seja necessária para alterar a expressão de DIDO nas linhagens. Em vista disso, alterações no protocolo utilizado para tratamento das linhagens celulares, como por exemplo, aumento na dose de inibidores de tirosina-quinase e tempos maiores de incubação das células com esses inibidores se fazem necessárias para melhor esclarecimento acerca dessa questão.

\section{V.2 Discussão dos resultados da expressão das diferentes isoformas de DIDO em pacientes resistentes e sensíveis ao mesilato de imatinibe}

Apesar de não ter sido estatisticamente significante, a expressão de DIDO tendeu a ser maior nos pacientes que atingiram RCC do que nos pacientes resistentes à terapia com mesilato de imatinibe. Observou-se que os genes DIDO 1, DIDO 3, DIDO PP e DIDO PD apresentaram mediana da URE maior nos pacientes que responderam ao tratamento com esse inibidor de TK do que nos pacientes resistentes. Tal resultado corrobora a hipótese da potencial modulação dos inibidores de tirosina-quinase na expressão das diferentes isoformas de DIDO. Nesse contexto, estudos com número maior de pacientes em cada grupo poderia ser útil para melhor caracterizar essa diferença de expressão de DIDO entre pacientes respondedores e resistentes ao mesilato de imatinibe.

Ademais, o fato de o gene DIDO apresentar tendência de maior expressão nos pacientes que respondem ao tratamento do que nos pacientes resistentes à terapia com mesilato de imatinibe nos conduz à hipótese de que as alterações de 
expressão desse gene estão relacionadas aos mecanismos que levam a resistência à terapia com o $\mathrm{Ml}$.

Não foi observada correlação entre expressão de $B C R-A B L 1$ e de DIDO 1, DIDO 3, DIDO PP e DIDO PD. Por outro lado, houve correlação positiva entre expressão de BCR-ABL1 (junção b2a2) e DIDO 2 nos pacientes com LMC sem tratamento, o que nos leva a acreditar que DIDO 2 possa estar relacionado à progressão da $L M C$, uma vez que sua expressão se correlaciona à expressão de $B C R-A B L 1$. Esse resultado suporta o aumento de expressão de DIDO $2 \mathrm{em}$ pacientes nas fases avançadas da doença quando comparados aos controles, anteriormente discutido.

Os índices prognósticos caracterizam os pacientes em dois ou mais grupos prognósticos que predizem sua sobrevida global e resposta ao tratamento (PFIRRMANN et al., 2015). O índice prognóstico de Sokal foi traçado com base em pacientes com LMC que não estavam em crise blástica e eram tratados com quimioterapia. Atualmente, outros dois índices prognósticos são também utilizados, o Euro e o EUTOS. O Euro foi traçado a partir de uma meta-análise de pacientes na fase crônica da LMC tratados com IFN- $\alpha$, enquanto EUTOS foi traçado com base em pacientes na fase crônica da doença que faziam uso de mesilato de imatinibe (SOKAL et al, 1984; PFIRRMANN et al., 2015; YAHNG et al., 2014).

Não houve correlação entre os índices de Sokal e expressão de DIDO 1, DIDO 3, DIDO PP e DIDO PD nos pacientes aqui estudados, mas uma correlação positiva foi encontrada entre índice de Sokal e expressão de DIDO 2. Tal fato reforça nossa hipótese de que possa existir uma relação entre expressão de DIDO $2 \mathrm{e}$ progressão da LMC, embora estudos adicionais, incluindo o entendimento da função de DIDO 2, seriam necessários nesse sentido.

Os índices de Sokal e Euro são insuficientes para demonstrar o impacto relativo dos grupos de risco em relação ao tratamento e sobrevivência frente ao uso dos inibidores de tirosina-quinase. O índice EUTOS é o que tem demonstrado ser mais equilibrado em predizer a resposta citogenética dos pacientes frente ao uso dos TKIs (YAHNG et al., 2014; HASFORD, et al., 2011). Assim sendo, como nossos resultados demonstram uma possível modulação de expressão de DIDO pelos inibidores de TK, seria útil correlacionar a expressão desse gene com outros índices prognósticos, como o EUTOS, por exemplo, que predizem melhor do que o índice de Sokal a resposta dos pacientes ao tratamento com TKIs. 
O cálculo desse índice não foi ainda realizado pois muitas das amostras usadas no presente estudo são do biorrepositório do laboratório de hematologia da FCFRP-USP. Dessa forma, nem todos os dados dos pacientes necessários para esse cálculo estavam disponíveis.

A maioria dos pacientes aqui estudados apresentou transcritos do gene $B C R$ $A B L 1$ com as junções b2a2 (também nomeada por e13a2) e/ou b3a2 (também nomeada por e14a2), que dão origem à proteína Bcr-Abl de 210 kDa (MELO, 1996). No entanto, alguns pacientes com LMC têm coexistindo com os transcritos b2a2 e b3a2 os transcritos e1a2 (éxon 1 de $B C R$ e éxon a2 de $A B L 1$ ), que dão origem a proteína Bcr-Abl de 190 kDa (VERMA et al., 2009), ainda que essa proteína seja mais comum nos pacientes com leucemia linfoblástica aguda. Uma pequena porção dos pacientes com LMC apresenta, também, transcritos e19a2 (éxon 19 de BCR e éxon a2 de $A B L 1$ ) (OSMAN et al. 2010).

A frequência de transcritos parece variar de acordo com a região geográfica pesquisada. Osman et al. (2010) estudaram 46 pacientes diagnosticados com LMC no Sudão e, dentre esses pacientes, 53,5\% apresentou transcritos b2a2 e 41,9\% apresentou transcritos b3a2, ao passo que uma pequena minoria apresentou concomitantemente os transcritos b2a2 e b3a2, ou então apresentou transcritos b2a2, tanto quanto b3a2 e e19a2. No Brasil, um estudo realizado no Rio de Janeiro no ano 2000, com 28 pacientes ao diagnóstico da LMC, encontrou que $43 \%$ dos pacientes apresentou transcritos b3a2, 32\% apresentou tanto transcritos b2a2 quanto transcritos $\mathrm{b} 3 \mathrm{a} 2,18 \%$ apresentou transcritos b2a2, enquanto $7 \%$ não apresentou nenhum transcrito (BARBOZA et al., 2000).

Dessa forma, assim como o estudo realizado por Barboza et al. (2000), nosso trabalho sugere que na população brasileira a frequência de pacientes que apresentam tanto transcritos b2a2 quanto b3a2 parece ser mais significativa que em outros lugares. O presente estudo mostra, ainda, que uma grande parcela dos pacientes estudados não apresentou nenhum dos transcritos pesquisados. Nesse contexto, é importante ressaltar que, dentre os 20 pacientes que não apresentaram nenhum tipo de transcrito, 12 estavam em RCC. Uma vez que pacientes em RCC não apresentam células Ph positivas (AN; TIWARI; SUN, 2010), isso poderia justificar a ausência de transcritos.

No caso dos 8 pacientes restantes que não apresentaram nenhum dos dois tipos de transcritos aqui pesquisados, seria útil, também, a pesquisa de transcritos 
e1a2 e e19a2. É importante realçar, ainda, que dentre os pacientes estudados que apresentaram RCC, 3 pacientes apresentaram tanto transcritos b2a2 quanto b3a2 e 3 pacientes apresentaram transcritos b2a2, revelando que também seria importante para o presente estudo 0 acesso aos dados da resposta molecular desses pacientes, além da resposta citogenética.

\section{V.3 Discussão dos resultados da expressão das diferentes isoformas de DIDO em linhagens celulares}

A expressão gênica de DIDO 1, DIDO 2, DIDO 3, DIDO PP e DIDO PD foi menor na linhagem LAMA $84 \mathrm{R}$ do que na linhagem LAMA $84 \mathrm{~S}$. Na linhagem KCL $22 \mathrm{R}$ a expressão de DIDO 2, DIDO PP e DIDO $P D$ foi também menor do que na linhagem KCL $22 \mathrm{~S}$. Esse resultado suporta o anteriormente discutido no grupo de pacientes de que há uma tendência de maior expressão de DIDO nos pacientes que respondem ao tratamento do que nos pacientes resistentes à terapia com Ml.

A expressão proteica de $\mathrm{Bcr}-\mathrm{Abl}$ de $210 \mathrm{kDa}$ e de fosfotirosina confirmou que as linhagens KCL $22 \mathrm{~S}, K C L 22 \mathrm{R}$, LAMA $84 \mathrm{~S}$ e LAMA $84 \mathrm{R}$ são linhagens celulares de leucemia mielóide crônica. A expressão de proteínas fosforiladas não foi diferente entre as linhagens KCL $22 \mathrm{~S}$ e KCL $22 \mathrm{R}$, mas foi menor em LAMA $84 \mathrm{~S}$ do que na LAMA 84 R. Essa diferença entre KCL 22 e LAMA 84 pode ser explicada pelo contexto celular distinto dessas linhagens. As células da linhagem $K C L 22$ carregam transcritos de $B C R-A B L 1$ com a junção b2a2 (DSMZ, 2015b), enquanto que as células da linhagem LAMA 84 carregam transcritos com a junção b3a2 (DSMZ, 2015a).

Os transcritos b2a2 e b3a2 se diferem no tamanho (b3a2 possui 75 pares de base a mais que b2a2) e também geram proteínas com aminoácidos diferentes, uma vez que b2a2 possui ácido glutâmico e b3a2 possui lisina na região correspondente ao ponto de fusão do gene $B C R-A B L 1$; tais diferenças sugerem que fenótipos diferentes de LMC podem ser gerados (DEININGER; GOLDMAN; MELO, 2000).

Quando tratadas por $4 \mathrm{~h}$ com $\mathrm{Ml}$, as linhagens $\mathrm{KCL} 22 \mathrm{~S}, \mathrm{KCL} 22 \mathrm{R}$, LAMA 84 $\mathrm{S}$ e LAMA $84 \mathrm{R}$ apresentaram aumento de expressão de DIDO 1 quando comparadas aos controles. Portanto, os inibidores de tirosina-quinase parecem modular a expressão desse gene e, como já discutido mais detalhadamente para o 
grupo de pacientes, tal fato pode ser devido à relação existente entre DIDO 1 e 0 desencadeamento do processo apoptótico.

A expressão de DIDO 2 também aumentou em KCL 22 S, KCL 22 R e LAMA $84 \mathrm{R}$ após $4 \mathrm{~h}$ de tratamento com mesilato de imatinibe, embora não tenha se alterado de forma relevante em LAMA 84 S. A expressão de DIDO 3, todavia, foi menor nas linhagens $\mathrm{KCL} 22 \mathrm{~S}$ e $\mathrm{KCL} 22 \mathrm{R}$ após $4 \mathrm{~h}$ de tratamento com $\mathrm{MI}$, enquanto nas linhagens LAMA 84 S e LAMA $84 \mathrm{R}$ a expressão de DIDO 3 não se alterou após $4 \mathrm{~h}$ de tratamento com esse inibidor de tirosina-quinase.

Esses resultados sugerem, assim como anteriormente observado para o grupo de pacientes, que os inibidores de tirosina-quinase modulam positivamente a expressão dos genes DIDO 2 e DIDO 3, mas tal modulação parece ser particularmente importante para DIDO 1, uma vez que o aumento da expressão desse gene foi observado em todas as linhagens sensíveis e resistentes estudadas, enquanto que as alterações de expressão de DIDO 2 e DIDO 3 foram variáveis.

Tal fato leva a sugerir, novamente, que DIDO 2 e DIDO 3 possuem funções ainda não esclarecidas na leucemia mieloide crônica, que provavelmente são diferentes das relatadas na literatura. Em contrapartida, a modulação mais evidente da expressão de DIDO 1 pelos TKIs pode estar relacionada ao seu papel já descrito no desencadeamento da apoptose.

Frente a esse fato, ao se comparar a expressão de DIDO 1 entre as linhagens KCL 22 S e KCL 22 R, observa-se que a expressão desse gene foi maior na linhagem KCL $22 \mathrm{~S}$ do que em KCL $22 \mathrm{R}$ após $4 \mathrm{~h}$ de tratamento com Ml, o que sugere, outra vez, que tais alterações nos níveis de expressão de DIDO 1 podem estar relacionadas com a resistência à terapia com o mesilato de imatinibe. Em contrapartida, o aumento da expressão de DIDO 1 após $4 \mathrm{~h}$ de tratamento com $\mathrm{MI}$ foi proporcional entre as linhagens LAMA $84 \mathrm{~S}$ e LAMA $84 \mathrm{R}$. Isso pode ser explicado pelas diferenças de contexto celular entre as linhagens KCL 22 e LAMA 84, principalmente com relação ao tipo de transcrito de $B C R-A B L 1$ que cada uma carrega.

Um estudo realizado por Sharma et al. (2010) demonstrou que pacientes com LMC que carregavam os transcritos com a junção b2a2 alcançaram resposta citogenética completa ou parcial à terapia com mesilato de imatinibe mais frequentemente do que os pacientes que carregavam transcritos com a junção b3a2. Em outro estudo, de Lemos et al. (2005) demonstraram que após 6 meses de 
tratamento com mesilato de imatinibe, pacientes com transcritos b2a2 apresentaram taxa menor de expressão da proteína Bcr-Abl do que pacientes com transcritos b3a2. Tais achados podem explicar, pelo menos em parte, porque as linhagens apresentaram diferentes resultados.

Nossos resultados demonstram, portanto, que DIDO 1 parece ser importante na LMC no contexto do tratamento com os inibidores de tirosina-quinase, possivelmente devido sua associação com o processo apoptótico. As isoformas DIDO 1 e 2 parecem ter relação com a progressão da fase crônica para as fases avançadas. A isoforma DIDO 3 parece não estar tão envolvida na fisiopatologia, progressão da doença ou resistência à apoptose na LMC.

Dessa forma, as diferentes isoformas de DIDO parecem ter papéis distintos quanto ao envolvimento na leucemia mielóide crônica. 
VI. Conclusões 
- As diferentes isoformas de DIDO parecem exercer funções distintas na leucemia mielóide crônica;

- O tratamento de pacientes e linhagens $B C R-A B L 1$ positivas com inibidores de tirosina-quinase aumenta expressão de DIDO 1;

- As isoformas DIDO 1 e 2 parecem ter relação com a progressão da fase crônica para as fases avançadas;

- A isoforma DIDO 3 parece não estar tão envolvida na fisiopatologia, progressão da doença ou resistência à apoptose na LMC. 
VII. Referências 
ALLAN, N. C. Therapeutic options in chronic myeloid leukaemia. Blood Reviews, v. 3, n. 1, p. 45-52, 1989.

AMARANTE-MENDES, G. P.; NAEKYUNG, K. C.; LIU, L. et al. Bcr-Abl exerts its antiapoptotic effect against diverse apoptotic stimuli through blockage of mitochondrial release of cytochrome $\mathrm{C}$ and activation of caspase-3. Blood, v. 91, n. 5, p. 1700-1705, 1998.

ANDERSSON, R.; SANDELIN, A.; DANKO, C. G. A unified architecture of transcriptional regulatory elements. Trends in Genetics, 2015. doi: http://dx.doi.org/10.1101/019844.

AN, X.; TIWARI, A. K.; SUN, Y. BCR-ABL tyrosine kinase inhibitors in the treatment of Philadelphia chromosome positive chronic myeloid leukemia: A review. Leukemia Research, v.34, p. 1255-1268, 2010.

APPERLEY, J. F. Part I: mechanisms of resistance to imatinib in chronic myeloid leukaemia. Lancet Oncology, v. 8, p. 1018-1029, 2007.

ATCC $^{\circledR}$. Products Characteristics HL-60 (ATCC $^{\circledR}$ CCL-240 ${ }^{\mathrm{TM}}$ ). Disponível em: <http://www.atcc.org/Products/All/CCL-240.aspx\#characteristics>. Acesso em: 11 maio 2015.

BACCARANI, M.; CORTES, J.; PANE, F. et al. Chronic myeloid leukemia: an update of concepts and management recommendations of European Leukemia Net. Journal of Clinical Oncology, v. 27, n. 35, p. 6041-6051, 2009.

BACCARANI, M.; SAGLIO, G.; GOLDMAN, J. et al. Evolving concepts in the management of chronic myeloid leukemia. Recommendations from an expert panel on behalf of the European Leukemia Net. Blood, v. 108, n. 6, p. 1809-1820, 2006.

BALBANOV, S.; BRAIG, M.; BRÜMMENDORF, T. H. Current aspects in resistance against tyrosine kinase inhibitors in chronic myelogenous leukemia. Drug Discovery Today: Technologies, v. 11, p. 89-99, 2014.

BARBOZA, L. P.; SOUZA, J. M.; SIMÕES, F. V. et al. Análise dos transcritos da translocação $\mathrm{t}(9 ; 22)$ em Leucemia Mielóide Crônica. Revista Brasileira de Hematologia e Hemoterapia, v. 22, n. 2, p. 89-98, 2000. 
BAUM, K. J.; REN, R. Effect of Ras inhibition in hematopoiesis and BCR/ABL leukemogenesis. Journal of Hematology \& Oncology, v.1, n. 5, 2008.

BEWRY, N. N.; NAIR, R. R.; EMMONS, M. F. et al. Stat3 contributes to resistance toward Bcr-Abl inhibitors in a bone marrow microenvironment model of drug resistance. Molecular Cancer Therapeutics, v. 7, n. 10, p. 3169-3175, 2008.

BRAIG, S.; BOSSERHOFF, A. K. Death inducer-obliterator 1 (Dido1) is a BMP target gene and promotes BMP-induced melanoma progression. Oncogene, v. 32, n. 7, p. 837-848, 2013.

BRUMATTI, G., WEINLICH, R., CHEHAB, C. F. et al. Comparison of the antiapoptotic effects of $\mathrm{Bcr}-\mathrm{Abl}, \mathrm{Bcl}-2$ and $\mathrm{Bcl}-\mathrm{x}(\mathrm{L})$ following diverse apoptogenic stimuli. FEBS Letters, v. 541, p. 57-63, 2003.

von BUBNOFF, N.; DUYSTER, J. Chronic Myelogenous Leukemia - Treatment and Monitoring. Deutsches Ärzteblatt International, v. 107, n. 7, p. 114-121, 2010.

BUENO-da-SILVA, A. E.; BRUMATTI, G.; RUSSO, F. O. et al. Bcr-Abl-mediated resistance to apoptosis is independent of constant tyrosine-kinase activity. Cell Death and Differentiation, v. 10, n. 5, p. 592-598, 2003.

de CASTRO, F. A.; PALMA, P. V.; MORAIS, F.R. et al. Immunological effects of interferon-alpha on chronic myelogenous leukemia. Leukemia \& Lymphoma, v. 44, n. 12, p.2061-2067, 2003.

CHAI, S. K.; NICHOLS, G. L.; ROTHMAN, P. Constitutive activation of JAKs and STATs in BCR-Abl-expressing cell lines and peripheral blood cells derived from leukemic patients. Journal of Immunology, v. 159, n. 10, p. 4720-4728, 1997.

CHEREDA, B.; MELO, J. V. Natural course and biology of CML. Annals of Hematology, v. 94, n. 2, p. 107-121, 2015.

CORSO, A.; LAZZARINO, M.; MORRA, E. et al. Chronic myelogenous leukemia and exposure to ionizing radiation - a retrospective study of 443 patients. Annals of Hematology, v. 70, n. 2, p. 79-82, 1995. 
CHRONIC MYELOID LEUKEMIA TRIALISTS' COLLABORATIVE GROUP. Interferon alfa versus chemotherapy for chronic myeloid leukemia: a meta-analysis of seven randomized trials: Chronic Myeloid Leukemia Trialists' Collaborative Group. Journal of the National Cancer Institute, v. 89, n. 21, p. 1616-1620, 1997.

CILLONI, D.; SAGLIO, G. CML: a model for targeted therapy. Best Practice \& Research Clinical Haematology, v. 22, p. 285-294, 2009.

CORBIN, A. S.; BUCHDUNGER, E.; PASCAL, F. et al. Analysis of the structural basis of specificity of inhibition of the Abl kinase by STI571. Journal of Biological Chemistry, v. 277, n. 35, p. 32214-32219, 2002.

le COUTRE, P.; TASSI, E.; VARELLA-GARCIA, M. et al. Induction of resistance to the Abelson inhibitor STI571 in human leukemic cells through gene amplification. Blood, v. 95, n. 5, p. 1758-1766, 2000.

DALEY, G. Q.; VAN ETTEN, R. A.; BALTIMORE, D. Induction of chronic myelogenous leukemia in mice by the $\mathrm{P} 210 \mathrm{bcr} / \mathrm{abl}$ gene of the Philadelphia chromosome. Science, v. 247, n. 4944, p. 824-830, 1990.

DEININGER, M. W. N.; GOLDMAN, J. M.; MELO, J. V. The molecular biology of chronic myeloid leukemia. Blood, v. 96, n. 10, p. 3343-3356, 2000.

DEININGER, M. W.; VIEIRA, S.; MENDIOLA, R. et al. BCR-ABL tyrosine kinase activity regulates the expression of multiple genes implicated in the pathogenesis of chronic myeloid leukemia. Cancer Research, v. 60, n. 7, p. 2049-2055, 2000.

DEININGER, M.; O'BRIEN, S. G.; GUILHOT, F. et al. International randomized study of interferon vs. STI571 (IRIS) 8-year follow up: sustained survival and low risk for progression of events in patients with newly diagnosed chronic myeloid leukemia in chronic phase (CML-CP) treated with imatinib. Blood, v. 114, 2009.

DEWALD, G. W.; SCHAD, C. R.; LILLA, V. C. et al. Frequency and photographs of HGM11 chromosome anomalies in bone marrow samples from 3,996 patients with malignant hematologic neoplasms. Cancer Genetics and Cytogenetics, v. 68, p. 60-69, 1993.

DRUKER, B. J.; LYDON, N. B. Lessons learned from the development of an abl tyrosine kinase inhibitor for chronic myelogenous leukemia. Journal of Clinical Investigation, v. 105, n. 1, p. 3-7, 2000. 
DRUKER, B. J.; GUILHOT, F.; O'BRIEN, S. G. et al. Five-year follow-up of patients receiving imatinib for chronic myeloid leukemia. New England Journal of Medicine, v. 355, n. 23, p. 2408-2417, 2006.

Leibniz Institute DSMZ-German Colletion of Microorganisms and Cell Cultures (DSMZ). Catologue Human and Animal Cell Lines, LAMA-84. Disponível em: $<$ http://www.dsmz.de/catalogues/details/culture/ACC-

168.html?tx_dsmzresources_pi5\%5BreturnPid\%5D=192>. Acesso em: 11 maio 2015a.

Leibniz Institute DSMZ-German Colletion of Microorganisms and Cell Cultures (DSMZ). Catologue Human and Animal Cell Lines, KCL-22. Disponível em: <http://www.dsmz.de/catalogues/details/culture/ACC-

519.html?tx_dsmzresources_pi5\%5BreturnPid\%5D=192>. Acesso em: 11 maio 2015b.

EUROPEAN LEUKEMIA-NET - BACCARANI (Project 4). CML-Score. 2010. Disponível em: <http://www.leukemianet.org/content/leukemias/cml/cml_score/index_eng.html>. Acesso em: 4 dez 2014.

FERREIRA, F. A.; OLIVEIRA, G. L. V. TOGNON, R. et al. Apoptosis-Related Gene Expression Profile in Chronic Myeloid Leukemia Patients after Imatinib Mesylate and Dasatinib Therapy. Acta Haematologica, v. 133, p. 354-364, 2015.

FÜTTERER, A.; CAMPANERO, M. R.; LEONARDO, E. et al. Dido gene expression alterations are implicated in the induction of hematological myeloid neoplasms. Journal of Clinical Investigation, v. 115, n. 9, p. 2351-2362, 2005.

FÜTTERER, A.; RAYA, A.; LLORENTE, M. et al. Ablation of Dido3 compromises lineage commitment of stem cells in vitro and during early embryonic development. Cell Death and Differentiation, v. 19, p. 132-143, 2012.

GALLAGHER, R.; COLLINS, S.; TRUJILLO, J. et al. Characterization of the continuous, differentiating myeloid cell line (HL-60) from a patient with acute promyelocytic leukemia. Blood, v. 54, n. 3, p. 713-733, 1979.

GALTON, D. A. Myleran in chronic myeloid leukaemia; results of treatment. Lancet, v. 264 , n. 6753 , p. $208-213,1953$.

GATCHALIAN, J.; FÜTTERER, A.; ROTHBART, S. B. et al. Dido3 PHD Modulates Cell Differentiation and Division. Cell Reports, v. 4, n. 1, p. 148-158, 2013. 
GARCÍA-DOMINGO, D.; LEONARDO, E.; GRANDIEN, A. et al. DIO-1 is a gene involved in onset of apoptosis in vitro, whose misexpression disrupts limb development. Proceedings of the National Academy of Sciences of the United States of America, v. 96, p. 7992-7997, 1999.

GARCÍA-DOMINGO, D.; RAMÍREZ, D.; BUITRAGO, G. G. et al. Death InducerObliterator 1 Triggers Apoptosis after Nuclear Translocation and Caspase Upregulation. Molecular and Cellular Biology, v. 23, n. 9, p. 3216-3225, 2003.

GORRE, M. E.; MOHAMMED, M.; ELLWOOD, K. et al. Clinical resistance to STI-571 cancer therapy caused by BCR-ABL gene mutation or amplification. Science, v. 293, n. 5531, p. 876-880, 2001.

GRAHAM, S. V.; TINDLE, R. W.; BIRNIE, G. D. Variation in MYC gene amplification and expression in sublines of HL60 cells. Leukemia Research, v. 9, n. 2, p. 239247, 1985.

de GROOT R. P.; RAAIJMAKERS, J. A.; LAMMERS, J. W. et al. STAT5 Dependent CyclinD1 and Bcl-xL expression in Bcr-Abltransformed cells. Molecular Cell Biology Research Communications, v. 3, n. 5, p. 299-305, 2000.

HANDA, H.; HEGDE, U. P.; KOTELNIKOV, V. M. et al. Bcl-2 and c-myc expression, cell cycle kinetics and apoptosis during the progression of chronic myelogenous leukemia from diagnosis to blastic phase. Leukemia Research, v. 21, n. 6, p. 479489, 1997.

HASFORD, J.; BACCARANI, M.; HOFFMANN, V. et al. Predicting complete cytogenetic response and subsequent progression-free survival in 2060 patients with CML on imatinib treatment: the EUTOS score. Blood, v. 118, n. 3, p. 686-692, 2011.

HEHLMANN, R.; HOCHHAUS, A.; BACCARANI, M. Chronic myeloid leukaemia. The Lancet, v. 370, p. 342-350, 2007.

HOELBL, A.; SCHUSTER, C.; KOVACIC, B. et al. Stat5 is indispensable for the maintenance of bcr/abl-positive leukaemia. EMBO Molecular Medicine, v. 2, n. 3, p. 98-110, 2010.

HORITA, M.; ANDREU, E. J.; BENITO, A. et al. Blockade of the Bcr-Abl kinase activity induces apoptosis of chronic myelogenous leukemia cells by suppressing signal transducer and activator of transcription 5-dependent expression of Bcl-xL. Journal of Experimental Medicine, v. 191, n. 6, p. 977-984, 2000. 
JABBOUR, E.; CORTES, J. E.; KANTARJIAN, H. M. Molecular monitoring in chronic myeloid leukemia: response to tyrosine kinase inhibitors and prognostic implications.

Cancer, v. 112, n. 10, p. 2112-2118, 2008.

JABBOUR, E.; KANTARJIAN, H. Chronic myeloid leukemia: 2014 update on diagnosis, monitoring, and management. American Journal of Hematology, v. 89, n. 5, p. 547-556, 2014.

JEMAL, A.; SIEGEL, R.; XU, J. et al. Cancer Statistics, 2010. CA - A Cancer Journal for Clinicians, v. 60, n.5, p. 277-300, 2010.

KANTARJIAN, H.M.; KEATING, M.J.; TALPAZ, M. et al. Chronic myelogenous leukemia in blast crisis. Analysis of 242 patients. American Journal of Medicine, v. 83, n. 3, p. 445-454, 1987.

KANTARJIAN, H. M.; O'BRIEN, S.; CORTES, J. E. et al. Complete cytogenetic and molecular responses to interferon-alpha-based therapy for chronic myelogenous leukemia are associated with excellent long-term prognosis. Cancer, v. 97, n. 4, p. 1033-1041, 2003.

KLEJMAN, A.; RUSHEN, L.; MORRIONE, A. et al. Phosphatidylinositol-3 kinase inhibitors enhance the anti-leukemia effect of STI571. Oncogene, v. 21, n. 38, p. 5868-5876, 2002.

de LEMOS, J. A. R.; de OLIVEIRA, C. M.; SCERNI, A. C. C. et al. Differential molecular response of the transcripts B2A2 and B3A2 to imatinib mesylate in chronic myeloid leukemia. Genetics and Molecular Research, v. 4, n. 4, p. 803-811, 2005.

MASTON, G. A.; EVANS, S. K.; GREEN, M. R. Transcriptional Regulatory Elements in the Human Genome. Annual Review of Genomics and Human Genetics, v. 7, p. 29-59, 2006.

MELO, J. V. The diversity of BCR-ABL fusion proteins and their relationship to leukemia phenotype. Blood, v. 88, n. 7, p. 2375-2384, 1996.

MENDIZABAL, A. M.; GARCIA-GONZALEZ, P.; LEVINE, P.H. Regional variations in age at diagnosis and overall survival among patients with chronic myeloid leukemia from low and middle income countries. Cancer Epidemiology, v. 37, n. 3, p. 247254, 2013. 
NESHAT, M. S.; RAITANO, A. B.; WANG, H. G. et al. The survival function of the Bcr-Abl oncogene is mediated by Baddependent and independent pathways: roles for phosphatidylinositol 3-kinase and Raf. Molecular Cell Biology, v. 20, n. 4, p. 1179-1186, 2000.

NOVARTIS BIOCIÊNCIAS S.A. Imatinib (Glivec ${ }^{\circledR}$ ): Revolutionising the treatment of chronic myeloid leukaemia (CML) through signal transduction inhibition. São Paulo, 2004. 1 CD.

NOWELL, P. C.; HUNGERFORD, D. A. A minute chromosome in human chronic granulocytic leukemia. Science, v. 32, n. 1, p. 497-501, 1960.

O'HARE, T.; WALTERS, D. K.; STOFFREGEN, E. P. et al. In vitro activity of Bcr-Abl inhibitors AMN107 and BMS-354825 against clinically relevant imatinib-resistant Abl kinase domain mutants. Cancer Research, v. 65, n. 11, p. 4500-4505, 2005.

OKUDA, K.; MATULONIS, U.; SALGIA, R. et al. Factor independence of human myeloid leukemia cell lines is associated with increased phosphorylation of the protooncogene Raf-1. Experimental Hematology, v. 22, n. 11, p. 1111-1117, 1994.

OSMAN, E. A. I.; HAMAD, K.; ELMULA, I. M. F. et al. Frequencies of BCR-ABL1 fusion transcripts among Sudanese chronic myeloid leukaemia patients. Genetics and Molecular Biology, v. 33, n. 2, p. 229-231, 2010.

PFIRRMANN, M.; LAUSEKER, M.; HOFFMANN, V. S. et al. Prognostic scores for patients with chronic myeloid leukemia under particular consideration of competing causes of death. Annals of Hematology, v. 94 , n. 2, p. 209-218, 2015.

QUINTÁS-CARDAMA, A.; CORTES, J. E. Chronic Myeloid Leukemia: Diagnosis and Treatment. Mayo Clinic Proceedings, v. 81, n. 7, p. 973-988, 2006.

RAITANO, A. B.; HALPERN, J. R.; HAMBUCH, T. M. et al. The Bcr-Abl leukemia oncogene activates Jun kinase and requires Jun for transformation. Proceedings of National Academy of Sciences of United States of America, v. 92, n. 25, p. 11746-11750, 1995.

REAVIE, L.; BUCKLEY, S. M.; LOIZOU, E. et al. Regulation of c-Myc ubiquitination controls chronic myelogenous leukemia initiation and progression. Cancer Cell, v. 23, n. 3, p. 362-375, 2013. 
REUTHER, J. Y.; REUTHER, G. W.; CORTEZ, D. et al. A requirement for NFkappaB activation in Bcr-Abl mediated transformation. Genes \& Development, v. 12, n. 7, p. 968-981, 1998.

ROSENHAHN, J.; WEISE, A.; MICHEL, S. et al. Cytogenetic characterisation and proteomic profiling of the Imatinib-resistant cell line KCL22-R. International Journal of Oncology, v. 31, p. 121-128, 2007.

SACHA, T. Imatinib in Chronic Myeloid Leukemia: an Overview. Mediterranean Journal of Hematology and Infectious Diseases, v. 6, n. 1, 2014. doi: 10.4084/MJHID.2014.007.

SALOMONI, P.; CONDORELLI, F.; SWEENEY, S. M. et al. Versatility of BCR/ABLexpressing leukemic cells in circumventing proapoptotic BAD effects. Blood, v. 96, n. 2, p. 676-684, 2000.

SANTOS, F. P. S.; KANTARJIAN, H.; QUINTÁS-CARDAMA, A. et al. Evolution of Therapies for Chronic Myelogenous Leukemia. Cancer Journal, v. 17, n. 6, p. 465476, 2011.

SCHINDLER, T.; BORNMANN, W.; PELLICENA, P. et al. Structural Mechanism for STI-571 Inhibition of Abelson Tyrosine Kinase. Science, v. 289, n. 5486, p. 19381942, 2000.

SCHOCH, C.; SCHNITTGER, S.; BURSCH, S. et al. Comparison of chromosome banding analysis, interphase- and hypermetaphase-FISH, qualitative and quantitative PCR for diagnosis and for follow-up in chronic myeloid leukemia: a study on 350 cases. Leukemia, v. 16, n. 1, p. 53-59, 2002.

SCORE, J.; CALASANZ, M. J.; OTTMAN, O. et al. Analysis of genomic breakpoints in p190 and p210 BCR-ABL indicate distinct mechanisms of formation. Leukemia, v. 24, n. 10, p. 1742-1750, 2010.

SHAH, N. P.; NICOLL, J. M.; NAGAR, B. et al. Multiple BCR-ABL kinase domain mutations confer polyclonal resistance to the tyrosine kinase inhibitor imatinib (STI571) in chronic phase and blast crisis chronic myeloid leukemia. Cancer Cell, v. 2, p. 117-125, 2002.

SHAH, N. P.; TRAN, C.; LEE, F. Y. et al. Overriding imatinib resistance with a novel ABL kinase inhibitor. Science, v. 305, p. 399-401, 2004. 
SHARMA, P.; KUMAR, L.; MOHANTY, S. et al. Response to Imatinib mesylate in chronic myeloid leukemia patients with variant BCR-ABL fusion transcripts. Annals of Hematology, v. 89, n. 3, p. 241-247, 2010.

SILVER, R. T.; WOOLF, S. H.; HEHLMANN, R. et al. An evidence-based analysis of the effect of busulfan, hydroxyurea, interferon, and allogeneic bone marrow transplantation in treating the chronic phase of chronic myeloid leukemia: developed for the American Society of Hematology. Blood, v. 94, n. 5, p. 1517-1536, 1999.

SKORSKI, T.; BELLACOSA, A.; NIEBOROWSKA-SKORSKA, M. et al. Transformation of hematopoietic cells by $\mathrm{BCR} / \mathrm{ABL}$ requires activation of a $\mathrm{Pl}-3 \mathrm{k} / \mathrm{Akt}-$ dependent pathway. EMBO Journal, v. 16, n. 20, p. 6151-6161, 1997.

SOKAL, J. E.; COX, E. B.; BACCARANI, M. et al. Prognostic discrimination in "goodrisk" chronic granulocytic leukemia. Blood, v. 63, n. 4, p. 789-799, 1984.

STEELMAN, L. S.; POHNERT, S. C.; SHELTON, J. G. et al. JAK/STAT, Raf/MEK/ERK, PI3K/Akt and BCR-ABL in cell cycle progression and leukemogenesis. Leukemia, v. 18, n. 2, p. 189-218, 2004.

STUPPIA, L.; CALABRESE, G.; PEILA, R. et al. p53 loss and point mutations are associated with suppression of apoptosis and progression of $\mathrm{CML}$ into myeloid blastic crisis. Cancer Genetics and Cytogenetics, v. 98, n. 28, p. 28-35, 1997.

TAYLOR, R. C.; CULLEN, S. P.; MARTIN, S. J. Apoptosis: controlled demolition at the cellular level. Molecular Cell Biology, v. 9, p. 231-241, 2008.

TRACHANA, V.; VAN WELY, K. H. M.; GUERRERO, A. A. et al. Dido disruption leads to centrosome amplification and mitotic checkpoint defects compromising chromosome stability. Proceedings of the National Academy of Sciences of the United States of America, v. 104, n. 8, p. 2691-2696, 2007.

TSIFTSOGLOU, A. S.; ROBINSON, S. H. Differentiation of leukemic cell lines: A review focusing on murine erythroleukemia and human hl-60 cells. International Joural of Cell Cloning, v. 3, n. 6, p. 349-366, 1985.

VERMA, D.; KANTARJIAN H. M.; JONES, D. et al. Chronic myeloid leukemia (CML) with P190BCR-ABL: analysis of characteristics, outcomes, and prognostic significance. Blood, v. 114, n. 11, p. 2232-2235, 2009. 
WANG, Y.; CHEN, Y.; CHEN, Z. et al. Gambogic acid induces death inducerobliterator 1-mediated apoptosis in Jurkat T cells. Acta Pharmacologica Sinica, v. 29, n. 3, p. 349-354, 2008.

WEISBERG, E.; MANLEY, P. W.; BREITENSTEIN, W. et al. Characterization of AMN107, a selective inhibitor of native and mutant Bcr-Abl. Cancer Cell, v. 7, n. 2, p. 129-141, 2005.

WU, J.; MENG, F.; KONG, L. Y. et al. Association Between Imatinib-Resistant BCR$A B L$ Mutation-Negative Leukemia and Persistent Activation of LYN Kinase. Journal of the National Cancer Institute, v. 100, n. 13, p. 926-939, 2008.

YAHNG, S. A.; JANG, E. J.; CHOI, S. Y. et al. Prognostic discrimination for early chronic phase chronic myeloid leukemia in imatinib era: comparison of Sokal, Euro, and EUTOS scores in Korean population. International Journal of Hematology, v. 100, n. 2, p. 132-140, 2014.

YANG, K.; FU, L. Mechanisms of resistance to BCR-ABL TKls and the therapeuticstrategies: A review. Critical Reviews in Oncology/Hematology, v. 93, p. 277-292, 2015.

ZHAO, J. J.; CHENG, H.; JIA, S.; et al. The p110 alpha isoform of PI3K is essential for proper growth factor signaling and oncogenic transformation. Proceedings of National Academy of Sciences of United States of America, v. 103, n. 44, p. 16296-16300, 2006. 


\section{ANEXO I. Aprovação do Comitê de Ética em Pesquisa da Faculdade de Ciências Farmacêuticas de Ribeirão Preto-USP.}

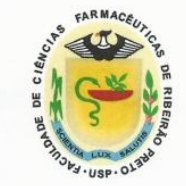

Of. CEP/FCFRP n ${ }^{\circ} .001 / 2015$

kms

\section{UNIVERSIDADE DE SÃO PAULO \\ Faculdade de Ciências Farmacêuticas de Ribeirão Preto \\ Comitê de Ética em Pesquisa}

À

Pós-graduanda Maria Gabriela Berzoti Coelho

Orientadora: Prof ${ }^{a}$. Dr ${ }^{\text {a }}$. Fabíola Attié de Castro

Departamento de Análises Clínicas, Toxicológicas e Bromatológicas

FCFRP/USP

Prezada Pesquisadora,

Informamos que o Comitê de Ética em Pesquisa da FCFRP aprovou, em sua $132^{\circ}$ reunião ordinária, realizada em $02 / 07 / 2014$, o projeto de pesquisa intitulado "EXPRESSÃO DE DIDO EM CÉLULAS BCR-ABL+: ASSOCIAÇÃO COM RESISTÊNCIA À APOPTOSE E FISIOPATOLOGIA DA LEUCEMIA MIELÓIDE CRÔNICA", apresentado por Vossa Senhoria a este Comitê, Protocolo CEP/FCFRP $\mathbf{n}^{\circ}$. 356. Segue anexa a declaração da instituição coparticipante aprovando a realização do projeto.

Lembramos que, de acordo com a Resolução 466/2012, item IV.5, letra d, o TCLE deverá "ser elaborado em duas vias, rubricadas em todas as suas páginas e assinadas, ao seu término, pelo convidado a participar da pesquisa, ou por seu representante legal, assim como pelo pesquisador responsável, ou pela(s) pessoa(s) por ele delegada(s), devendo as páginas de assinaturas estar na mesma folha. Em ambas as vias deverão constar o endereço e contato telefônico ou outro, dos responsáveis pela pesquisa e do CEP local".

Informamos que deverá ser encaminhado ao CEP/FCFRP o relatório

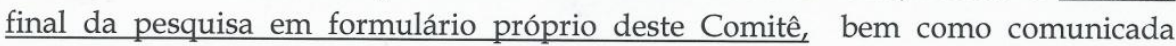
qualquer alteração, intercorrência ou interrupção do mesmo, tais como eventos adversos e eventuais modificações no protocolo ou nos membros da equipe, através da interposição de emenda na Plataforma Brasil.

Atenciosamente,

$$
\text { Omimachadi. }
$$

PROFa. DRa. ClENI MARA MARZOCCHI MACHADO

Coordenadora do CEP/FCFRP

Avenida do Café S/NN - Monte Alegre - CEP 14040-903 - Ribeirão Preto - SP

Comitê de Ética em Pesquisa - cep@fćrp.usp.br

Fone: (16) 3602-4213 ou 3602-4216 - Fax: (16) 3602-4892 


\section{ANEXO II. Concordância do Comitê de Ética do Hospital das Clínicas da Faculdade de Medicina de Ribeirão Preto-USP.}

Projeto de pesquisa: "EXPRESSÃO DE DIDO EM CÉLULAS BCR-ABL+: ASSOCIAÇÃO COM RESISTÊNCIA À APOPTOSE E FISIOPATOLOGIA DA LEUCEMIA MIELÓIDE CRÕNICA"

Pesquisador responsável: Maria Gabriela Berzoti Coelho

Instituição Proponente: Faculdade de Ciências Farmacêuticas de Ribeirão Preto - USP

"O CEP do HC e da FMRP-USP concorda com o parecer ético emitido pelo CEF da Instituição Proponente, que cumpre as Resoluções Éticas Brasileiras, erı especial a Resolução CNS 466/12. Diante disso, o HCFMRP-USP, como instituição co-participante do referido projeto de pesquisa, está ciente de suas co-responsabilidades e de seu compromisso no resguardo da segurança e bemestar dos sujeitos desta pesquisa, dispondo de infra-estrutura necessária para a garantia de tal segurança e bem-estar".

Ciente e de acordo:

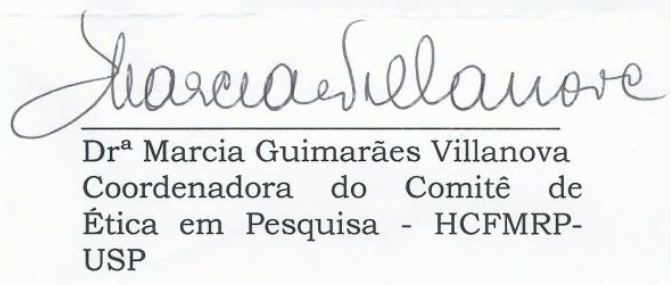

USP

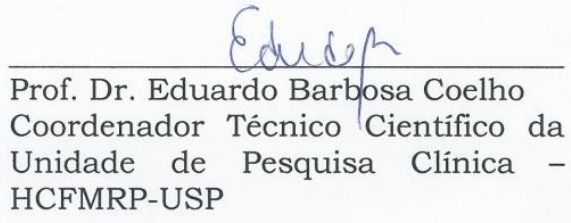

Comitê de Ética em Pesquisa do HCRP e FMRP-USP FWA-00002733; IRB-00002186 Registro Plataforma Brasil/CONEP $n^{\circ} 5440$ (016) $3602-2228$
cep@hcrp.usp.br
Campus Universitário - Monte Alegre 14048-900 Ribeirão Preto SP

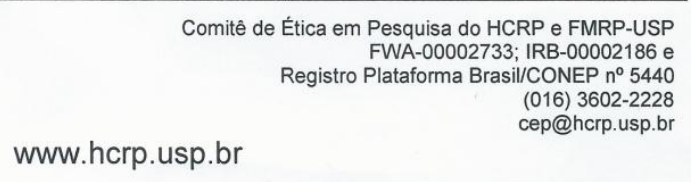

www.hcrp.usp.br 
ANEXO III. Termo de Consentimento Livre e Esclarecido (Pacientes).

\author{
TERMO DE CONSENTIMENTO LIVRE E ESCLARECIDO \\ (Participante de Pesquisa: Paciente)
}

Nome do Paciente:

Idade:

Responsável Legal (se necessário):

RG do paciente:

Título do Projeto de pesquisa: "Expressão de DIDO em células BCR-ABL+: associação com resistência à apoptose e Fisiopatologia da Leucemia Mielóide Crônica"

Responsável Clínico pelo Projeto: Profa. Dra. Belinda Pinto Simões, Docente de Hematologia da FMRP-USP e responsável pelo ambulatório de Hematologia.

Pesquisadoras responsáveis:

Mestranda: Maria Gabriela Berzoti Coelho (telefone: 016-981665909)

Profa. Dra. Fabíola Attié de Castro - Departamento de Análises Clínicas, Toxicológicas e Bromatológicas da FCFRP-USP (telefone: 016-36020657 e 011-981829203)

Prezado (a),

Convidamos você a participar de nossa pesquisa.

A Leucemia Mielóide Crônica leva a um aumento do número de células brancas e vermelhas do sangue. Esse aumento de células deixa o sangue mais espesso (grosso, viscoso), de modo que esse passa a circular nas veias do nosso corpo com maior dificuldade, prejudicando sua função adequada. As causas do aparecimento desta doença são desconhecidas. Por isso, essa pesquisa quer estudar quais são as alterações nas células do sangue que causam esse aumento do número de células e que fazem com que algumas pessoas desenvolvam essa doença.

Você foi admitido no Hospital das Clínicas de Ribeirão Preto para tratamento da Leucemia Mielóide Crônica e, por esse motivo, o convidamos para participar de nossa pesquisa, pois o maior conhecimento sobre essa doença poderá ajudar os pesquisadores a desenvolver melhores formas de tratamento, beneficiando, no futuro, pessoas que também possam estar doentes.

Caso você aceite, você doará $30 \mathrm{ml}$ de sangue (o que corresponde a duas colheres de sopa) que será colhido das veias do seu braço. As células do sangue serão usadas para estudar alguns de seus componentes chamados de proteínas e genes, que controlam a vida e o aumento dessas células. A colheita de seu sangue será realizada por profissionais de saúde com experiência, como enfermeiros, biomédicos ou farmacêuticos e com material descartável para que não haja riscos de contaminação. Os riscos dessa colheita serão mínimos, existindo uma pequena chance de você sentir um pouco de dor durante o 
procedimento, de aparecer inchaços roxos ou apenas inchaços em seu braço no local da colheita de sangue.

Se aceitar participar desse estudo, as células de seu sangue e seus componentes serão guardados sob a responsabilidade da Professora Fabíola Attié de Castro, na Faculdade de Ciências Farmacêuticas de Ribeirão Preto-USP. Você tem a liberdade de aceitar ou não que sua amostra seja empregada nesse estudo e que seja guardada, sem que the cause qualquer prejuízo ou punição durante o seu tratamento no Hospital das Clínicas. Além disso, gostaríamos de saber se você autoriza que a amostra do seu sangue, além de ser usada nessa pesquisa, seja guardada para ser usada em outras pesquisas sobre a mesma doença (Leucemia Mielóide Crônica). Caso seja necessária a realização de mais estudos, a pesquisadora the consultará sobre essa possibilidade se você assim desejar.

Somente os resultados da pesquisa serão divulgados, sem que seu nome apareça, ele ficará em segredo. As amostras do seu sangue e os seus dados serão também guardados em segredo pelas pesquisadoras responsáveis. As amostras e componentes de seu sangue serão identificados por números codificados e somente as pesquisadoras terão acesso. Se você quiser, podemos lhe informar sobre os resultados das pesquisas sempre que desejar, tendo a garantia de receber a resposta a qualquer pergunta ou esclarecimento de quaisquer dúvidas acerca dos procedimentos, riscos, benefícios e outros relacionados com a pesquisa.

Você não terá nenhuma despesa a mais por participar dessa pesquisa e você não será pago por doar o sangue para a pesquisa. Sua doação será voluntária. No momento, a pesquisa não lhe trará nenhum benefício, mas poderá trazer benefícios no futuro, para outras pessoas que também tenha, essa doença.

Caso aceite participar desse estudo e em algum momento quiser desistir, você também terá total liberdade para isso. Você poderá recorrer às leis vigentes no Brasil para indenização de qualquer dano que the seja causado pelo estudo. Para a sua segurança, você receberá segunda via desse termo.

$\mathrm{Eu}$, RG: declaro que concordo em ser voluntário e autorizo a retirada de $30 \mathrm{~mL}$ do meu sangue para a realização da pesquisa. Fui devidamente informado em detalhes pelos responsáveis do projeto sobre os meus direitos, que o volume de sangue retirado não causará danos, que esta pesquisa ajudará a entender o que causa o aumento do número de células do sangue nos pacientes com Leucemia Mielóide Crônica e que terei minha identidade mantida em sigilo.

Concordo em permitir que as amostras e componentes de meu sangue sejam armazenados para uso em outras pesquisas sobre a leucemia mieloide crônica, desde que novamente consultado.

Nome do doador:

Assinatura:

Ribeirão Preto, de de 
Eu, Maria Gabriela Berzoti Coelho, RG: 46.280.524-4, declaro que tudo o que foi exposto anteriormente é verdade e será devidamente cumprido.

Nome do pesquisador responsável pelo estudo: Maria Gabriela Berzoti Coelho

Assinatura:

Ribeirão Preto, de de

Se o paciente não puder assinar:

Nome do representante:

Assinatura:

Ribeirão Preto, de de

Informações importantes:

Telefone do Comitê de ética da FCFRP-USP: Fone: (16) 3602-4213. Fax: (16) 3602-4892

Endereço: FCFRP-USP, Av. do Café, s/n - Campus Universitário - Monte Alegre - Ribeirão Preto, CEP: $14049-903$

Telefone do Comitê de ética do Hospital das Clínicas de Ribeirão Preto: Fone: (16) 36022228. Fax: (16) 3633-1144

Endereço: HCFMRP-USP, Av. Bandeirantes, 3.900 - Campus Universitário - Monte Alegre Ribeirão Preto, CEP: 14.048-900 
ANEXO IV. Termo de Consentimento Livre e Esclarecido (Controles).

\section{TERMO DE CONSENTIMENTO LIVRE E ESCLARECIDO}

(Participante de Pesquisa: Grupo Controle)

Nome do Participante: Idade:

Responsável Legal (se necessários): RG do participante:

Título do Projeto de pesquisa: "Expressão de Dido em células BCR-ABL': associação com resistência à apoptose e Fisiopatologia da Leucemia Mielóide Crônica"

Responsável Clínico pelo Projeto: Profa. Dra. Belinda Pinto Simões, Docente de Hematologia da FMRP-USP e responsável pelo ambulatório de Hematologia.

\section{Pesquisadoras responsáveis:}

Mestranda: Maria Gabriela Berzoti Coelho (telefone: 016-981665909)

Profa. Dra. Fabíola Attié de Castro - Departamento de Análises Clínicas, Toxicológicas e Bromatológicas da FCFRP-USP (telefone: 016-36020657 e 011-981829203)

\section{Prezado (a),}

Convidamos você a participar de nossa pesquisa.

A Leucemia Mielóide Crônica leva a um aumento do número de células brancas e vermelhas do sangue. Esse aumento de células deixa o sangue mais espesso (grosso, viscoso), de modo que esse passa a circular nas veias do nosso corpo com maior dificuldade, prejudicando sua função adequada. As causas do aparecimento desta doença são desconhecidas. Por isso, essa pesquisa quer estudar quais são as alterações nas células do sangue que causam esse aumento do número de células e que fazem com que algumas pessoas desenvolvam essa doença.

Prezado doador voluntário, por não ser portador de Leucemia Mielóide Crônica, o convidamos para participar de nossa pesquisa, para que seja integrante de nosso grupo controle (grupo de pessoas que não apresentam a doença), pois o maior conhecimento sobre ela poderá ajudar os pesquisadores a desenvolver melhores formas de tratamento, beneficiando, no futuro, pessoas que possam estar doentes.

Caso você aceite, você doará $30 \mathrm{ml}$ de sangue (o que corresponde a duas colheres de sopa) que será colhido das veias do seu braço. As células do sangue serão usadas para estudar alguns de seus componentes chamados de proteínas e genes, que controlam a vida e o aumento dessas células. A colheita de seu sangue será realizada por profissionais de saúde com experiência, como enfermeiros, biomédicos ou farmacêuticos e com material descartável para que não haja riscos de contaminação. Os riscos dessa colheita serão mínimos, existindo uma pequena chance de você sentir um pouco de dor durante o 
procedimento, de aparecer inchaços roxos ou apenas inchaços em seu braço no local da colheita de sangue.

Se aceitar participar desse estudo, as células de seu sangue e seus componentes serão guardados sob a responsabilidade da Professora Fabíola Attié de Castro, na Faculdade de Ciências Farmacêuticas de Ribeirão Preto-USP. Você tem a liberdade de aceitar ou não que sua amostra seja empregada nesse estudo e que seja guardada, sem que lhe cause qualquer prejuízo ou punição. Além disso, gostaríamos de saber se você autoriza que a amostra do seu sangue, além de ser usada nessa pesquisa, seja guardada para ser usada em outras pesquisas sobre a mesma doença (Leucemia Mielóide Crônica). Caso seja necessária a realização de mais estudos, a pesquisadora the consultará sobre essa possibilidade se você assim desejar.

Somente os resultados da pesquisa serão divulgados, sem que seu nome apareça, ele ficará em segredo. As amostras do seu sangue e os seus dados serão também guardados em segredo pelas pesquisadoras responsáveis. As amostras e componentes de seu sangue serão identificados por números codificados e somente as pesquisadoras terão acesso. Se você quiser, podemos lhe informar sobre os resultados das pesquisas sempre que desejar, tendo a garantia de receber a resposta a qualquer pergunta ou esclarecimento de quaisquer dúvidas acerca dos procedimentos, riscos, benefícios e outros relacionados com a pesquisa.

Você não terá nenhuma despesa a mais por participar dessa pesquisa e você não será pago por doar o sangue para a pesquisa. Sua doação será voluntária. Caso aceite participar desse estudo e em algum momento quiser desistir, você também terá total liberdade para isso. Você poderá recorrer às leis vigentes no Brasil para indenização de qualquer dano que lhe seja causado pelo estudo. Para a sua segurança, você receberá segunda via desse termo.

$\mathrm{Eu}$, RG: , declaro que concordo em ser voluntário e autorizo a retirada de $30 \mathrm{~mL}$ do meu sangue para a realização da pesquisa. Fui devidamente informado em detalhes pelos responsáveis do projeto sobre os meus direitos, que o volume de sangue retirado não causará danos, que esta pesquisa ajudará a entender o que causa o aumento do número de células do sangue nos pacientes com Leucemia Mielóide Crônica e que terei minha identidade mantida em sigilo.

Concordo em permitir que as amostras e componentes de meu sangue sejam armazenados para uso em outras pesquisas sobre a leucemia mieloide crônica, desde que novamente consultado.

Nome do doador:

Assinatura:

Ribeirão Preto, de de 
Eu, Maria Gabriela Berzoti Coelho, RG: 46.280.524-4, declaro que tudo o que foi exposto anteriormente é verdade e será devidamente cumprido.

Nome do pesquisador responsável pelo estudo: Maria Gabriela Berzoti Coelho

Assinatura:

Ribeirão Preto, de de

Se o paciente não puder assinar:

Nome do representante:

Assinatura:

Ribeirão Preto, de de

Informações importantes:

Telefone do Comitê de ética da FCFRP-USP: Fone: (16) 3602-4213. Fax: (16) 3602-4892

Endereço: FCFRP-USP, Av. do Café, s/n - Campus Universitário - Monte Alegre - Ribeirão Preto, CEP: 14049-903

Telefone do Comitê de ética do Hospital das Clínicas de Ribeirão Preto: Fone: (16) 36022228. Fax: (16) 3633-1144

Endereço: HCFMRP-USP, Av. Bandeirantes, 3.900 - Campus Universitário - Monte Alegre Ribeirão Preto, CEP: 14.048-900 
ANEXO V. Termo de Consentimento Livre e Esclarecido (Biorrepositório).

\section{TERMO DE CONSENTIMENTO LIVRE E ESCLARECIDO Armazenamento de Amostras Biológicas}

O(a) Senhor(a) está sendo convidado a doar uma amostra de sangue periférico para futuras pesquisas científicas. A cada nova pesquisa com esse material, o (a) Senhor (a) será procurado para receber explicações e autorizar ou não a utilização da sua amostra já armazenada.

Caso concorde, o(a) Senhor(a) doará uma amostra de sangue periférico. A coleta deste material poderá causar desconforto local (no braço puncionado) e eventual tontura leve. Esta sua amostra e os seus dados coletados serão identificados por números sequenciais (ex: SPP113), de modo que garanta seu sigilo. Após coletada, a amostra será guardada por 10 anos em um BIORREPOSITÓRIO (banco de amostras biológicas), intitulado Biorrepositório do Laboratório de Hematologia da FCFRP, localizado no laboratório de hematologia, sala multiusuários 46A-M, segundo andar do bloco $\mathrm{M}$ da Faculdade de Ciências Farmacêuticas USP-RP em condições adequeadas de armazenamento, sob responsabilidade da Prof $\stackrel{\text { a }}{\text {. Dr }}{ }^{\mathrm{a}}$ Fabíola Attié de Castro. Ao final deste tempo de armazenamento, a amostra será jogada fora.

O(a) Senhor(a) poderá desistir de participar da pesquisa a qualquer momento. Para isso, basta entrar em contato comigo nos telefones citados no final deste documento, para que eu possa suspender o armazenamento da sua amostra, que poderá ser entregue ao/à Senhor(a), se assim desejar, ou jogada fora após seu consentimento por escrito.

Caso não concorde em doar sangue periférico ou desista de permitir que se guarde esta amostra, essa decisão não Ihe trará qualquer penalização ou prejuízo do atendimento que lhe for prestado.

A coleta deste material biológico nesse momento não trará nenhum benefício imediato para o(a) Senhor(a). Entretanto, no futuro, os dados obtidos com novas pesquisas poderão ajudar outras pessoas.

Coloco-me à disposição para Ihe fornecer o resultado da pesquisa realizada com sua amostra.

Declaro que toda nova pesquisa, utilizando sua amostra biológica, será realizada somente quando o projeto for aprovado no Comitê de Ética em Pesquisa da FCFRP-USP. 
Prof. ${ }^{a}$ Dra . Fabiola Attié de Castro

(16)3602-4163/ (16)98177-9222

gabrielaberzoti@usp.br

\section{Consentimento do Sujeito de Pesquisa}

$\mathrm{Eu}$,

$R G$ :

residente na Rua (número, bairro, cidade,

telefone / celular), aceito que minha amostra biológica de sangue (DNA, cDNA, RNA) seja armazenada pela Prof. ${ }^{a}$ Dr ${ }^{a}$. Fabiola Attié de Castro na Faculdade de Ciências Farmacêuticas de Ribeirão Preto da USP para fins de pesquisa científica.

Declaro estar ciente de que a previsão de guarda do material é de no máximo 10 anos.

Ribeirão Preto, de de 